\title{
FREEFLOW-AXI: Um Ambiente de Simulação de Escoamentos Axissimétricos com Superfícies Livres
}

\author{
Maria Luísa Bambozzi de Oliveira ${ }^{1}$ \\ Antonio Castelo Filho ${ }^{2}$
}

\footnotetext{
${ }^{1}$ Apoio Financeiro da FAPESP

${ }^{2}$ Orientador
} 

"Morre lentamente quem abandona um projeto antes de iniciá-lo, nunca pergunta sobre um assunto que desconhece e nem responde quando lhe perguntam sobre algo que sabe."

(Autor desconhecido) 



\section{Agradecimentos}

Aos meus pais, Mara e Luiz, pela vida, pelo amor e carinho, e pelo apoio e compreensão.

Ao meu orientador, prof. Antonio Castelo Filho, pela dedicação, pela paciência e pelo incentivo durante o decorrer deste trabalho.

Aos professores do grupo de Análise Numérica, que contribuíram com valiosas sugestões e ensinamentos. Em especial ao prof. Norberto Mangiavacchi, ao prof. Murilo Francisco Tomé, e ao prof. José Alberto Cuminato.

Aos amigos Ricardo, Fabrício, Luciane, Marcelo, Juliana Maria, Helton e Valdemir, pela amizade, pelas risadas e, principalmente, pela ajuda e compreensão.

Aos funcionários do ICMC, em especial à Beth, à Laura, ao Paulinho e à Tatiana, pela atenção, disponibilidade e paciência.

À FAPESP, pelo apoio financeiro no desenvolvimento deste trabalho.

Finalmente, agradeço a todos que direta ou indiretamente contribuíram para a realização deste trabalho. 



\section{Resumo}

Este trabalho apresenta um ambiente de simulação de escoamentos com simetria radial e superfícies livres, baseado no sistema Freeflow. O sistema é formado por três módulos: um modelador de moldes, um simulador e um visualizador de escoamentos.

O simulador implementa o método GENSMAC para a solução das equações de Navier-Stokes em coordenadas cilíndricas, utilizando diferenças finitas em uma malha diferenciada. São introduzidos os efeitos da tensão superficial e do ângulo de contato nas simulações com simetria radial.

Alguns resultados de simulações utilizando este sistema e uma validação do código são apresentados, comparando simulações com soluções analíticas e experimentais, e estudando a convergência do método. 



\section{Abstract}

This work presents an environment for the simulation of axisymmetric free surface flows, based on the Freeflow system. The system contains three modules: a geometric model modeller, a simulator and a visualizator.

The simulator implements the GENSMAC method for the solution of the Navier-Stokes equations in cylindrical coordinates, using finite differences in a staggered grid. The effects of surface tension and contact angle are introduced in the axisymmetric simulations.

Some results from simulations using this system and a validation of the code are presented, comparing the simulations with analytical and experimental solutions, and studying the convergence of the method. 



\section{Sumário}

Introdução . . . . . . . . . . . . . . . . . . . . . . . . 1

1 Equações Governantes do Escoamento de Fluidos . . . . . . . . . . . . . 5

1.1 Conceitos Fundamentais . . . . . . . . . . . . . . . . 5

1.1.1 Tensão Superficial e Ângulo de Contato . . . . . . . . . . . . . . . 6

1.2 Equações de Navier-Stokes . . . . . . . . . . . . . . . . . . . . . . . . . . . 8

1.3 Condições de Contorno na Superfície Livre . . . . . . . . . . . . . . . . . . 10

2 Método GENSMAC . . . . . . . . . . . . . . . . . . . . 11

2.1 Algoritmo Computacional . . . . . . . . . . . . . . . . . 11

2.2 Condições de Fronteira no Contorno Rígido . . . . . . . . . . . . . . . . . . 14

2.3 Modificações no Método GENSMAC . . . . . . . . . . . . . . 15

3 Aproximação por Diferenças Finitas . . . . . . . . . . . . . . . 17

3.1 Malha Diferenciada . . . . . . . . . . . . . . . . . . . . . 17

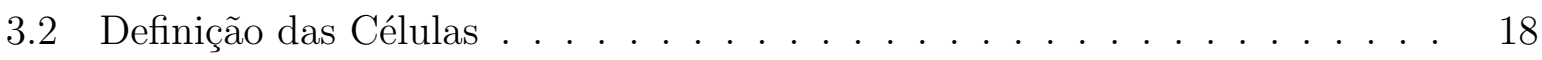

3.3 Cálculo das Velocidades Intermediárias . . . . . . . . . . . . . . . . . 19

3.3 .1 Funções de Interpolação . . . . . . . . . . . . . . . . . . . . . . 20

3.4 Aproximação da Equação de Poisson . . . . . . . . . . . . . . . . . . . . . . . . . 21

3.5 Condições de Fronteira no Contorno Rígido . . . . . . . . . . . . . . . . . . 22

3.6 Condições de Fronteira na Superfície Livre . . . . . . . . . . . . . . . . . . 25

3.6.1 Determinação de $n_{r}$ e $n_{z} \ldots \ldots$. . . . . . . . . . . . . . . 26

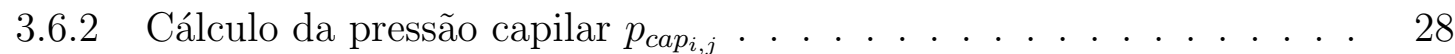

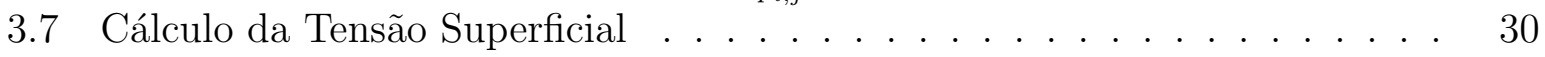

3.7 .1 Eliminação de Pequenas Ondulações . . . . . . . . . . . . . . . . . . . 30

3.8 Ângulo de Contato . . . . . . . . . . . . . . . . . . . . . . . . . . . . . . . . . . . . . . . . . . .

3.9 Cálculo do Passo no Tempo . . . . . . . . . . . . . . . . . . 34

4 Ambiente de Simulação Freeflow-2D . . . . . . . . . . . . . . . . . . . 35

4.1 Estrutura de Dados . . . . . . . . . . . . . . . . . . . . . . . . . 35

4.2 Modelador de Moldes . . . . . . . . . . . . . . . . . . . . . . . . . . . . . . . . . . . . . . . . . . . . . .

4.3 Simulador . . . . . . . . . . . . . . . . . . . . . . . . . . . . . . . . . . . . . . . . 37

4.4 Visualizador de Escoamentos . . . . . . . . . . . . . . . . . . . . . . . 38 
4.5 Reiniciador . . . . . . . . . . . . . . . . . . . 38

5 Ambiente de Simulação Freeflow-3D . . . . . . . . . . . . . . . . . . . . . . 39

5.1 Estrutura de Dados . . . . . . . . . . . . . . . . . . . . . . 39

5.2 Modelador de Moldes . . . . . . . . . . . . . . . . . . . . . . . . . . . . . . . . . . . . . . 41

5.3 Simulador . . . . . . . . . . . . . . . . . . . . . 41

5.4 Visualizador . . . . . . . . . . . . . . . . . . . . . . 42

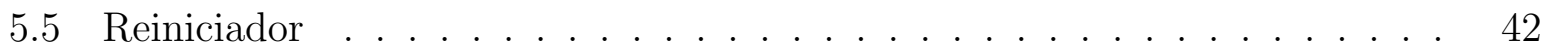

6 Implementações . . . . . . . . . . . . . . . . . . . . . . . . . 43

6.1 Modelador Axissimétrico . . . . . . . . . . . . . . . . . . . . 43

6.2 Simulador Axissimétrico . . . . . . . . . . . . . . . . . . . . . . . . . . . . . . . . . 44

6.3 Visualizador de Escoamentos Axissimétricos . . . . . . . . . . . . . . 44

7 Validação do Código . . . . . . . . . . . . . . . . . . . . . . . . . . 49

7.1 Exemplos Numéricos e Validação Qualitativa . . . . . . . . . . . . . . 49

7.1 .1 Jato Vertical ("Jet Flow") . . . . . . . . . . . . . . . . . . . . 49

7.1.2 "Splashing Drop" . . . . . . . . . . . . . . . . . . 51

7.1.3 Enchimento de Cavidade ("Container Filling") . . . . . . . . . . . 52

7.2 Validação Quantitativa . . . . . . . . . . . . . . . . . . . . 52

7.2.1 Comparação com Solução Analítica . . . . . . . . . . . . . . 52

7.2.2 Refinamento de Malhas . . . . . . . . . . . . . . . . . 55

7.2.3 Estudo da Convergência . . . . . . . . . . . . . . . . . . 59

7.3 Efeito da Tensão Superficial e do Ângulo de Contato . . . . . . . . . . . . 62

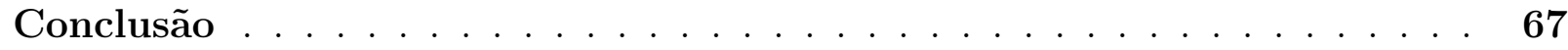

Referências Bibliográficas . . . . . . . . . . . . . . . . . . 69 


\section{Lista de Figuras}

1.1 Tensão superficial . . . . . . . . . . . . . . . . . . . . . . . . . . . . . . 6

1.2 Inseto sobre superfície da água . . . . . . . . . . . . . . 7

1.3 Ângulo de contato . . . . . . . . . . . . . . . . . . 7

3.1 Célula computacional . . . . . . . . . . . . . . . . . . . . . . . . . . . 17

3.2 Definição das células . . . . . . . . . . . . . . . . . . . . . . . . . 18

3.3 Condição de fronteira: fronteira à esquerda . . . . . . . . . . . . . . 23

3.4 Condição de fronteira: fronteira à direita . . . . . . . . . . . . . . . . . 23

3.5 Condição de fronteira: fronteira acima . . . . . . . . . . . . . . . 24

3.6 Condição de fronteira: fronteira abaixo . . . . . . . . . . . . . . . 24

3.7 Ângulo de contato . . . . . . . . . . . . . . . . . . . . . . . . . 32

4.1 Níveis hierárquicos da estrutura de dados halfedge-2D . . . . . . . . . . 36

5.1 Níveis hierárquicos da estrutura de dados halfedge . . . . . . . . . . . . . 40

6.1 Modelo de esfera de fluido axissimétrica: 2D e 3D . . . . . . . . . . . . 43

6.2 Modelo de injetor de fluido axissimétrico: 2D e 3D . . . . . . . . . . . . 44

6.3 Modelo de caixa axissimétrica: 2D e 3D . . . . . . . . . . . . . 44

6.4 Visualização Fio de Arame . . . . . . . . . . . . . . . . . . . . . . . . 45

6.5 Visualização Pintado . . . . . . . . . . . . . . . . . . . . . . . . 45

6.6 Visualização da Pressão . . . . . . . . . . . . . . . . . . . . . . . . . . 46

6.7 Visualização da Velocidade na direção $\mathrm{r} \ldots$. . . . . . . . . . . . . . . . . . 46

6.8 Visualização da Velocidade na direção z . . . . . . . . . . . . . . . . . . . 47

6.9 Janela "3D View" . . . . . . . . . . . . . . . . . . . . . . . . . . . . . . . . 47

6.10 Exemplo de varredura rotacional fechada: 2D e 3D . . . . . . . . . . 48

6.11 Visualização tridimensional Fio de Arame . . . . . . . . . . . . . . . . 48

6.12 Visualização tridimensional Pintado . . . . . . . . . . . . . . . . . . . 48

7.1 Simulação "Jet Flow" em diversos tempos (vista frontal) . . . . . . . . . . 50

7.2 Simulação "Jet Flow": comparação com dados experimentais . . . . . . . . 51

7.3 Simulação "Splashing Drop" em diversos tempos . . . . . . . . . . . . . . . 53

7.4 Simulação "Container Filling" em diversos tempos . . . . . . . . . . . . . . 54

7.5 Evolução temporal da elevação da superfície em $r=0 \ldots \ldots \ldots$. . . . . 56

7.6 Variação espacial da elevação da superfície em $t=\frac{\pi}{2 \sigma} \ldots \ldots \ldots . . \ldots 56$ 
7.7 Refinamento de malha - simulação "Splashing Drop" . . . . . . . . . . . . 58

7.8 Refinamento de malha - simulação "Cavity Filling" . . . . . . . . . . . . . 60

7.9 Normas $l_{2}$ dos erros das componentes de velocidade para cada malha . . . 61

7.10 Normas $l_{2}$ dos erros da pressão para cada malha . . . . . . . . . . . . . . . 62

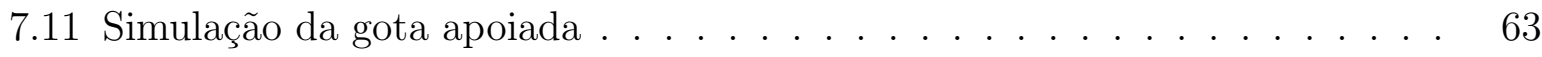

7.12 Validação da gota apoiada . . . . . . . . . . . . . . . . . . . . . . . . . . . . . . . . . . . . . . 64

7.13 Validação do ângulo de contato . . . . . . . . . . . . . . . . . . 65 


\section{Introdução}

No passado, existiam apenas duas maneiras para desvendar as leis da natureza: o método experimental e o método teórico. O método experimental consiste em descobrir as leis da natureza através da observação, utilizando experimentos e instrumentos de medida. Já o método teórico consiste em converter as leis da natureza em relações entre quantidades matemáticas, empregando a linguagem do cálculo diferencial e integral. Estes dois métodos possuem alguns obstáculos, como, por exemplo, o custo para desenvolver um equipamento específico para um experimento, ou a complexidade de equações matemáticas que não permitem que soluções analíticas sejam obtidas.

Atualmente, utiliza-se a simulação numérica para unir o método experimental e o teórico. Este novo método consiste em discretizar as equações desenvolvidas pelo método teórico e resolver aproximadamente estas equações em pontos no espaço definido pelo problema. A precisão da solução depende do número de pontos utilizados na simulação.

Com o surgimento de computadores cada vez mais rápidos e com maior capacidade de armazenar dados, as simulações tornam-se mais próximas da solução real e, assim, podem ser utilizadas para simular experimentos estudados pelo método experimental.

$\mathrm{Na}$ área de dinâmica de fluidos, algumas das aplicações das simulações numéricas têm sido nas áreas científicas e industriais, como por exemplo a previsão do tempo e a injeção de materiais em moldes (injeção de plástico, ligas metálicas e fluidos empregados na indústria alimentícia).

Durante as últimas três décadas têm sido estudados muitos problemas em dinâmica dos fluidos, como o escoamento de fluidos com superfícies livres. O método MAC (Markerand-Cell) [7, 16], desenvolvido por Harlow e Welch, que utiliza partículas virtuais que representam o fluido e que movem-se de uma célula a outra de acordo com a velocidade calculada, foi uma das primeiras técnicas desenvolvidas para a simulação de escoamentos de fluidos com superfícies livres.

Outros métodos foram desenvolvidos a partir do método MAC. Entre eles estão o método SMAC (Simplified-Marker-and-Cell) [3] e o código GENSMAC (Generalized-Simplified-Marker-and-Cell) [14], este último introduzido por Tomé e McKee. O método GENSMAC foi desenvolvido para resolver escoamentos transientes bidimensionais com superfícies livres em um domínio arbitrário com condições de contorno do tipo de não escorregamento e escorregamento livre e a possibilidade de inclusão de diversos injetores e ejetores.

Existe um projeto em desenvolvimento no ICMC-USP denominado SNENS III (Solução Numérica das Equações de Navier-Stokes), que trata da simulação de escoamentos de 
fluidos com superfícies livres em duas e três dimensões.

Os principais objetivos do SNENS III são:

- a extensão dos ambientes de simulação para simular escoamentos turbulentos, escoamentos de fluidos apresentando tensão superficial, escoamento de fluidos não newtonianos e escoamentos de fluidos visco-elásticos;

- a extensão dos ambientes de simulação para que possam tratar igualmente escoamentos de fluidos com superfícies livres e escoamentos internos em domínios complexos;

- a adoção de técnicas de computação paralela para a redução dos tempos de computação, que atualmente está na ordem de alguns dias;

- o desenvolvimento de ambientes de simulação de escoamentos bidimensionais e axissimétricos a serem integrados em um único ambiente de simulação.

Define-se um escoamento axissimétrico como um escoamento com simetria radial. Muitos modelos tridimensionais podem ser classificados como sendo axissimétricos devido à simetria radial. Esses modelos tridimensionais podem ser simulados em duas dimensões, tomando um corte longitudinal ao longo do eixo de simetria. A simulação de modelos axissimétricos em duas dimensões em vez de três dimensões permite a obtenção de resultados mais rapidamente, com o tempo de simulação reduzido significativamente.

No projeto SNENS foi desenvolvido um ambiente de modelagem, simulação e visualização de escoamentos de fluidos tridimensionais, denominado Freeflow-3D [5]. Este ambiente é composto de três módulos: Modflow-3D (modelador de moldes e escoamentos), Simflow3D (simulador de escoamentos) e Visflow-3D (visualizador de escoamento). O ambiente de simulação bidimensional, denominado Freeflow-2D, foi desenvolvido em um projeto de Mestrado por Juliana de Oliveira [10], concluído em 1999.

Este projeto de Mestrado tem como objetivo implementar um ambiente de simulação de escoamentos axissimétricos, composto por um modelador de moldes, um simulador de escoamentos e um visualizador de escoamentos, baseado no sistema Freeflow.

A dissertação foi dividida nos seguintes capítulos:

- Capítulo 1: são apresentados alguns conceitos fundamentais de Mecânica dos Fluidos, e as equações governantes do escoamento de fluidos Newtonianos com superfície livre são apresentadas e desenvolvidas em coordenadas cilíndricas;

- Capítulo 2: o método GENSMAC é detalhado, descrevendo o algoritmo computacional para resolver os escoamentos axissimétricos com superfícies livres;

- Capítulo 3: as aproximações por diferenças finitas das equações introduzidas no Capítulo 1 são apresentadas; 
- Capítulo 4: estuda-se o ambiente de simulação de escoamentos bidimensionais Freeflow2D;

- Capítulo 5: o ambiente de simulação tridimensional Freeflow-3D é estudado;

- Capítulo 6: são descritas as implementações dos módulos modelador, simulador e visualizador axissimétricos;

- Capítulo 7: os resultados das validações qualitativa e quantitativa do código são apresentados;

Finalmente, são apresentadas as conclusões e as contribuições para futuros trabalhos. 



\section{Capítulo 1}

\section{Equações Governantes do Escoamento de Fluidos}

Este capítulo apresenta alguns conceitos fundamentais de Mecânica dos Fluidos, as equações governantes do escoamento de fluidos e o desenvolvimento das equações em coordenadas cilíndricas.

\subsection{Conceitos Fundamentais}

Os líquidos e gases que se movimentam sob a ação de uma tensão de cisalhamento, não importando a dimensão desta tensão, são denominados fluidos. A componente tangencial da força sobre uma superfície é denominada força de cisalhamento. A razão entre a força de cisalhamento e a área onde ela atua é a tensão de cisalhamento.

Os fluidos podem ser classificados como newtonianos ou não newtonianos. Nos fluidos newtonianos, a tensão de cisalhamento é diretamente proporcional ao gradiente da velocidade. Os fluidos não newtonianos são todos aqueles que não são newtonianos.

Em um escoamento laminar, o fluido escoa sem haver mistura significante entre as partículas vizinhas do fluido. Já em um escoamento turbulento, o fluido apresenta um movimento irregular, de modo que as partículas do fluido apresentam uma variação aleatória nas coordenadas temporais e espaciais.

O regime do escoamento depende de 3 parâmetros físicos que descrevem as condições de escoamento:

- escala de comprimento do campo de escoamento (L), como o diâmetro de um cano;

- escala de velocidade (V), como a média espacial da velocidade;

- viscosidade cinemática $\nu=\frac{\mu}{\rho}$, onde $\mu$ é o coeficiente de viscosidade do fluido e $\rho$ é a massa específica do fluido.

Combinando os 3 fatores para prever o regime do escoamento, obtém-se o número de Reynolds, adimensional:

$$
\operatorname{Re}=\frac{V L}{\nu}
$$


O número de Reynolds caracteriza o escoamento. Outro fator que caracteriza escoamentos onde a gravidade é um fator importante, como aqueles com superfícies livres, é o número de Froude:

$$
\operatorname{Fr}=\frac{V}{\sqrt{g L}} .
$$

Um escoamento incompressível existe se a massa específica de cada partícula de fluido permanece relativamente constante conforme se movimenta através do campo de escoamento.

\subsubsection{Tensão Superficial e Ângulo de Contato}

As moléculas de um fluido sofrem forças de atração e repulsão entre si, além de sofrerem ação da força gravitacional e de agitação térmica. Estas forças impedem que as moléculas do fluido se espalhem pelo espaço, formando, assim, uma superfície bem definida entre o fluido e o ar ao seu redor. Isto gera uma diferença entre as moléculas no interior do fluido e em sua superfície. Enquanto as moléculas no interior do fluido sofrem interações com as demais moléculas ao seu redor, em todas as direções, anulando-se mutuamente em média, as moléculas da superfície do fluido somente interagem com as moléculas de um lado (do interior do fluido). Assim, há uma atração da película de fluido na superfície para o seu interior. Veja a figura 1.1.

Com a incompressibilidade do fluido, as moléculas no interior limitam o deslocamento da película na superfície para o interior. No equilíbrio, as moléculas da superfície se arranjam para formar a menor área possível para um dado volume, o que corresponde à situação de menor energia. A forma espacial que tem a menor área para um dado volume é a esfera. Este fenômeno é descrito como sendo devido à tensão superficial. É a tensão superficial que permite que uma agulha de aço permaneça na superfície da água sem afundar, ou que um inseto caminhe sobre a superfície da água sem afundar (figura 1.2).

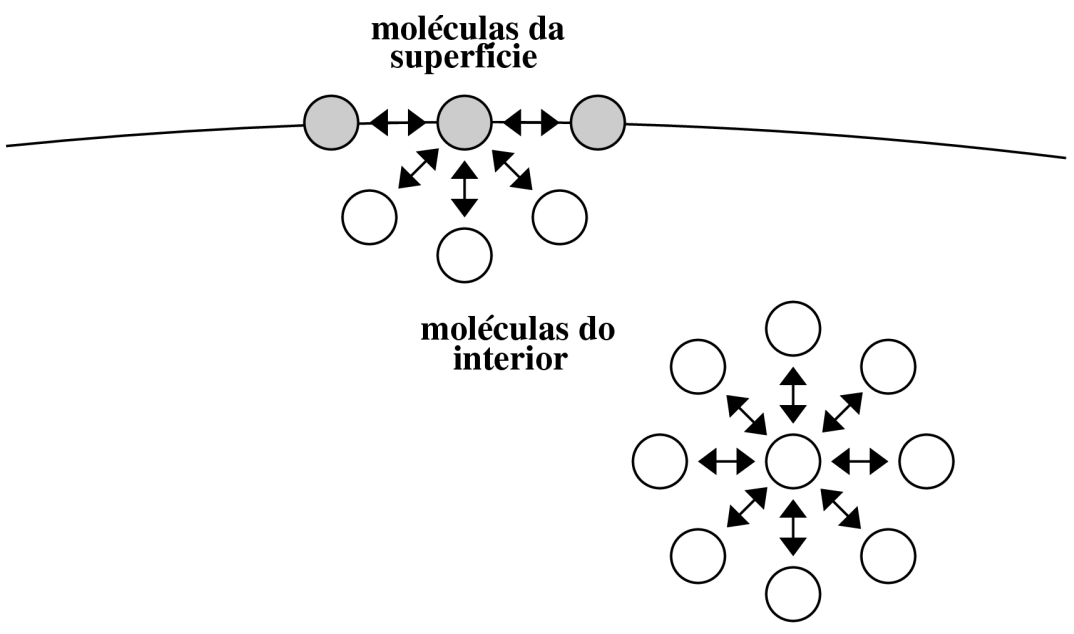

Figura 1.1: Tensão superficial 


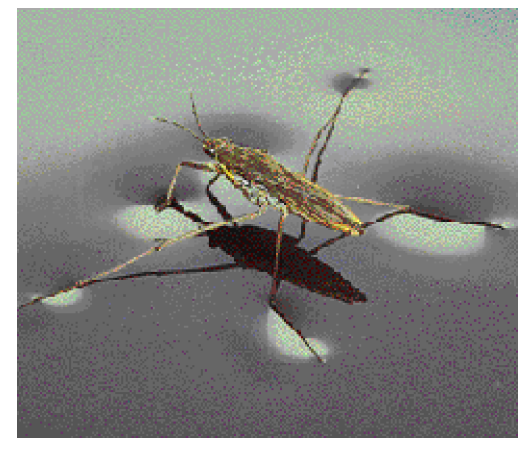

Figura 1.2: Inseto sobre superfície da água [1]

O fator adimensional que caracteriza escoamentos com efeitos de tensão superficial é o número de Weber:

$$
\mathrm{We}=\frac{\rho L V^{2}}{\sigma},
$$

onde $\rho$ é a massa específica do fluido e $\sigma$ é o coeficiente de tensão superficial do fluido.

$\mathrm{O}$ ângulo entre o plano tangente da superfície do fluido e o plano tangente da superfície do sólido, em qualquer ponto ao longo de sua linha de contato, é denominado ângulo de contato $\phi$ (veja a figura 1.3). O ângulo de contato entre um fluido e um sólido determina o grau de absorção do fluido pelo sólido. Um ângulo de contato maior implica em uma absorção menor do fluido pelo sólido. A absorção total do fluido pelo sólido ocorre com um ângulo de contato zero, e um ângulo de contato $180^{\circ}$ implica em absorção nula.

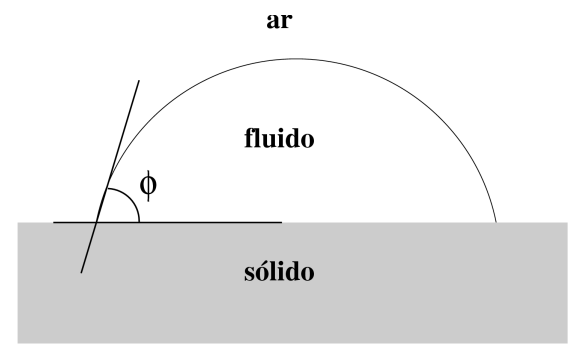

Figura 1.3: Ângulo de contato

O estudo e as medidas de ângulos de contato de líquidos e sólidos possuem grande importância tecnológica. A água, por exemplo, age de diversas formas em contato com os sólidos. Ela pode ser absorvida mais, ou menos, de acordo com o ângulo de contato que forma com o sólido. Com a pele humana, a água forma um ângulo de contato de $90^{\circ}$. Se fosse zero, a água penetraria pelos poros da pele e provavelmente seria absorvida pelo sangue. A estrutura de uma pena de passarinho é gerada de modo que o ângulo de contato da água com a pena pode chegar a $150^{\circ}$. Na fabricação de tintas para impressões, o ângulo de contato formado por uma gota de tinta sobre o papel determina a qualidade 
de impressão da tinta. Foi observado experimentalmente que $\phi$ deve estar idealmente entre $90^{\circ}$ e $110^{\circ}$. Se for menor que $90^{\circ}$, a tinta se espalhará sobre o papel. Se for maior que $110^{\circ}$, ocorrerão falhas na impressão.

Os algoritmos para a aplicação dos efeitos da tensão superficial e para a introdução do ângulo de contato serão desenvolvidos no Capítulo 3.

\subsection{Equações de Navier-Stokes}

A Equação da Conservação de Quantidade de Movimento

$$
\rho \frac{D \mathbf{u}}{D t}=\nabla \cdot \mathbf{T}+\rho \mathbf{g}
$$

e a Equação da Continuidade

$$
\nabla \cdot \mathbf{u}=0
$$

onde $\rho$ é a massa específica, $\mathbf{u}(\mathbf{x}, t)$ é a velocidade ( $\mathbf{x}$ é a posição no espaço e $t$ é a posição no tempo) e $\mathbf{T}$ é o tensor de tensões, são denominadas Equações de Navier-Stokes.

Para escoamentos incompressíveis, têm-se as seguintes equações:

$$
\begin{aligned}
\mathbf{T} & =-p \mathbf{I}+\tau \\
\tau & =2 \mu \mathbf{d} ; \\
\mathbf{d} & =\frac{1}{2}\left[(\nabla \mathbf{u})+(\nabla \mathbf{u})^{T}\right],
\end{aligned}
$$

onde $p, \mathbf{I}, \tau$ e $\mathbf{d}$ representam a pressão, o tensor identidade, o tensor extra tensão e o tensor razão de deformação de um fluido, respectivamente, e $\mu$ é a viscosidade aparente.

Substituindo (1.4), (1.5) e (1.6) em (1.2), obtém-se

$$
\rho \frac{D \mathbf{u}}{D t}=-\nabla p+\mu \nabla^{\mathbf{2}} \mathbf{u}+\rho \mathbf{g}
$$

O termo $\frac{D \mathbf{u}}{D t}$ pode ser expresso como

$$
\frac{D \mathbf{u}}{D t}=\frac{\partial \mathbf{u}}{\partial t}+(\mathbf{u} \cdot \nabla) \mathbf{u}
$$

$\mathrm{Na}$ forma conservativa, torna-se

$$
\frac{D \mathbf{u}}{D t}=\frac{\partial \mathbf{u}}{\partial t}+\nabla \cdot\left(\mathbf{u u}^{T}\right)
$$

Sendo o escoamento axissimétrico, onde não há variação em relação à direção $\theta$, e usando coordenadas cilíndricas $O_{r z}, \operatorname{com} \mathbf{u}=u(r, z, t) \mathbf{e}_{\mathbf{r}}+v(r, z, t) \mathbf{e}_{\mathbf{z}}$,

$$
\frac{D \mathbf{u}}{D t}=\frac{D}{D t}\left[\begin{array}{l}
u(r, z, t) \\
v(r, z, t)
\end{array}\right]
$$


Como $\nabla \cdot \mathbf{F}=\frac{1}{r} \frac{\partial\left(r F_{r}\right)}{\partial r}+\frac{1}{r} \frac{\partial F_{\theta}}{\partial \theta}+\frac{\partial F_{z}}{\partial z}[2] \mathrm{e}$

$$
\mathbf{u u}^{\mathbf{T}}=\left[\begin{array}{cc}
u^{2} & u v \\
v u & v^{2}
\end{array}\right]
$$

então

$$
\frac{D \mathbf{u}}{D t}=\left[\begin{array}{l}
\frac{\partial u}{\partial t}+\frac{1}{r} \frac{\partial\left(r u^{2}\right)}{\partial r}+\frac{\partial(v u)}{\partial z} \\
\frac{\partial v}{\partial t}+\frac{1}{r} \frac{\partial(r u v)}{\partial r}+\frac{\partial\left(v^{2}\right)}{\partial z}
\end{array}\right]
$$

Desenvolvendo o termo $\nabla^{\mathbf{2}} \mathbf{u}$ em coordenadas cilíndricas, sendo

$$
\nabla^{\mathbf{2}} \mathbf{F}=\frac{1}{r} \frac{\partial}{\partial r}\left(r \frac{\partial \mathbf{F}}{\partial r}\right)+\frac{1}{r^{2}} \frac{\partial^{2} \mathbf{F}}{\partial \theta^{2}}+\frac{\partial^{2} \mathbf{F}}{\partial z^{2}}
$$

(ver [2]), tem-se que

$$
\begin{aligned}
& \nabla^{2} \mathbf{u}=\frac{1}{r} \frac{\partial}{\partial r}\left(r \frac{\partial \mathbf{u}}{\partial r}\right)+\frac{1}{r^{2}} \frac{\partial^{2} \mathbf{u}}{\partial \theta^{2}}+\frac{\partial^{2} \mathbf{u}}{\partial z^{2}}= \\
& =\left(\frac{1}{r} \frac{\partial}{\partial r}\left(r \frac{\partial u}{\partial r}\right)+\frac{\partial^{2} u}{\partial z^{2}}-\frac{u}{r^{2}}\right) \mathbf{e}_{\mathbf{r}}+\left(\frac{1}{r} \frac{\partial}{\partial r}\left(r \frac{\partial v}{\partial r}\right)+\frac{\partial^{2} v}{\partial z^{2}}+\right) \mathbf{e}_{\mathbf{z}}
\end{aligned}
$$

Substituindo as equações (1.9) e (1.10) em (1.7), obtêm-se

$$
\frac{\partial u}{\partial t}+\frac{1}{r} \frac{\partial\left(r u^{2}\right)}{\partial r}+\frac{\partial(v u)}{\partial z}=-\frac{1}{\rho} \frac{\partial p}{\partial r}+\frac{\mu}{\rho}\left(\frac{1}{r} \frac{\partial}{\partial r}\left(r \frac{\partial u}{\partial r}\right)+\frac{\partial^{2} u}{\partial z^{2}}-\frac{u}{r^{2}}\right)+g_{r}
$$

e

$$
\frac{\partial v}{\partial t}+\frac{1}{r} \frac{\partial(r u v)}{\partial r}+\frac{\partial\left(v^{2}\right)}{\partial z}=-\frac{1}{\rho} \frac{\partial p}{\partial z}+\frac{\mu}{\rho}\left(\frac{1}{r} \frac{\partial}{\partial r}\left(r \frac{\partial v}{\partial r}\right)+\frac{\partial^{2} v}{\partial z^{2}}\right)+g_{z}
$$

$\operatorname{com} \mathbf{g}=g_{r} \mathbf{e}_{\mathbf{r}}+g_{z} \mathbf{e}_{\mathbf{z}}$ e $\nu=\frac{\mu}{\rho}$.

A equação da Continuidade (1.3), em coordenadas cilíndricas, torna-se

$$
\frac{1}{r} \frac{\partial(r u)}{\partial r}+\frac{\partial v}{\partial z}=0
$$

Sendo o escoamento caracterizado por uma dimensão $L$, velocidade $V$ e viscosidade cinemática $\nu$, e sendo

$$
\begin{array}{ll}
u=V \bar{u} ; & v=V \bar{v} ; \quad r=L \bar{r} ; \\
z=L \bar{z} ; \quad t=\frac{L}{V} \bar{t} ; \quad p=\rho V^{2} \bar{p} ; \\
\mathbf{g}=g \overline{\mathbf{g}}, \quad \text { com } g=|\mathbf{g}|
\end{array}
$$

as equações (1.11) e (1.12) podem ser reescritas como:

$$
\begin{aligned}
& \frac{\partial \bar{u}}{\partial \bar{t}}=-\frac{\partial \bar{p}}{\partial \bar{r}}-\frac{1}{\bar{r}} \frac{\partial\left(\bar{r}^{2}\right)}{\partial \bar{r}}-\frac{\partial(\overline{v u})}{\partial \bar{z}}+\frac{1}{\operatorname{Re}}\left[\frac{1}{\bar{r}} \frac{\partial}{\partial \bar{r}}\left(\bar{r} \frac{\partial \bar{u}}{\partial \bar{r}}\right)+\frac{\partial^{2} \bar{u}}{\partial \bar{z}^{2}}-\frac{\bar{u}}{\bar{r}^{2}}\right]+\frac{1}{\operatorname{Fr}^{2}} \bar{g}_{r} \\
& \frac{\partial \bar{v}}{\partial \bar{t}}=-\frac{\partial \bar{p}}{\partial \bar{z}}-\frac{1}{\bar{r}} \frac{\partial(\overline{r u v})}{\partial \bar{r}}-\frac{\partial\left(\bar{v}^{2}\right)}{\partial \bar{z}}+\frac{1}{\operatorname{Re}}\left[\frac{1}{\bar{r}} \frac{\partial}{\partial \bar{r}}\left(\bar{r} \frac{\partial \bar{v}}{\partial \bar{r}}\right)+\frac{\partial^{2} \bar{v}}{\partial \bar{z}^{2}}\right]+\frac{1}{\operatorname{Fr}^{2}} \bar{g}_{z},
\end{aligned}
$$


substituindo o número de Reynolds $\operatorname{Re}=\frac{V L}{\nu}$ e o número de Froude $\mathrm{Fr}=\frac{V}{\sqrt{L g}}$.

Removendo as barras para simplificar a notação, as equações (1.14) e (1.15) tornam-se

$$
\begin{aligned}
& \frac{\partial u}{\partial t}=-\frac{\partial p}{\partial r}-\frac{1}{r} \frac{\partial\left(r u^{2}\right)}{\partial r}-\frac{\partial(v u)}{\partial z}+\frac{1}{\operatorname{Re}}\left[\frac{1}{r} \frac{\partial}{\partial r}\left(r \frac{\partial u}{\partial r}\right)+\frac{\partial^{2} u}{\partial z^{2}}-\frac{u}{r^{2}}\right]+\frac{1}{\mathrm{Fr}^{2}} g_{r} \\
& \frac{\partial v}{\partial t}=-\frac{\partial p}{\partial z}-\frac{1}{r} \frac{\partial(r u v)}{\partial r}-\frac{\partial\left(v^{2}\right)}{\partial z}+\frac{1}{\operatorname{Re}}\left[\frac{1}{r} \frac{\partial}{\partial r}\left(r \frac{\partial v}{\partial r}\right)+\frac{\partial^{2} v}{\partial z^{2}}\right]+\frac{1}{\operatorname{Fr}^{2}} g_{z} .
\end{aligned}
$$

\subsection{Condições de Contorno na Superfície Livre}

Na superfície livre estão definidas as tensões normal e tangencial à superfície. Sendo $\mathbf{n}$ um vetor unitário normal exterior à superfície, $\mathbf{m}$ um vetor unitário tangente à superfície, e $\mathbf{T}$ o tensor de tensões, as condições de fronteira exigem:

$$
\begin{gathered}
\mathbf{n} \cdot(\mathbf{T} \cdot \mathbf{n})=p_{c a p} \\
\mathbf{m} \cdot(\mathbf{T} \cdot \mathbf{n})=0
\end{gathered}
$$

onde

$$
p_{\text {cap }}=-\frac{\kappa}{\mathrm{We}}
$$

é definida como a pressão capilar adimensional, com $\kappa$ sendo a curvatura adimensional e We sendo o número de Weber.

Em coordenadas cilíndricas, $\mathbf{m}, \mathbf{n}$ e $\mathbf{T}$ são definidos como:

$$
\begin{aligned}
\mathbf{m} & =\left(-n_{z}, 0, n_{r}\right) ; \\
\mathbf{n} & =\left(n_{r}, 0, n_{z}\right) ; \\
\mathbf{T}=-p \mathbf{I}+\frac{1}{\operatorname{Re}}\left(\nabla \mathbf{u}+(\nabla \mathbf{u})^{T}\right)= & {\left[\begin{array}{ccc}
-p+\frac{2}{\operatorname{Re}} \frac{\partial u}{\partial r} & 0 & \frac{1}{\operatorname{Re}}\left(\frac{\partial u}{\partial z}+\frac{\partial v}{\partial r}\right) \\
0 & -p+\frac{2}{\operatorname{Re}} \frac{u}{r} & 0 \\
\frac{1}{\operatorname{Re}}\left(\frac{\partial v}{\partial r}+\frac{\partial u}{\partial z}\right) & 0 & -p+\frac{2}{\operatorname{Re}} \frac{\partial v}{\partial z}
\end{array}\right] . }
\end{aligned}
$$

O produto escalar $\mathbf{T} \cdot \mathbf{n}$ é dado por:

$$
\begin{aligned}
& \mathbf{T} \cdot \mathbf{n}=\left[\begin{array}{ccc}
-p+\frac{2}{\operatorname{Re}} \frac{\partial u}{\partial r} & 0 & \frac{1}{\operatorname{Re}}\left(\frac{\partial u}{\partial z}+\frac{\partial v}{\partial r}\right) \\
0 & -p+\frac{2}{\operatorname{Re}} \frac{u}{r} & 0 \\
\frac{1}{\operatorname{Re}}\left(\frac{\partial v}{\partial r}+\frac{\partial u}{\partial z}\right) & 0 & -p+\frac{2}{\operatorname{Re}} \frac{\partial v}{\partial z}
\end{array}\right]\left[\begin{array}{c}
n_{r} \\
0 \\
n_{z}
\end{array}\right]= \\
& =\left[\begin{array}{c}
\left(-p+\frac{2}{\operatorname{Re}} \frac{\partial u}{\partial r}\right) n_{r}+\frac{1}{\operatorname{Re}}\left(\frac{\partial u}{\partial z}+\frac{\partial v}{\partial r}\right) n_{z} \\
0 \\
\frac{1}{\operatorname{Re}}\left(\frac{\partial v}{\partial r}+\frac{\partial u}{\partial z}\right) n_{r}+\left(-p+\frac{2}{\operatorname{Re}} \frac{\partial v}{\partial z}\right) n_{z}
\end{array}\right] .
\end{aligned}
$$

Aplicando a equação (1.24) em (1.18) e (1.19), obtêm-se:

$$
-p+\frac{2}{\operatorname{Re}}\left[\frac{\partial u}{\partial r} n_{r}^{2}+\left(\frac{\partial u}{\partial z}+\frac{\partial v}{\partial r}\right) n_{r} n_{z}+\frac{\partial v}{\partial z} n_{z}^{2}\right]=p_{c a p}
$$

$\mathrm{e}$

$$
\left(\frac{\partial v}{\partial r}+\frac{\partial u}{\partial z}\right)\left(n_{r}^{2}-n_{z}^{2}\right)+2\left(\frac{\partial v}{\partial z}-\frac{\partial u}{\partial r}\right) n_{r} n_{z}=0
$$




\section{Capítulo 2}

\section{Método GENSMAC}

O método GENSMAC (Generalized-Simplified-Marker-and-Cell), desenvolvido por Tomé e McKee, é uma técnica de solução de diferenças finitas aplicada sobre uma malha diferenciada que utiliza partículas marcadoras para a visualização do escoamento e localização da superfície livre do fluido.

\subsection{Algoritmo Computacional}

Para resolver as equações (1.13), (1.16) e (1.17), aplica-se o método das projeções, descrito a seguir.

Supondo que, em um dado momento $t_{o}$, o campo de velocidade $\mathbf{u}\left(r, z, t_{o}\right)$ é conhecido e as condições de fronteira para a velocidade e pressão são dadas, o campo de velocidade atualizado $\mathbf{u}(r, z, t)$ em $t=t_{o}+\delta t$ é calculado através dos seguintes passos:

1. Determina-se $\tilde{p}\left(r, z, t_{o}\right)$, o campo de pressão que satisfaz a condição de tensão normal correta na superfíe livre em $t=t_{o}$.

2. Calcula-se $\tilde{\mathbf{u}}(r, z, t)$, o campo de velocidade intermediário, de

$$
\frac{\partial \tilde{u}}{\partial t}=-\frac{\partial \tilde{p}}{\partial r}-\frac{1}{r} \frac{\partial\left(r u^{2}\right)}{\partial r}-\frac{\partial(v u)}{\partial z}+\frac{1}{\operatorname{Re}}\left[\frac{1}{r} \frac{\partial}{\partial r}\left(r \frac{\partial u}{\partial r}\right)+\frac{\partial^{2} u}{\partial z^{2}}-\frac{u}{r^{2}}\right]+\frac{1}{\mathrm{Fr}^{2}} g_{r}
$$

e

$$
\frac{\partial \tilde{v}}{\partial t}=-\frac{\partial \tilde{p}}{\partial z}-\frac{1}{r} \frac{\partial(r u v)}{\partial r}-\frac{\partial\left(v^{2}\right)}{\partial z}+\frac{1}{\operatorname{Re}}\left[\frac{1}{r} \frac{\partial}{\partial r}\left(r \frac{\partial v}{\partial r}\right)+\frac{\partial^{2} v}{\partial z^{2}}\right]+\frac{1}{\mathrm{Fr}^{2}} g_{z},
$$

com $\tilde{\mathbf{u}}\left(r, z, t_{o}\right)=\mathbf{u}\left(r, z, t_{o}\right)$, utilizando a condição de fronteira correta para $\mathbf{u}\left(r, z, t_{o}\right)$. As equações (2.1) e (2.2) são resolvidas utilizando aproximação por diferenças finitas explícita.

$\mathrm{Na}$ forma vetorial, as equações (2.1) e (2.2) podem ser escritas como

$$
\frac{\partial \tilde{\mathbf{u}}}{\partial t}=-\nabla \tilde{p}+N(\mathbf{u})
$$


com

$$
N_{1}=-\frac{1}{r} \frac{\partial\left(r u^{2}\right)}{\partial r}-\frac{\partial(v u)}{\partial z}+\frac{1}{\operatorname{Re}}\left(\frac{1}{r} \frac{\partial}{\partial r}\left(r \frac{\partial u}{\partial r}\right)+\frac{\partial^{2} u}{\partial z^{2}}-\frac{u}{r^{2}}\right)+\frac{1}{\operatorname{Fr}^{2}} g_{r}
$$

e

$$
N_{2}=-\frac{1}{r} \frac{\partial(r u v)}{\partial r}-\frac{\partial\left(v^{2}\right)}{\partial z}+\frac{1}{\operatorname{Re}}\left(\frac{1}{r} \frac{\partial}{\partial r}\left(r \frac{\partial v}{\partial r}\right)+\frac{\partial^{2} v}{\partial z^{2}}\right)+\frac{1}{\mathrm{Fr}^{2}} g_{z}
$$

Escrevendo as equações (1.16) e (1.17) também na forma vetorial, tem-se

$$
\frac{\partial \mathbf{u}}{\partial t}=-\nabla p+N(\mathbf{u}) \text {. }
$$

Subtraindo a equação (2.3) de (2.4), obtém-se

$$
\frac{\partial(\mathbf{u}-\tilde{\mathbf{u}})}{\partial t}=-\nabla(p-\tilde{p}) .
$$

Aplicando o produto vetorial $\nabla \times$ a ambos os lados da equação, ela se torna

$$
\nabla \times\left[\frac{\partial(\mathbf{u}-\tilde{\mathbf{u}})}{\partial t}\right]=0
$$

Escrevendo de outra maneira,

$$
\frac{\partial}{\partial t}[\nabla \times(\mathbf{u}-\tilde{\mathbf{u}})]=0
$$

Pode-se dizer, então, que

$$
\nabla \times(\mathbf{u}-\tilde{\mathbf{u}})=f(r, z)
$$

para algum $f(r, z)$ com $t \in\left[t_{o}, t_{o}+\delta t\right]$.

Sendo $\tilde{\mathbf{u}}\left(r, z, t_{o}\right)=\mathbf{u}\left(r, z, t_{o}\right)$, então $f(r, z)=0$, pois $\nabla \times \mathbf{u}=\nabla \times \tilde{\mathbf{u}}$ em $t=t_{o}$. Assim,

$$
\nabla \times(\mathbf{u}-\tilde{\mathbf{u}})=0
$$

para qualquer $t \in\left[t_{o}, t_{o}+\delta t\right]$, mostrando que as vorticidades associadas às velocidades $\tilde{\mathbf{u}}(r, z, t)$ e $\mathbf{u}(r, z, t)$ são iguais e $\tilde{\mathbf{u}}(r, z, t)$ possui a vorticidade correta em $t$. No entanto, $\tilde{\mathbf{u}}(r, z, t)$ não satisfaz $\nabla \cdot \tilde{\mathbf{u}}=0$. Sendo $\psi(r, z, t)$ uma função escalar, então

$$
\mathbf{u}(r, z, t)=\tilde{\mathbf{u}}(r, z, t)-\nabla \psi(r, z, t) .
$$

Aplicando o divergente em ambos os lados da equação, obtém-se

$$
\nabla \cdot \mathbf{u}(r, z, t)=\nabla \cdot \tilde{\mathbf{u}}(r, z, t)-\nabla^{2} \psi(r, z, t) .
$$

Substituindo a equação da Continuidade (1.3) na equação acima, tem-se a equação de Poisson para a função $\psi(r, z, t)$ :

$$
\nabla^{2} \psi(r, z, t)=\nabla \cdot \tilde{\mathbf{u}}(r, z, t) .
$$

Assim, $\mathbf{u}(r, z, t)$ satisfaz a equação da Continuidade e a vorticidade permanece inalterada. 
3. Resolve-se a equação de Poisson $\nabla^{2} \psi(r, z, t)=\nabla \cdot \tilde{\mathbf{u}}(r, z, t)$. A equação de Poisson discretizada gera um sistema linear resolvido através do método dos gradientes conjugados.

4. Calcula-se a velocidade atualizada $\mathbf{u}(r, z, t)=\tilde{\mathbf{u}}(r, z, t)-\nabla \psi(r, z, t)$.

5. Calcula-se a nova pressão $p=\tilde{p}+\frac{\psi(r, z, t)}{\delta t}$, onde $\delta t$ é o passo no tempo.

Calculada a nova velocidade $\mathbf{u}(r, z, t)$ pode-se atualizar a pressão através da equação

$$
\frac{\partial(\mathbf{u}-\tilde{\mathbf{u}})}{\partial t}=-\nabla(p-\tilde{p}) .
$$

Substituindo a equação (2.5) nesta, tem-se

$$
\frac{\partial(-\nabla \psi)}{\partial t}=-\nabla(p-\tilde{p}) .
$$

Invertendo a ordem dos operadores no lado esquerdo da equação, fica

$$
-\nabla\left(\frac{\partial \psi}{\partial t}\right)=-\nabla(p-\tilde{p})
$$

Logo,

$$
\frac{\partial \psi(r, z, t)}{\partial t}=p-\tilde{p}
$$

podendo ser aproximada por

$$
\frac{\psi(r, z, t)-\psi\left(r, z, t_{o}\right)}{\delta t}=p-\tilde{p}
$$

Sendo $\mathbf{u}\left(r, z, t_{o}\right)=\tilde{\mathbf{u}}\left(r, z, t_{o}\right)$, e através da equação $(2.5)$, tem-se que

$$
\nabla \psi\left(r, z, t_{o}\right)=0
$$

implicando que $\psi\left(r, z, t_{o}\right)$ é constante. $\operatorname{Com} \psi\left(r, z, t_{o}\right)=0$, a equação (2.6) torna-se

$$
p=\tilde{p}+\frac{\psi(r, z, t)}{\delta t}
$$

onde $\delta t$ é o passo no tempo. Assim, o método GENSMAC resolve as equações da conservação de quantidade de movimento explicitamente e um sistema simétrico esparso (a equação de Poisson discretizada) para o potencial de velocidade $\psi$.

6. Atualizam-se as posições das partículas marcadoras. As partículas são criadas no injetor e são injetadas no domínio para representar o fluido. Elas são partículas virtuais cujas coordenadas são armazenadas a cada passo no tempo e atualizadas resolvendo $\frac{d r}{d t}=u$ e $\frac{d z}{d t}=v$ pelo método de Euler. Isto fornece as novas coordenadas da partícula e, então, determina se ela se moverá para uma nova célula ou se deixará o domínio através do ejetor. 


\subsection{Condições de Fronteira no Contorno Rígido}

As condições de fronteira impostas sobre o potencial de velocidade $\psi$ para resolver a equação de Poisson são:

$$
\begin{array}{cc}
\psi=0 & \text { na superfície livre; } \\
\frac{\partial \psi}{\partial \mathbf{n}}=0 & \text { na fronteira rígida, }
\end{array}
$$

onde $\mathbf{n}$ representa a direção normal ao contorno rígido.

As condições de fronteira que podem ser impostas no contorno rígido são:

- condição de não escorregamento ("no-slip"): o fluido não transpõe a fronteira rígida e o fluido possui velocidade nula na região adjacente à fronteira, isto é,

$$
\begin{aligned}
& u_{n}(r, z)=0 \\
& u_{t}(r, z)=0
\end{aligned}
$$

onde $u_{n}(r, z)$ é a velocidade normal à fronteira e $u_{t}(r, z)$ é a velocidade tangente à fronteira.

- condição de simetria ("free-slip"): o fluido não transpõe a fronteira rígida, e não há perda friccional na região adjacente à fronteira, isto é,

$$
\begin{aligned}
u_{n}(r, z) & =0, \\
\frac{\partial u_{t}(r, z)}{\partial \mathbf{n}} & =0 .
\end{aligned}
$$

Esta condição é imposta geralmente sobre uma linha ou um plano de simetria, como por exemplo o eixo de simetria de um escoamento axissimétrico, onde $r=0$.

- condição de injeção: as componentes da velocidade são dadas, isto é,

$$
\begin{aligned}
& u_{n}(r, z)=u_{n}^{i}, \\
& u_{t}(r, z)=0,
\end{aligned}
$$

com $u_{n}^{i}$ sendo um valor conhecido.

- condição de ejeção prescrita: as componentes de velocidade no ejetor são dadas:

$$
\begin{aligned}
& u_{n}(r, z)=u_{n}^{o}, \\
& u_{t}(r, z)=0 .
\end{aligned}
$$

- condição de ejeção contínua: não há variação da velocidade na direção normal à fronteira, isto é,

$$
\begin{aligned}
& \frac{\partial u_{n}(r, z)}{\partial \mathbf{n}}=0, \\
& \frac{\partial u_{t}(r, z)}{\partial \mathbf{n}}=0 .
\end{aligned}
$$




\subsection{Modificações no Método GENSMAC}

Para a implementação do método GENSMAC em coordenadas cilíndricas, é necessário adaptar os três primeiros passos do método para as equações em coordenadas cilíndricas a partir da implementação bidimensional.

No primeiro passo, a pressão $\tilde{p}(r, z, t)$ é determinada através das condições de fronteira na superfície livre, dadas pelas equações (1.25) e (1.26), onde os valores de $n_{r}$ e $n_{z}$ são dados de acordo com a orientação da superfície livre, e a pressão capilar $p_{\text {cap }}$ é calculada a partir da determinação da curvatura $\kappa$ da célula.

No segundo passo, a velocidade intermediária $\tilde{\mathbf{u}}(r, z, t)$ é calculada a partir das equações da conservação de quantidade de movimento (2.1) e (2.2).

No terceiro passo, a equação de Poisson é resolvida em coordenadas cilíndricas através da seguinte equação:

$$
\frac{\partial}{\partial r}\left(r \frac{\partial \psi}{\partial r}\right)+r \frac{\partial^{2} \psi}{\partial z^{2}}=\frac{\partial(r \tilde{u})}{\partial r}+r \frac{\partial \tilde{v}}{\partial z} .
$$





\section{Capítulo 3}

\section{Aproximação por Diferenças Finitas}

As equações desenvolvidas na seção anterior devem ser discretizadas para que possam ser implementadas no sistema Freeflow. Serão discretizadas as equações (1.25), (1.26), (2.1), (2.2), (2.13) e (1.13).

\subsection{Malha Diferenciada}

A técnica de diferenças finitas é aplicada utilizando-se uma malha diferenciada ("staggered grid") com células de dimensões $\delta r$ por $\delta z, \operatorname{com} \delta r=\frac{R}{M}$ e $\delta z=\frac{H}{N}$, onde $R$ e $H$ são as dimensões máximas do domínio e $M+1$ e $N+1$ são o número de pontos na direção $r$ e na direção $z$, respectivamente. Cada quadrado formado pelos pontos corresponde a uma célula. Assim, o domínio é formado por $M \times N$ células.

A pressão $p_{i, j}$ e o potencial de velocidade $\psi_{i, j}$ estão localizados no centro da célula, enquanto as velocidades $u$ e $v$ (componentes da velocidade na direção $r$ e na direção $z$, respectivamente) estão localizadas nas faces da célula, de modo que seus índices tornam-se $u_{i+\frac{1}{2}, j}$ e $v_{i, j+\frac{1}{2}}$ (as velocidades localizam-se na face direita e na face superior, respectivamente). Veja a figura 3.1 .

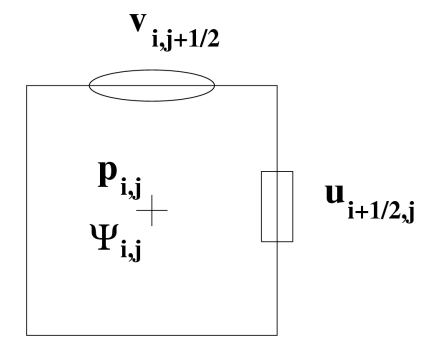

Figura 3.1: Célula computacional 


\subsection{Definição das Células}

Como o fluido está continuamente em movimento, é necessário empregar um procedimento para identificar a região com fluido e superfície livre. Então, as células que formam a malha diferenciada são marcadas da seguinte maneira:

- V (Vazia) - células vazias, que não contêm fluido;

- I (Injetor) - células de entrada do fluido, que simulam a entrada de fluido na região de domínio do fluido, se possuem pelo menos metade de seu volume em um injetor;

- E (Ejetor) - células de saída do fluido, que simulam a saída de fluido da região de domínio do fluido, se possuem pelo menos metade de seu volume em um ejetor;

- F (Fronteira) - células que definem o contorno rígido, se possuem metade ou mais de seu volume no contorno rígido;

- S (Superfície) - células que contêm fluido e possuem pelo menos uma célula vizinha vazia, e definem a posição da superfície livre;

- C (Cheia) - células que contêm fluido e não têm contato com células vazias.

Estas células marcadas podem ser visualizadas na figura 3.2, onde o símbolo das células vazias (V) foi desconsiderado, para facilitar a visualização.

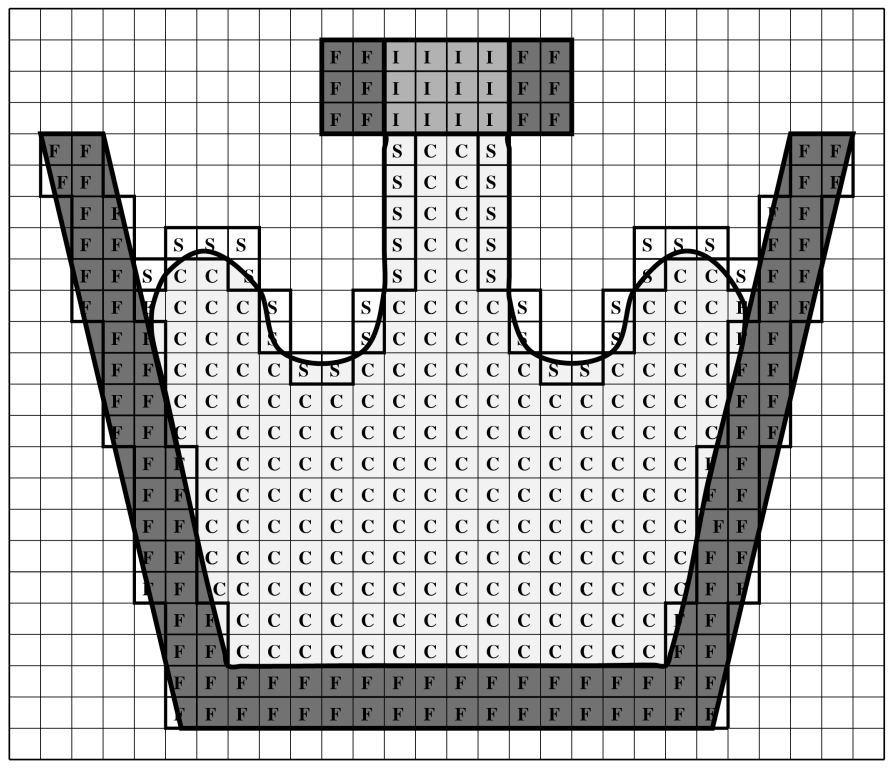

Figura 3.2: Definição das células 


\subsection{Cálculo das Velocidades Intermediárias}

Para discretizar as velocidades intermediárias $\tilde{u}$ e $\tilde{v}$, é necessário, inicialmente, determinar as aproximações a serem utilizadas em cada derivada.

As derivadas no tempo serão aproximadas utilizando diferenças avançadas e os gradientes de pressão serão aproximados por diferenças centrais, ou seja:

$$
\begin{aligned}
\left.\frac{\partial \tilde{u}}{\partial t}\right|_{i+1 / 2, j} & =\frac{\tilde{u}_{i+1 / 2, j}^{n+1}-\tilde{u}_{i+1 / 2, j}^{n}}{\delta t} ; \\
\left.\frac{\partial \tilde{v}}{\partial t}\right|_{i, j+1 / 2} & =\frac{\tilde{v}_{i, j+1 / 2}^{n+1}-\tilde{v}_{i, j+1 / 2}^{n}}{\delta t} ; \\
\left.\frac{\partial \tilde{p}}{\partial r}\right|_{i+1 / 2, j} & =\frac{\tilde{p}_{i+1, j}-\tilde{p}_{i, j}}{\delta r} ; \\
\left.\frac{\partial \tilde{p}}{\partial z}\right|_{i, j+1 / 2} & =\frac{\tilde{p}_{i, j+1}-\tilde{p}_{i, j}}{\delta z}
\end{aligned}
$$

As derivadas de segunda ordem podem ser aproximadas por:

$$
\begin{aligned}
{\left[\frac{1}{r} \frac{\partial}{\partial r}\left(r \frac{\partial u}{\partial r}\right)\right]_{i+1 / 2, j} } & =\frac{1}{r_{i+1 / 2}} \frac{r_{i+1} u_{i+3 / 2, j}-2 r_{i+1 / 2} u_{i+1 / 2, j}+r_{i} u_{i-1 / 2, j}}{(\delta r)^{2}} \\
{\left[\frac{1}{r} \frac{\partial}{\partial r}\left(r \frac{\partial v}{\partial r}\right)\right]_{i, j+1 / 2} } & =\frac{1}{r_{i}} \frac{r_{i+1 / 2} v_{i+1, j+1 / 2}-2 r_{i} v_{i, j+1 / 2}+r_{i-1 / 2} v_{i-1, j+1 / 2}}{(\delta r)^{2}} \\
\left.\frac{\partial^{2} u}{\partial z^{2}}\right|_{i+1 / 2, j} & =\frac{u_{i+1 / 2, j+1}-2 u_{i+1 / 2, j}+u_{i+1 / 2, j-1}}{(\delta z)^{2}} \\
\left.\frac{\partial^{2} v}{\partial z^{2}}\right|_{i, j+1 / 2} & =\frac{v_{i, j+3 / 2}-2 v_{i, j+1 / 2}+v_{i, j-1 / 2}}{(\delta z)^{2}}
\end{aligned}
$$

Os termos convectivos

$$
\begin{aligned}
\operatorname{CONV}\left(\mathrm{U}^{2}\right) & =-\frac{1}{r} \frac{\partial\left(r u^{2}\right)}{\partial r} \\
\operatorname{CONV}(\mathrm{VU}) & =-\frac{\partial(v u)}{\partial z} \\
\operatorname{CONV}(\mathrm{UV}) & =-\frac{1}{r} \frac{\partial(r u v)}{\partial r},
\end{aligned}
$$

e

$$
\operatorname{CONV}\left(\mathrm{V}^{2}\right)=-\frac{\partial v^{2}}{\partial z}
$$

podem ser aproximados utilizando as funções de interpolação VONOS [15] e esquema híbrido [6], detalhadas a seguir. 


\subsubsection{Funções de Interpolação}

Para aproximar a derivada parcial de variáveis genéricas $(\varphi \phi)$ no ponto $P_{o}$, ou seja:

$$
\left.\frac{\partial(\varphi \phi)}{\partial s}\right|_{P_{o}}=\frac{\varphi_{B} \phi_{B}-\varphi_{A} \phi_{A}}{\Delta s},
$$

onde $s$ representa uma direção (neste caso, $r$ ou $z$ ), $\phi_{A}$ e $\phi_{B}$ são os valores das variáveis genéricas nos pontos $P_{A}$ e $P_{B}$, respectivamente, e sendo $\varphi_{A}$ e $\varphi_{B}$ os valores das velocidades de convecção dos pontos $P_{A}$ e $P_{B}$, respectivamente, podem ser utilizadas as funções de interpolação:

\section{- VONOS (Variable-Order Non-Oscillatory Scheme):}

$$
\begin{aligned}
& \text { se } \varphi_{B} \geq 0, \quad \phi_{B}= \begin{cases}\phi_{0} & \text { se } \widehat{\phi}_{B} \notin[0,1] \\
10 \phi_{0}-9 \phi_{-1} & \text { se } \widehat{\phi}_{B} \in[0,3 / 74) \\
\frac{3}{8} \phi_{1}+\frac{6}{8} \phi_{0}-\frac{1}{8} \phi_{-1} & \text { se } \widehat{\phi}_{B} \in[3 / 74,1 / 2) ; \\
\frac{3}{2} \phi_{0}-\frac{1}{2} \phi_{-1} & \text { se } \widehat{\phi}_{B} \in[1 / 2,2 / 3) \\
\phi_{1} & \text { se } \widehat{\phi}_{B} \in[2 / 3,1]\end{cases} \\
& \text { se } \varphi_{B}<0, \quad \phi_{B}= \begin{cases}\phi_{1} & \text { se } \widehat{\phi}_{B} \notin[0,1] \\
10 \phi_{1}-9 \phi_{2} & \text { se } \widehat{\phi}_{B} \in[0,3 / 74) \\
\frac{3}{8} \phi_{0}+\frac{6}{8} \phi_{1}-\frac{1}{8} \phi_{2} & \text { se } \widehat{\phi}_{B} \in[3 / 74,1 / 2) ; \\
\frac{3}{2} \phi_{1}-\frac{1}{2} \phi_{2} & \text { se } \widehat{\phi}_{B} \in[1 / 2,2 / 3) \\
\phi_{0} & \text { se } \widehat{\phi}_{B} \in[2 / 3,1]\end{cases} \\
& \text { se } \varphi_{A} \geq 0, \quad \phi_{A}= \begin{cases}\phi_{-1} & \text { se } \widehat{\phi}_{A} \notin[0,1] \\
10 \phi_{-1}-9 \phi_{-2} & \text { se } \widehat{\phi}_{A} \in[0,3 / 74) \\
\frac{3}{8} \phi_{0}+\frac{6}{8} \phi_{-1}-\frac{1}{8} \phi_{-2} & \text { se } \widehat{\phi}_{A} \in[3 / 74,1 / 2) ; \\
\frac{3}{2} \phi_{-1}-\frac{1}{2} \phi_{-2} & \text { se } \widehat{\phi}_{A} \in[1 / 2,2 / 3) \\
\phi_{0} & \text { se } \widehat{\phi}_{A} \in[2 / 3,1]\end{cases} \\
& \text { se } \varphi_{A}<0, \quad \phi_{A}= \begin{cases}\phi_{0} & \text { se } \widehat{\phi}_{A} \notin[0,1] \\
10 \phi_{0}-9 \phi_{1} & \text { se } \widehat{\phi}_{A} \in[0,3 / 74) \\
\frac{3}{8} \phi_{-1}+\frac{6}{8} \phi_{0}-\frac{1}{8} \phi_{1} & \text { se } \widehat{\phi}_{A} \in[3 / 74,1 / 2), \\
\frac{3}{2} \phi_{0}-\frac{1}{2} \phi_{1} & \text { se } \widehat{\phi}_{A} \in[1 / 2,2 / 3) \\
\phi_{-1} & \text { se } \widehat{\phi}_{A} \in[2 / 3,1]\end{cases}
\end{aligned}
$$

com

$$
\widehat{\phi}_{A}=\left.\frac{\phi_{U}-\phi_{R}}{\phi_{D}-\phi_{R}}\right|_{P_{A}} \text { e } \widehat{\phi}_{B}=\left.\frac{\phi_{U}-\phi_{R}}{\phi_{D}-\phi_{R}}\right|_{P_{B}},
$$

onde $\phi_{U}$ corresponde ao valor da velocidade $\phi$ montante (upstream), $\phi_{R}$ o valor da velocidade $\phi$ montante remota (remote-upstream) e $\phi_{D}$ o valor da velocidade $\phi$ jusante (downstream). 
- Esquema Híbrido: o esquema híbrido é composto de dois esquemas, o Upwind de Primeira Ordem e o esquema de Diferenças Centrais. Então, o esquema híbrido pode ser escrito como:

$$
\begin{aligned}
& \text { se } \mathrm{Pe}_{B} \geq 2, \quad \phi_{B}=\left\{\begin{array}{ll}
\phi_{0} & \text { se } \varphi_{B} \geq 0 \\
\phi_{1} & \text { se } \varphi_{B}<0
\end{array} ;\right. \\
& \text { se } \mathrm{Pe}_{B}<2, \quad \phi_{B}=\frac{\phi_{1}+\phi_{0}}{2} ; \\
& \text { se } \mathrm{Pe}_{A} \geq 2, \quad \phi_{A}= \begin{cases}\phi_{-1} & \text { se } \varphi_{A} \geq 0 \\
\phi_{0} & \text { se } \varphi_{A}<0\end{cases} \\
& \text { se } \mathrm{Pe}_{A}<2, \quad \phi_{A}=\frac{\phi_{0}+\phi_{-1}}{2},
\end{aligned}
$$

com

$$
\mathrm{Pe}_{A}=\frac{\left|\varphi_{A}\right| \Delta s}{\operatorname{Re}} \text { e } \mathrm{Pe}_{B}=\frac{\left|\varphi_{B}\right| \Delta s}{\operatorname{Re}}
$$

Assim, utilizando as aproximações desenvolvidas para o cálculo de $\tilde{u}$ e $\tilde{v}$, o valor de $\tilde{u}_{i+1 / 2, j}^{n+1}$ é dado por

$$
\begin{aligned}
\tilde{u}_{i+1 / 2, j}^{n+1}= & u_{i+1 / 2, j}^{n}+\delta t\left[\operatorname{CONV}\left(\mathrm{U}^{2}\right)+\operatorname{CONV}(\mathrm{VU})-\frac{\tilde{p}_{i+1, j}-\tilde{p}_{i, j}}{\delta r}\right. \\
& +\frac{1}{\operatorname{Re}}\left(\frac{1}{r_{i+1 / 2}} \frac{r_{i+1} u_{i+3 / 2, j}-2 r_{i+1 / 2} u_{i+1 / 2, j}+r_{i} u_{i-1 / 2, j}}{(\delta r)^{2}}\right. \\
& \left.\left.+\frac{u_{i+1 / 2, j+1}-2 u_{i+1 / 2, j}+u_{i+1 / 2, j-1}}{(\delta z)^{2}}-\frac{u_{i+1 / 2, j}}{r_{i+1 / 2}^{2}}\right)+\frac{1}{\mathrm{Fr}^{2}} g_{r}\right],
\end{aligned}
$$

e o valor de $\tilde{v}_{i, j+1 / 2}^{n+1}$ é dado por

$$
\begin{aligned}
\tilde{v}_{i, j+1 / 2}^{n+1}= & v_{i, j+1 / 2}^{n}+\delta t\left[\operatorname{CONV}(\mathrm{UV})+\operatorname{CONV}\left(\mathrm{V}^{2}\right)-\frac{\tilde{p}_{i, j+1}-\tilde{p}_{i, j}}{\delta z}\right. \\
& +\frac{1}{\operatorname{Re}}\left(\frac{1}{r_{i}} \frac{r_{i+1 / 2} v_{i+1, j+1 / 2}-2 r_{i} v_{i, j+1 / 2}+r_{i-1 / 2} v_{i-1, j+1 / 2}}{(\delta r)^{2}}\right. \\
& \left.\left.+\frac{v_{i, j+3 / 2}-2 v_{i, j+1 / 2}+v_{i, j-1 / 2}}{(\delta z)^{2}}\right)+\frac{1}{\operatorname{Fr}^{2}} g_{z}\right]
\end{aligned}
$$

\subsection{Aproximação da Equação de Poisson}

As derivadas da equação de Poisson (2.13) podem ser aproximadas utilizando diferenças centrais:

$$
\left.\frac{\partial}{\partial r}\left(r \frac{\partial \psi}{\partial r}\right)\right|_{i, j}=\frac{1}{\delta r}\left(\left.r_{i+1 / 2} \frac{\partial \psi}{\partial r}\right|_{i+1 / 2, j}-\left.r_{i-1 / 2} \frac{\partial \psi}{\partial r}\right|_{i-1 / 2, j}\right)
$$


ou seja, sendo

$$
\begin{gathered}
\left.\frac{\partial}{\partial r}\left(r \frac{\partial \psi}{\partial r}\right)\right|_{i, j}=\frac{1}{(\delta r)^{2}}\left(r_{i+1 / 2} \psi_{i+1, j}-2 r_{i} \psi_{i, j}+r_{i-1 / 2} \psi_{i-1, j}\right) \\
\left(r \frac{\partial^{2} \psi}{\partial z^{2}}\right)_{i, j}=\frac{r_{i}}{(\delta z)^{2}}\left(\psi_{i, j+1}-2 \psi_{i, j}+\psi_{i, j-1}\right) \\
\left.\frac{\partial(r \tilde{u})}{\partial r}\right|_{i, j}=\frac{1}{\delta r}\left(r_{i+1 / 2} \tilde{u}_{i+1 / 2, j}-r_{i-1 / 2} \tilde{u}_{i-1 / 2, j}\right) \\
\left(r \frac{\partial \tilde{v}}{\partial z}\right)_{i, j}=\frac{r_{i}}{\delta z}\left(\tilde{v}_{i, j+1 / 2}-\tilde{v}_{i, j-1 / 2}\right)
\end{gathered}
$$

tem-se:

$$
\begin{array}{r}
\frac{1}{(\delta r)^{2}}\left(r_{i+1 / 2} \psi_{i+1, j}-2 r_{i} \psi_{i, j}+r_{i-1 / 2} \psi_{i-1, j}\right)+\frac{r_{i}}{(\delta z)^{2}}\left(\psi_{i, j+1}-2 \psi_{i, j}+\psi_{i, j-1}\right)= \\
\frac{1}{\delta r}\left(r_{i+1 / 2} \tilde{u}_{i+1 / 2, j}-r_{i-1 / 2} \tilde{u}_{i-1 / 2, j}\right)+\frac{r_{i}}{\delta z}\left(\tilde{v}_{i, j+1 / 2}-\tilde{v}_{i, j-1 / 2}\right),
\end{array}
$$

$\mathrm{Ou}$

$$
\begin{array}{r}
-r_{i+1 / 2} \psi_{i+1, j}+2 r_{i}\left[1+\left(\frac{\delta r}{\delta z}\right)^{2}\right] \psi_{i, j}-r_{i-1 / 2} \psi_{i-1, j}-r_{i}\left(\frac{\delta r}{\delta z}\right)^{2} \psi_{i, j+1} \\
-r_{i}\left(\frac{\delta r}{\delta z}\right)^{2} \psi_{i, j-1}=-\left(r_{i+1 / 2} \tilde{u}_{i+1 / 2, j}-r_{i-1 / 2} \tilde{u}_{i-1 / 2, j}\right)-r_{i} \frac{\delta r}{\delta z}\left(\tilde{v}_{i, j+1 / 2}-\tilde{v}_{i, j-1 / 2}\right) .
\end{array}
$$

A equação (3.3) resulta em um sistema de equações lineares que pode ser representado por $A \mathbf{x}=\mathbf{b}$, onde $A$ é uma matriz $n \times n$, simétrica e definida positiva, $\mathbf{x}$ é o vetor solução de ordem $n$ e $\mathbf{b}$ é o vetor de ordem $n$ do lado direito da equação de Poisson, que não depende de $\psi$. $n$ é o número de células Cheias, dentro da malha. Resolve-se este sistema através do método dos gradientes conjugados, aplicando a equação de Poisson para cada

célula Cheia dentro da malha. A matriz $A$ é montada tomando as condições de fronteira (2.7) e (2.8).

\subsection{Condições de Fronteira no Contorno Rígido}

Para a condição de não escorregamento, as equações (2.9) e (2.10) podem ser aproximadas por:

1. fronteira rígida vertical:

(a) Supondo uma fronteira rígida à esquerda, as velocidades $u_{i+1 / 2, j}$ e $v_{i, j+1 / 2}$ com a célula $(i, j)$ pertencente à fronteira são dadas por:

$$
\begin{aligned}
& u_{i+1 / 2, j}=0 \\
& v_{i, j+1 / 2}=-v_{i+1, j+1 / 2} .
\end{aligned}
$$


Veja a figura 3.3.

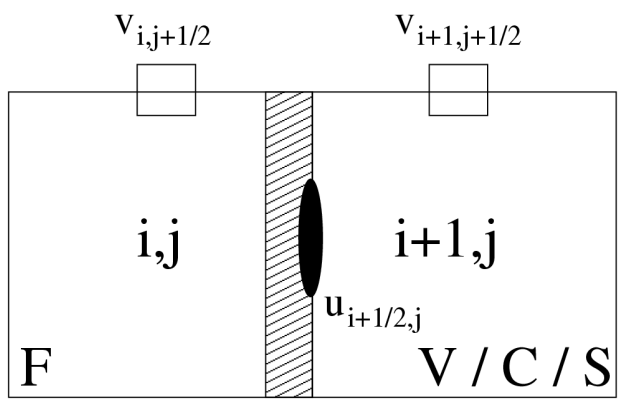

Figura 3.3: Fronteira à esquerda

(b) Supondo uma fronteira rígida à direita, as velocidades $u_{i-1 / 2, j}$ e $v_{i, j+1 / 2}$ com a célula $(i, j)$ pertencente à fronteira são dadas por:

$$
\begin{aligned}
& u_{i-1 / 2, j}=0 ; \\
& v_{i, j+1 / 2}=-v_{i-1, j+1 / 2} .
\end{aligned}
$$

Veja a figura 3.4.

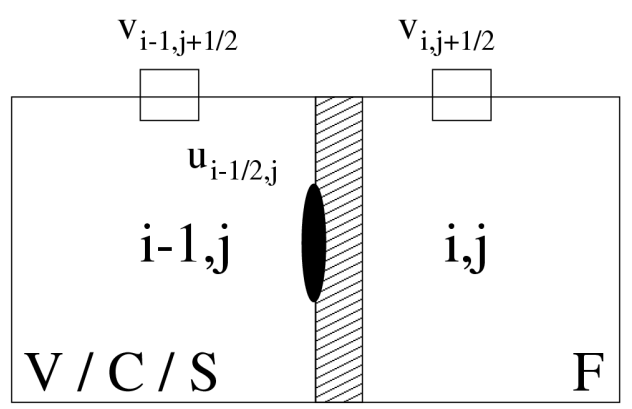

Figura 3.4: Fronteira à direita

2. fronteira rígida horizontal:

(a) Supondo uma fronteira rígida acima, as velocidades $u_{i+1 / 2, j}$ e $v_{i, j-1 / 2}$ com a célula $(i, j)$ pertencente à fronteira são dadas por:

$$
\begin{aligned}
& u_{i+1 / 2, j}=-u_{i+1 / 2, j-1} \\
& v_{i, j-1 / 2}=0 .
\end{aligned}
$$

Veja a figura 3.5. 


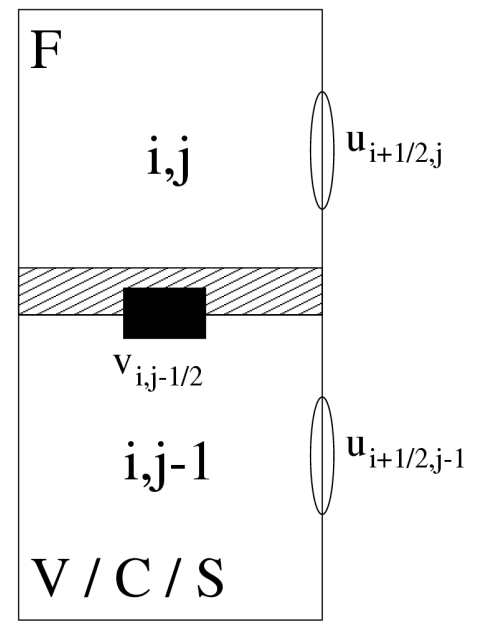

Figura 3.5: Fronteira acima

(b) Supondo uma fronteira rígida abaixo, as velocidades $u_{i+1 / 2, j}$ e $v_{i, j+1 / 2}$ com a célula $(i, j)$ pertencente à fronteira são dadas por:

$$
\begin{aligned}
& u_{i+1 / 2, j}=-u_{i+1 / 2, j+1} ; \\
& v_{i, j+1 / 2}=0 .
\end{aligned}
$$

Veja a figura 3.6.

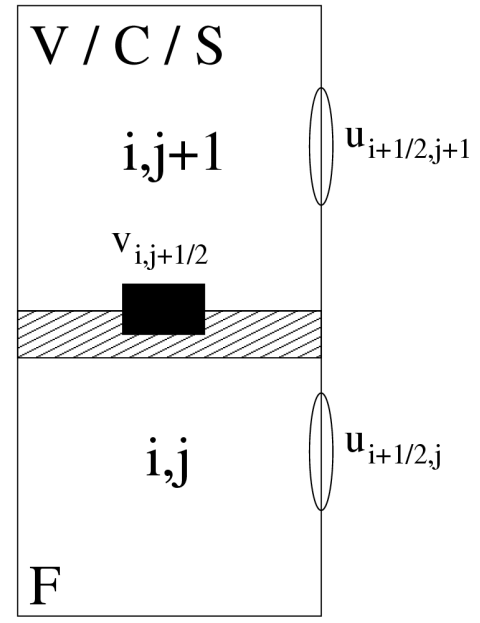

Figura 3.6: Fronteira abaixo

Para a condição de escorregamento livre, as equações (2.11) e (2.12) podem ser aproximadas por: 
1. fronteira rígida vertical:

(a) Supondo uma fronteira rígida à esquerda, as velocidades $u_{i+1 / 2, j}$ e $v_{i, j+1 / 2}$ com a célula $(i, j)$ pertencente à fronteira são dadas por:

$$
\begin{aligned}
& u_{i+1 / 2, j}=0 \\
& v_{i, j+1 / 2}=v_{i+1, j+1 / 2} .
\end{aligned}
$$

(b) Supondo uma fronteira rígida à direita, as velocidades $u_{i-1 / 2, j}$ e $v_{i, j+1 / 2}$ com a célula $(i, j)$ pertencente à fronteira são dadas por:

$$
\begin{aligned}
& u_{i-1 / 2, j}=0 \\
& v_{i, j+1 / 2}=v_{i-1, j+1 / 2} .
\end{aligned}
$$

2. fronteira rígida horizontal:

(a) Supondo uma fronteira rígida acima, as velocidades $u_{i+1 / 2, j}$ e $v_{i, j-1 / 2}$ com a célula $(i, j)$ pertencente à fronteira são dadas por:

$$
\begin{aligned}
& u_{i+1 / 2, j}=u_{i+1 / 2, j-1} \\
& v_{i, j-1 / 2}=0 .
\end{aligned}
$$

(b) Supondo uma fronteira rígida abaixo, as velocidades $u_{i+1 / 2, j}$ e $v_{i, j+1 / 2}$ com a célula $(i, j)$ pertencente à fronteira são dadas por:

$$
\begin{aligned}
& u_{i+1 / 2, j}=u_{i+1 / 2, j+1} \\
& v_{i, j+1 / 2}=0 .
\end{aligned}
$$

\subsection{Condições de Fronteira na Superfície Livre}

As condições de fronteira na superfície livre são dadas pelas equações (1.25) e (1.26), juntamente com a equação da Continuidade (1.13), que podem ser discretizadas do seguinte modo: aplicando as equações no centro da célula $(i, j)$, obtêm-se

$$
\begin{array}{rlr}
\left.\frac{1}{r} \frac{\partial(r u)}{\partial r}\right|_{i, j} & = & \frac{1}{r_{i}} \frac{r_{i+1 / 2} u_{i+1 / 2, j}-r_{i-1 / 2} u_{i-1 / 2, j}}{\delta r} ; \\
\left.\frac{\partial u}{\partial r}\right|_{i, j} & = & \frac{u_{i+1 / 2, j}-u_{i-1 / 2 . j}}{\delta r} ; \\
\left.\frac{\partial v}{\partial z}\right|_{i, j} & = & \frac{v_{i, j+1 / 2}-v_{i, j-1 / 2}}{\delta z} ; \\
\left.\frac{\partial u}{\partial z}\right|_{i, j} & = & \frac{u_{i+1 / 2, j}+u_{i-1 / 2, j}-u_{i+1 / 2, j-1}-u_{i-1 / 2, j-1}}{2 \delta z} ;
\end{array}
$$

$\mathrm{e}$

$$
\left.\frac{\partial v}{\partial r}\right|_{i, j}=\quad \frac{v_{i, j+1 / 2}+v_{i, j-1 / 2}-v_{i-1, j+1 / 2}-v_{i-1, j-1 / 2}}{2 \delta r},
$$


tornando as equações das condições de fronteira

$$
\begin{aligned}
-p_{i, j}+\frac{2}{\operatorname{Re}}[ & \frac{u_{i+1 / 2, j}-u_{i-1 / 2 . j}}{\delta r} n_{r}^{2}+\left(\frac{u_{i+1 / 2, j}+u_{i-1 / 2, j}-u_{i+1 / 2, j-1}-u_{i-1 / 2, j-1}}{2 \delta z}+\right. \\
& \left.+\frac{v_{i, j+1 / 2}+v_{i, j-1 / 2}-v_{i-1, j+1 / 2}-v_{i-1, j-1 / 2}}{2 \delta r}\right) n_{r} n_{z}+ \\
& \left.+\frac{v_{i, j+1 / 2}-v_{i, j-1 / 2}}{\delta z} n_{z}^{2}\right]=p_{c a p_{i, j}}, \\
& {\left[\frac{v_{i, j+1 / 2}+v_{i, j-1 / 2}-v_{i-1, j+1 / 2}-v_{i-1, j-1 / 2}}{2 \delta r}+\right.} \\
& \left.+\frac{u_{i+1 / 2, j}+u_{i-1 / 2, j}-u_{i+1 / 2, j-1}-u_{i-1 / 2, j-1}}{2 \delta z}\right]\left(n_{r}^{2}-n_{z}^{2}\right)+ \\
& +2\left(\frac{v_{i, j+1 / 2}-v_{i, j-1 / 2}}{\delta z}-\frac{u_{i+1 / 2, j}-u_{i-1 / 2 . j}}{\delta r}\right) n_{r} n_{z}=0
\end{aligned}
$$

e

$$
\frac{1}{r_{i}} \frac{r_{i+1 / 2} u_{i+1 / 2, j}-r_{i-1 / 2} u_{i-1 / 2, j}}{\delta r}+\frac{v_{i, j+1 / 2}-v_{i, j-1 / 2}}{\delta z}=0
$$

Para resolver as equações (3.4), (3.5) e (3.6), é necessário primeiramente determinar os valores de $n_{r}$ e $n_{z}$ e, assim, a direção dos vetores normal e tangencial à superfície livre do fluido, e, em seguida, o valor da pressão capilar $p_{c a p_{i, j}}$ na célula.

\subsubsection{Determinação de $n_{r}$ e $n_{z}$}

Os valores de $n_{r}$ e $n_{z}$ variam de acordo com a orientação da superfície livre:

1. superfície livre horizontal ou vertical:

(a) célula da superfície (S) com somente o lado superior ou inferior em contato com célula vazia $(\mathrm{V})$ : os valores são $\left(n_{r}, n_{z}\right)=(0, \pm 1)$, tornando as condições de fronteira no centro da célula $(i, j)$

$$
\begin{gathered}
p_{i, j}=\frac{2}{\operatorname{Re}}\left(\frac{v_{i, j+1 / 2}-v_{i, j-1 / 2}}{\delta z}\right)-p_{c a p_{i, j}}, \\
\frac{v_{i, j+1 / 2}+v_{i, j-1 / 2}-v_{i-1, j+1 / 2}-v_{i-1, j-1 / 2}}{\delta r}= \\
=-\frac{u_{i+1 / 2, j}+u_{i-1 / 2, j}-u_{i+1 / 2, j-1}-u_{i-1 / 2, j-1}}{\delta z}, \\
\frac{1}{r_{i}} \frac{r_{i+1 / 2} u_{i+1 / 2, j}-r_{i-1 / 2} u_{i-1 / 2, j}}{\delta r}=-\frac{v_{i, j+1 / 2}-v_{i, j-1 / 2}}{\delta z} .
\end{gathered}
$$


(b) célula da superfície (S) com somente o lado esquerdo ou direito em contato com célula vazia $(\mathrm{V})$ : os valores são $\left(n_{r}, n_{z}\right)=( \pm 1,0)$, tornando as condições de fronteira no centro da célula $(i, j)$

$$
\begin{gathered}
p_{i, j}=\frac{2}{\operatorname{Re}}\left(\frac{u_{i+1 / 2, j}-u_{i-1 / 2 . j}}{\delta r}\right)-p_{c a p_{i, j}}, \\
\frac{v_{i, j+1 / 2}+v_{i, j-1 / 2}-v_{i-1, j+1 / 2}-v_{i-1, j-1 / 2}}{\delta r}= \\
=-\frac{u_{i+1 / 2, j}+u_{i-1 / 2, j}-u_{i+1 / 2, j-1}-u_{i-1 / 2, j-1}}{\delta z}, \\
\frac{1}{r_{i}} \frac{r_{i+1 / 2} u_{i+1 / 2, j}-r_{i-1 / 2} u_{i-1 / 2, j}}{\delta r}=-\frac{v_{i, j+1 / 2}-v_{i, j-1 / 2}}{\delta z} .
\end{gathered}
$$

2. superfície livre a $45^{\circ}$, onde há uma célula $\mathrm{S}$ com dois lados contíguos com células $\mathrm{V}$ :

(a) célula $\mathrm{S}$ em contato com células $\mathrm{V}$ acima e à direita: os valores são $\left(n_{r}, n_{z}\right)=$ $\left(+\frac{\sqrt{2}}{2},+\frac{\sqrt{2}}{2}\right)$, tornando as condições de fronteira no centro da célula $(i, j)$

$$
\begin{aligned}
& p_{i, j}=\frac{1}{\operatorname{Re}}[ \frac{u_{i+1 / 2, j}-u_{i-1 / 2 . j}}{\delta r}+\left(\frac{u_{i+1 / 2, j}+u_{i-1 / 2, j}-u_{i+1 / 2, j-1}-u_{i-1 / 2, j-1}}{2 \delta z}+\right. \\
&+\left.\frac{v_{i, j+1 / 2}+v_{i, j-1 / 2}-v_{i-1, j+1 / 2}-v_{i-1, j-1 / 2}}{2 \delta r}\right)+ \\
&+\left.\frac{v_{i, j+1 / 2}-v_{i, j-1 / 2}}{\delta z}\right]-p_{c a p_{i, j}}, \\
& \frac{v_{i, j+1 / 2}-v_{i, j-1 / 2}}{\delta z}=\frac{u_{i+1 / 2, j}-u_{i-1 / 2 . j}}{\delta r}, \\
& \frac{1}{r_{i}} \frac{r_{i+1 / 2} u_{i+1 / 2, j}-r_{i-1 / 2} u_{i-1 / 2, j}}{\delta r}=-\frac{v_{i, j+1 / 2}-v_{i, j-1 / 2}}{\delta z} .
\end{aligned}
$$

(b) célula $\mathrm{S}$ em contato com células $\mathrm{V}$ acima e à esquerda: os valores são $\left(n_{r}, n_{z}\right)=$ $\left(-\frac{\sqrt{2}}{2},+\frac{\sqrt{2}}{2}\right)$, tornando as condições de fronteira no centro da célula $(i, j)$

$$
\begin{aligned}
& p_{i, j}=\frac{1}{\operatorname{Re}}[ \frac{u_{i+1 / 2, j}-u_{i-1 / 2 . j}}{\delta r}-\left(\frac{u_{i+1 / 2, j}+u_{i-1 / 2, j}-u_{i+1 / 2, j-1}-u_{i-1 / 2, j-1}}{2 \delta z}+\right. \\
&+\left.\frac{v_{i, j+1 / 2}+v_{i, j-1 / 2}-v_{i-1, j+1 / 2}-v_{i-1, j-1 / 2}}{2 \delta r}\right)+ \\
&+\left.\frac{v_{i, j+1 / 2}-v_{i, j-1 / 2}}{\delta z}\right]-p_{c a p_{i, j}}, \\
& \frac{v_{i, j+1 / 2}-v_{i, j-1 / 2}}{\delta z}=\frac{u_{i+1 / 2, j}-u_{i-1 / 2 . j}}{\delta r}, \\
& \frac{1}{r_{i}} \frac{r_{i+1 / 2} u_{i+1 / 2, j}-r_{i-1 / 2} u_{i-1 / 2, j}}{\delta r}=-\frac{v_{i, j+1 / 2}-v_{i, j-1 / 2}}{\delta z} .
\end{aligned}
$$


(c) célula $\mathrm{S}$ em contato com células $\mathrm{V}$ abaixo e à direita: os valores são $\left(n_{r}, n_{z}\right)=$ $\left(+\frac{\sqrt{2}}{2},-\frac{\sqrt{2}}{2}\right)$, tornando as condições de fronteira no centro da célula $(i, j)$

$$
\begin{aligned}
& p_{i, j}=\frac{1}{\operatorname{Re}}[ \frac{u_{i+1 / 2, j}-u_{i-1 / 2 . j}}{\delta r}-\left(\frac{u_{i+1 / 2, j}+u_{i-1 / 2, j}-u_{i+1 / 2, j-1}-u_{i-1 / 2, j-1}}{2 \delta z}+\right. \\
&\left.+\frac{v_{i, j+1 / 2}+v_{i, j-1 / 2}-v_{i-1, j+1 / 2}-v_{i-1, j-1 / 2}}{2 \delta r}\right)+ \\
&+\left.\frac{v_{i, j+1 / 2}-v_{i, j-1 / 2}}{\delta z}\right]-p_{c a p_{i, j}}, \\
& \frac{v_{i, j+1 / 2}-v_{i, j-1 / 2}}{\delta z}=\frac{u_{i+1 / 2, j}-u_{i-1 / 2 . j}}{\delta r}, \\
& \frac{1}{r_{i}} \frac{r_{i+1 / 2} u_{i+1 / 2, j}-r_{i-1 / 2} u_{i-1 / 2, j}}{\delta r}=-\frac{v_{i, j+1 / 2}-v_{i, j-1 / 2}}{\delta z} .
\end{aligned}
$$

(d) célula $\mathrm{S}$ em contato com células $\mathrm{V}$ abaixo e à esquerda: os valores são $\left(n_{r}, n_{z}\right)=$ $\left(-\frac{\sqrt{2}}{2},-\frac{\sqrt{2}}{2}\right)$, tornando as condições de fronteira no centro da célula $(i, j)$

$$
\begin{aligned}
& p_{i, j}=\frac{1}{\operatorname{Re}}[ \frac{u_{i+1 / 2, j}-u_{i-1 / 2 . j}}{\delta r}+\left(\frac{u_{i+1 / 2, j}+u_{i-1 / 2, j}-u_{i+1 / 2, j-1}-u_{i-1 / 2, j-1}}{2 \delta z}+\right. \\
&\left.+\frac{v_{i, j+1 / 2}+v_{i, j-1 / 2}-v_{i-1, j+1 / 2}-v_{i-1, j-1 / 2}}{2 \delta r}\right)+ \\
&\left.+\frac{v_{i, j+1 / 2}-v_{i, j-1 / 2}}{\delta z}\right]-p_{c a p_{i, j}}, \\
& \frac{v_{i, j+1 / 2}-v_{i, j-1 / 2}}{\delta z}=\frac{u_{i+1 / 2, j}-u_{i-1 / 2 . j}}{\delta r}, \\
& \frac{1}{r_{i}} \frac{r_{i+1 / 2} u_{i+1 / 2, j}-r_{i-1 / 2} u_{i-1 / 2, j}}{\delta r}=-\frac{v_{i, j+1 / 2}-v_{i, j-1 / 2}}{\delta z} .
\end{aligned}
$$

3. célula da superfície livre adjacente a duas células vazias em lados opostos ou adjacentes a três células vazias: neste caso, a pressão é igual a $-p_{c a p}$ e a velocidade é ajustada de modo que a equação da continuidade (1.13) seja satisfeita na célula da superfície livre.

\subsubsection{Cálculo da pressão capilar $p_{c a p_{i, j}}$}

A pressão capilar $p_{c a p}$, definida na equação (1.20), pode ser determinada em cada célula $(i, j)$ calculando-se as curvaturas $\kappa$ em cada célula. A curvatura total $\kappa$ é calculada a partir de duas curvaturas:

$$
\kappa=\kappa_{1}+\kappa_{2}
$$


onde $\kappa_{1}$ é a curvatura da superfície livre no plano $r-z$, e

$$
\kappa_{2}=\frac{1}{r\left(1+\frac{n_{z}^{2}}{n_{r}^{2}}\right)^{1 / 2}},
$$

onde $r$ é a distância até o eixo de simetria e $\mathbf{n}_{\mathbf{s}}=\left(n_{r}, n_{z}\right)^{t}$ é a normal à superfície. Assim, para calcular a curvatura total, é necessário calcular, para cada célula de superfície $\mathbf{S}$, os valores de $\kappa_{1}, r$ e $\mathbf{n}_{\mathbf{s}}$.

\section{Cálculo de $\mathbf{n}_{\mathrm{s}}$ e $\kappa_{1}$}

A curvatura da superfície livre em uma célula $\mathbf{S}$ é calculada determinando a curva que melhor se ajusta aos pontos da superfície na célula e suas vizinhas, utilizando o método dos mínimos quadrados. A curva a ser ajustada aos pontos da superfície livre será aproximada por um polinômio quadrático, escolhido por gerar resultados precisos mais consistentes [8]. Será detalhado a seguir o método utilizado para a aproximação da curva.

Considere as partículas $\mathbf{x}_{\mathbf{i}}=\left(x_{i}, y_{i}\right)^{t}$, com $i=1, \ldots, m$, da superfície nas vizinhanças da célula $\mathbf{S}$.

A curvatura da superfície é calculada em dois passos. Inicialmente, a normal à superfície na célula é calculada ajustando-se uma reta que melhor aproxima a posição das partículas em uma vizinhança quadrada do centro da célula, utilizando o método dos mínimos quadrados. Para cada $\mathbf{x}_{\mathbf{i}}$, tem-se a equação $a x_{i}+b=y_{i}, i=1, \ldots, m$. A aproximação por mínimos quadrados pode, então, ser obtida resolvendo o sistema de equações normais:

$$
\left(\begin{array}{ll}
\mathbf{A}^{t} \cdot \mathbf{A} & \mathbf{A}^{t} \cdot \mathbf{B} \\
\mathbf{B}^{t} \cdot \mathbf{A} & \mathbf{B}^{t} \cdot \mathbf{B}
\end{array}\right)\left(\begin{array}{c}
a \\
b
\end{array}\right)=\left(\begin{array}{c}
\mathbf{Y}^{t} \cdot \mathbf{A} \\
\mathbf{Y}^{t} \cdot \mathbf{B}
\end{array}\right)
$$

onde

$$
\mathbf{A}=\left(\begin{array}{c}
x_{1} \\
\vdots \\
x_{m}
\end{array}\right), \mathbf{B}=\left(\begin{array}{c}
1 \\
\vdots \\
1
\end{array}\right), \text { e } \mathbf{Y}=\left(\begin{array}{c}
y_{1} \\
\vdots \\
y_{m}
\end{array}\right)
$$

Se a matriz do sistema (3.9) é singular, a melhor aproximação é dada por $x=c$ e o vetor normal será $\mathbf{n}_{\mathbf{s}}=\left(n_{r}, n_{z}\right)=(1,0)$. Senão, a melhor aproximação será dada por $a x-y+b=0$, e o vetor normal será

$$
\mathbf{n}_{\mathbf{s}}=\left(n_{r}, n_{z}\right)=\left(\frac{a}{\sqrt{a^{2}+1}}, \frac{-1}{\sqrt{a^{2}+1}}\right) .
$$

Tomando a normal à superfície no centro da célula $\mathbf{n}_{\mathbf{c}}=\left(n_{c_{r}}, n_{c_{z}}\right)$, dada pela configuração das células vizinhas, se $n_{c_{z}}=0$, permutam-se os valores de $n_{r}$ e $n_{z}$.

Determinada a normal à superfície, calcula-se uma aproximação quadrática, em um sistema de coordenadas $\xi-\eta$, rotacionado e transladado em relação ao sistema de coordenadas $x-y$, de modo que $\eta$ se alinhe com o vetor normal à superfície, e passando pelo 
centro da célula. As coordenadas neste sistema referencial serão calculadas utilizando

$$
\xi=\left(x-x_{c}\right) n_{z}-\left(y-y_{c}\right) n_{r} ; \quad \eta=\left(x-x_{c}\right) n_{r}+\left(y-y_{c}\right) n_{z},
$$

onde $\mathbf{x}_{\mathbf{c}}=\left(x_{c}, y_{c}\right)$, e $x_{c}, y_{c}$ são as coordenadas do centro da célula.

Neste novo sistema de coordenadas, determinam-se os coeficientes $d$, e e $f$ que geram a melhor aproximação para $\eta=d \xi^{2}+e \xi+f$ para os pontos da célula e sua vizinhança.

Para cada $\mathbf{x}_{\mathbf{i}}$, tem-se $\eta_{i}=d \xi_{i}^{2}+e \xi_{i}+f, i=1, \ldots, m$. A aproximação por mínimos quadrados pode ser obtida resolvendo as equações normais

$$
\left(\begin{array}{lll}
\mathbf{D}^{t} \cdot \mathbf{D} & \mathbf{D}^{t} \cdot \mathbf{E} & \mathbf{D}^{t} \cdot \mathbf{B} \\
\mathbf{E}^{t} \cdot \mathbf{D} & \mathbf{E}^{t} \cdot \mathbf{E} & \mathbf{E}^{t} \cdot \mathbf{B} \\
\mathbf{B}^{t} \cdot \mathbf{D} & \mathbf{B}^{t} \cdot \mathbf{E} & \mathbf{B}^{t} \cdot \mathbf{B}
\end{array}\right)\left(\begin{array}{c}
d \\
e \\
f
\end{array}\right)=\left(\begin{array}{c}
\mathbf{F}^{t} \cdot \mathbf{D} \\
\mathbf{F}^{t} \cdot \mathbf{E} \\
\mathbf{F}^{t} \cdot \mathbf{B}
\end{array}\right)
$$

onde

$$
\mathbf{D}=\left(\begin{array}{c}
\xi_{1}^{2} \\
\vdots \\
\xi_{m}^{2}
\end{array}\right), \mathbf{E}=\left(\begin{array}{c}
\xi_{1} \\
\vdots \\
\xi_{m}
\end{array}\right), \mathbf{B}=\left(\begin{array}{c}
1 \\
\vdots \\
1
\end{array}\right), \mathrm{e} \mathbf{F}=\left(\begin{array}{c}
\eta_{1} \\
\vdots \\
\eta_{m}
\end{array}\right)
$$

Então, o valor da curvatura $\kappa_{1}$ é dado por $\kappa_{1}=-2 d$. Se o sistema (3.10) for singular, a curvatura é definida como sendo nula $\left(\kappa_{1}=0\right)$.

Este procedimento determina $\kappa_{1}$ exceto pelo sinal, que pode ser obtido comparando a normal no centro da célula $\mathbf{n}_{\mathbf{c}}$, determinada a partir da classificação das células vizinhas, e a normal da melhor aproximação $\mathbf{n}_{\mathbf{s}}$. Se $\mathbf{n}_{\mathbf{c}}^{\mathbf{t}} \cdot \mathbf{n}_{\mathbf{s}}<0$, a orientação da normal $\mathbf{n}_{\mathbf{s}}$ e o sinal da curvatura $\kappa_{1}$ precisam ser invertidos.

\subsection{Cálculo da Tensão Superficial}

O cálculo do efeito da tensão superficial deve ser realizado em dois níveis: primeiramente, em um nível subcelular, removem-se pequenas ondulações na superfície livre e, em seguida, em um nível celular, a curvatura da superfície livre no centro da célula é aproximada.

O cálculo da curvatura, no segundo nível, foi desenvolvido na seção anterior, na aplicação das condições de fronteira na superfície livre. Agora será desenvolvido um método para a eliminação de pequenas ondulações na superfície livre.

\subsubsection{Eliminação de Pequenas Ondulações}

Em simulações onde o número de Reynolds é alto (acima de 50), podem surgir pequenas ondulações na superfície livre devido a variações no campo de velocidade de célula para célula, e serem amplificadas em regiões onde a área superficial estiver diminuindo. Estas ondulações são, frequentemente, muito menores que uma célula computacional. Estes 
efeitos são puramente numéricos, resultados do fato que o método GENSMAC não é capaz de resolver fenômenos que ocorram no interior de uma célula.

Há diversas técnicas que podem ser utilizadas para reduzir estas ondulações, como a substituição da posição de cada partícula na superfície pela média de seus vizinhos, entre outros. No entanto, em simulações de escoamentos de fluidos é importante que a técnica aplicada não altere a massa ou o volume do escoamento.

No simulador bidimensional foi implementada a técnica TSUR (Trapezoidal Sub-Grid Ondulations Removal) [4], que consiste em alterar simultaneamente a posição de duas partículas adjacentes, de modo que a área delineada por estas duas partículas e suas vizinhas não seja alterada.

No caso axissimétrico, similarmente ao caso bidimensional, a posição das duas partículas adjacentes também são alteradas simultaneamente, mas, nesse caso, é preservado o volume de rotação $V$ delineado pelas duas partículas e suas vizinhas, $\mathbf{x}_{\mathbf{i}}, \mathbf{x}_{\mathbf{i}+\mathbf{1}}, \mathbf{x}_{\mathbf{i}+\mathbf{2}}$ e $\mathbf{x}_{\mathbf{i}+\mathbf{3}}$. Este volume de rotação pode ser calculado através da integral

$$
V=2 \pi \iint r d r d z
$$

Para calcular o volume de rotação do quadrilátero formado pelos quatro pontos antes da modificação, divide-se o quadrilátero em dois triângulos, calcula-se o volume de rotação de cada triângulo usando (3.11), e então os dois volumes são somados para se obter o volume total. Para um triângulo com coordenadas $\mathbf{x}_{\mathbf{i}}=\left(x_{i}, y_{i}\right), \mathbf{x}_{\mathbf{j}}=\left(x_{j}, y_{j}\right)$ e $\mathbf{x}_{\mathbf{k}}=\left(x_{k}, y_{k}\right)$ :

- se $x_{i} \neq x_{j}$ :

$$
V_{i j k}=2 \pi\left(y_{k}-y_{p}\right)\left[\left(x_{p}-x_{i}\right)\left(\frac{x_{i}}{2}+\frac{x_{p}-x_{i}}{3}\right)+\left(x_{j}-x_{p}\right)\left(\frac{x_{p}}{2}+\frac{x_{j}-x_{p}}{6}\right)\right],
$$

onde

$$
x_{p}=x_{k} ; \quad y_{p}=y_{i}+\left(y_{j}-y_{i}\right) \frac{x_{p}-x_{i}}{x_{j}-x_{i}}
$$

- se $x_{i}=x_{j}$ :

$$
V_{i j k}=\pi\left[x_{k}+\frac{2}{3}\left(x_{j}-x_{k}\right)\right]\left[\left(x_{j}-x_{i}\right)\left(y_{k}-y_{i}\right)-\left(x_{k}-x_{i}\right)\left(y_{j}-y_{i}\right)\right] ;
$$

Para calcular o volume de rotação do trapézio isósceles obtido após a aplicação do método, serão definidos dois parâmetros:

- o comprimento

$$
L=\frac{1}{3}\left\|\mathbf{x}_{\mathbf{i}+\mathbf{3}}-\mathbf{x}_{\mathbf{i}}\right\|
$$

- o vetor unitário tangente a $\mathbf{x}_{\mathbf{i}+\mathbf{3}}-\mathbf{x}_{\mathbf{i}}$

$$
\mathbf{n}=\left(n_{r}, n_{z}\right) .
$$


Dados estes valores, obtém-se o volume de rotação do trapézio isósceles $V_{t}$

$$
V_{t}=2 \pi L h\left(2 x_{i}+3 L n_{r}-\frac{5}{6} h n_{z}\right) .
$$

Para que o volume de rotação final (3.12) seja igual ao volume de rotação inicial (calculado usando a equação (3.11)),$h$ deve satisfazer:

- se $n_{z} \neq 0$ :

$$
h^{2}-\frac{6}{5}\left(\frac{2 x_{i}}{n_{z}}+\frac{3 L n_{r}}{n_{z}}\right) h+\frac{6}{5} \frac{V}{2 \pi L n_{z}}=0 .
$$

Resolvendo a equação para $h$, a equação gera duas soluções, e deve ser selecionada a solução com coordenadas radiais positivas para as posições finais dos dois pontos internos do estêncil;

- se $n_{z}=0$ :

$$
h=\frac{V}{2 \pi} \frac{1}{\left(2 x_{i} L n_{r}+3 L^{2}\right)} .
$$

\section{8 Ângulo de Contato}

A aplicação do ângulo de contato prescrito é introduzida nas condições de contorno rígidas, através da modificação do cálculo da curvatura nas células de superfície adjacentes a células do contorno rígido. Para o cálculo da curvatura e, consequentemente, da pressão capilar para estas células de superfície, aplica-se o procedimento a seguir.

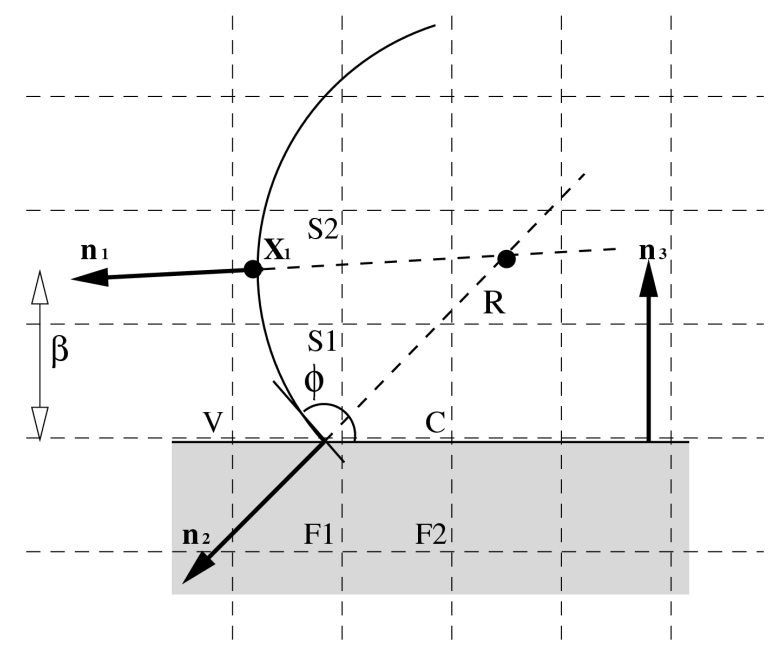

Figura 3.7: Ângulo de contato

Considere uma gota de fluido em repouso sobre uma superfície sólida (figura 3.7). Para calcular a curvatura na célula de superfície $\mathbf{S} 1$, adjacente à célula do contorno rígido $\mathbf{F} 1$, 
obtêm-se, inicialmente, a normal $\mathbf{n}_{\mathbf{1}}$ e o ponto $\mathbf{X}_{\mathbf{1}}=\left(x_{1}, y_{1}\right)$ da célula de superfície $\mathbf{S} 2$, com $\mathbf{X}_{\mathbf{1}}$ sendo o ponto onde a normal $\mathbf{n}_{\mathbf{1}}$ foi calculada anteriormente através do sistema (3.9). Em seguida, calcula-se a normal à superfície rígida $\mathbf{n}_{\mathbf{3}}$.

O cálculo de $\mathbf{n}_{\mathbf{3}}$ é feito a partir dos pontos de intersecção do contorno rígido na célula $\mathbf{F} 1$, com coordenadas $(i, j)$, com as seis retas:

$$
\begin{aligned}
& x=r_{i-\frac{1}{2}} ; \\
& x=r_{i} ; \\
& x=r_{i+\frac{1}{2}} ; \\
& y=z_{j-\frac{1}{2}} ; \\
& y=z_{j} ; \\
& y=z_{j+\frac{1}{2}},
\end{aligned}
$$

e resolvendo o sistema (3.9) para estes pontos. Ao resolver o sistema, obtém-se a equação da reta aproximada por estes pontos,

$$
\begin{gathered}
a x-y+b=0 \\
\text { ou } \\
x=c,
\end{gathered}
$$

onde, na equação (3.13), $a$ é a inclinação da reta e $b$ é o deslocamento da reta com relação ao eixo $x$. A equação (3.14) deve ser utilizada quando o contorno rígido está na vertical.

As componentes de $\mathbf{n}_{\mathbf{3}}, n_{3_{r}}$ e $n_{3_{z}}$, são dadas por

$$
\begin{aligned}
& n_{3_{r}}=\sin (\theta) \\
& n_{3_{z}}=\cos (\theta),
\end{aligned}
$$

onde $\theta=\arctan (a)$ é o ângulo que o contorno rígido faz com a horizontal.

No caso da segunda equação (3.14), $n_{3_{r}}$ e $n_{3_{z}}$ são dadas por $\left(n_{3_{r}}, n_{3_{z}}\right)=(1,0)$, e o ângulo $\theta$ é $\frac{\pi}{2}$.

Desse modo, a normal $\mathbf{n}_{\mathbf{3}}$ fica determinada exceto pelo sinal de suas componentes. Compara-se o sinal das componentes de $\mathbf{n}_{\mathbf{3}}$ calculadas e das componentes da normal da célula dada pela configuração de células. Se as componentes estão invertidas, troca-se o sinal das componentes $n_{3_{r}}$ e $n_{3 z}$.

$\mathbf{n}_{\mathbf{2}}$ é a normal à superfície livre no ponto de contato $\mathbf{X}_{\mathbf{2}}$, e é obtida a partir do ângulo de contato $\phi$ e do ângulo do contorno rígido $\theta$ na célula de fronteira $\mathbf{F} 1$.

A distância normal do ponto $\mathbf{X}_{\mathbf{1}}$ até o contorno rígido, $\beta$, é calculada através do ponto $\mathbf{X}_{\mathbf{1}}=\left(x_{1}, y_{1}\right)$ e da equação da reta do contorno rígido. Se $\theta$ é menor que $\frac{\pi}{2}$, obtém-se

$$
\beta=\left|\frac{a x_{1}-y_{1}+b}{1+a^{2}}\right| ;
$$

senão,

$$
\beta=\left|x_{1}-c\right| .
$$


Com todos estes dados, uma circunferência pode ser construída, com as normais $\mathbf{n}_{\mathbf{1}} \mathrm{e}$ $\mathbf{n}_{\mathbf{2}}$. Sendo $R$ o raio dessa circunferência, obtém-se

$$
\mathbf{X}_{1}-\mathbf{X}_{2}=R\left(\mathbf{n}_{1}-\mathbf{n}_{2}\right)
$$

Pode ser afirmado, também, que

$$
\beta=\left(\mathbf{X}_{1}-\mathbf{X}_{\mathbf{2}}\right) \cdot \mathbf{n}_{\mathbf{3}} .
$$

Assim, substituindo (3.15) em (3.16), obtém-se $R\left(\mathbf{n}_{\mathbf{1}}-\mathbf{n}_{\mathbf{2}}\right) \cdot \mathbf{n}_{\mathbf{3}}=\beta$, e, assim, a curvatura $\kappa$ para a célula $\mathbf{S} 1$ será

$$
\kappa=\frac{1}{R}=\frac{\left(\mathbf{n}_{1}-\mathbf{n}_{2}\right) \cdot \mathbf{n}_{\mathbf{3}}}{\beta} .
$$

Com $\kappa$, a pressão capilar na célula S1 é calculada sem a utilização das partículas marcadoras desta célula. Assim, na análise dos resultados, a posição da superfície livre nas células próximas ao contorno rígido é somente aproximada, podendo ser desconsiderada. O procedimento descrito acima é generalizado e, em princípio, pode ser utilizado para qualquer ângulo de contato.

\subsection{Cálculo do Passo no Tempo}

Em cada ciclo de cálculo no método GENSMAC determina-se um passo no tempo $\delta t$. Este passo no tempo é calculado segundo as seguintes restrições de estabilidade:

1. Nenhuma partícula pode cruzar mais do que uma célula em um dado intervalo de tempo, isto é,

$$
\delta t<\frac{\delta r}{|u|} \text { e } \delta t<\frac{\delta z}{|v|}
$$

É suficiente que

$$
\delta t<\frac{\delta r}{\left|U_{\max }\right|} \text { e } \delta t<\frac{\delta z}{\left|V_{\max }\right|} .
$$

para satisfazer a equação (3.18), onde $U_{\max }$ e $V_{\max }$ são os valores máximos de $u$ e $v$, respectivamente.

2. Devido à discretização explícita das equações da conservação de quantidade de movimento, adota-se a restrição de estabilidade, que envolve o número de Reynolds:

$$
\delta t<\frac{\operatorname{Re}}{2}\left(\frac{\delta r^{2} \delta z^{2}}{\delta r^{2}+\delta z^{2}}\right)
$$




\section{Capítulo 4}

\section{Ambiente de Simulação Freeflow-2D}

Para a modelagem, simulação e visualização de escoamentos bidimensionais incompressíveis com superfícies livres é utilizado o sistema integrado Freeflow-2D [10], que é dividido em quatro partes:

- Modflow-2D: modelador de moldes e escoamentos;

- Simflow-2D: simulador de escoamentos;

- Visflow-2D: visualizador de escoamentos;

- Resimflow-2D: reiniciador de simulações de escoamentos.

\subsection{Estrutura de Dados}

A estrutura de dados do ambiente bidimensional é baseada na estrutura de dados do Freeflow-3D, que representa os objetos geométricos por suas fronteiras (faces, arestas, vértices e relações topológicas). No futuro, os ambientes bi e tridimensionais poderão ser integrados devido a esta similaridade entre as estruturas de dados.

No ambiente bidimensional, a estrutura de dados está dividida em quatro partes: fatia, face, semi-aresta e vértice. Esta estrutura foi denominada halfedge-2D, que é uma adaptação da estrutura halfedge utilizada no ambiente Freeflow-3D [5]. Os níveis hierárquicos desta estrutura estão representados na Figura 4.1. 


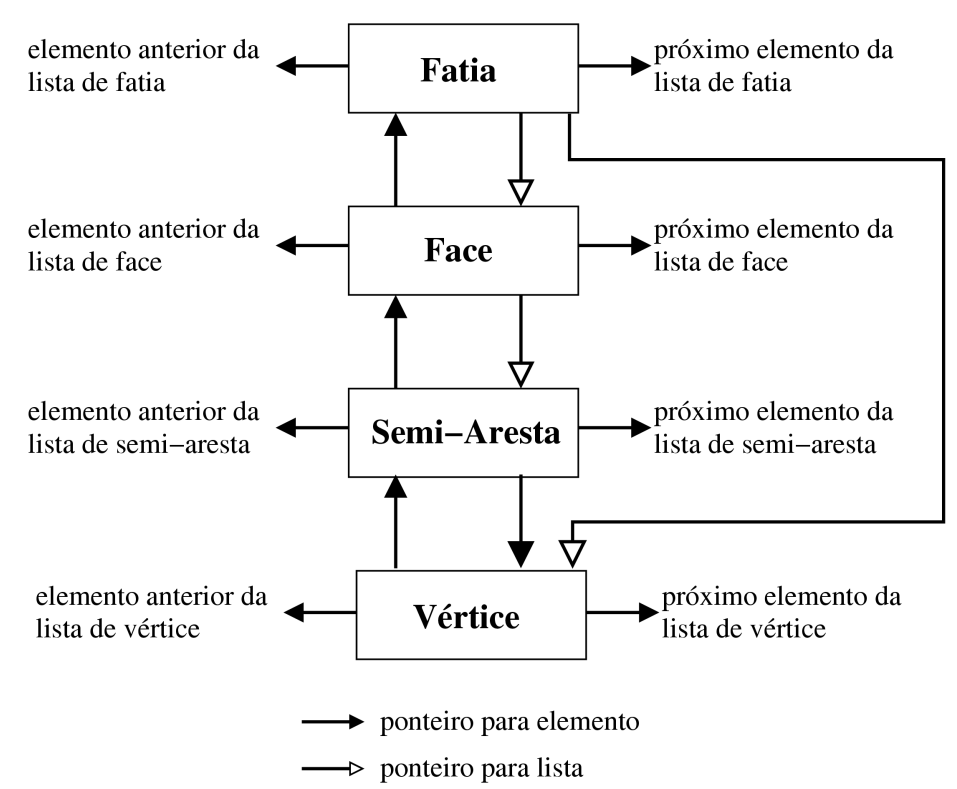

Figura 4.1: Níveis hierárquicos da estrutura de dados halfedge-2D

A lista semi-aresta é fechada, e as listas fatia, face e vértice são abertas.

O ambiente Freeflow-2D tem duas classes de dados:

- dados diretos: contêm os dados referentes ao domínio, velocidades, pressão, células e parâmetros utilizados pelo simulador, e a representação de objetos geométricos do modelo.

Esta classe de dados é subdividida em duas subclasses: dados estáticos e dinâmicos. Os dados estáticos são os dados que definem o domínio, a discretização, parâmetros adimensionalizados e propriedades de fluido independente do tempo e de fluxo do fluido. Os dados dinâmicos são os dados que especificam as velocidades, a pressão, o tipo de células e a representação dos objetos geométricos.

As velocidades e a pressão são armazenadas em matrizes, e as células são armazenadas tanto em matrizes quanto em árvores. Os objetos geométricos são representados pela estrutura de dados halfedge-2D.

- dados indiretos: a representação dos dados desta classe foi desenvolvida para a melhor representação dos objetos por fronteiras, melhor desempenho dos algoritmos no simulador e a minimização da interdependência entre dados. Esta estrutura é composta por três tipos: Recipiente, Injetor e Ejetor, representando recipientes, injetores e ejetores, respectivamente.

A estrutura de dados Recipiente é composta de dados geométricos ( $B$-Rep), tipos de condição de fronteira, e informações guardadas em uma árvore sobre as células que definem o recipiente e atributos específicos do recipiente.

A estrutura de dados Injetor é composta de dados geométricos ( $B$-Rep), propriedades de injeção, informações sobre o recipiente e o fluido relacionado com o injetor, e uma 
árvore que guarda informações sobre as células que definem o injetor e atributos específicos da injeção.

A estrutura de dados Ejetor é composta de dados geométricos, tipos de condições de contorno, informações sobre o recipiente, e uma árvore que guarda informações sobre as células que definem o ejetor e atributos específicos do ejetor.

As estruturas de dados descritas acima são usadas pelo Modflow-2D para construir a configuração inicial para o escoamento que será desenvolvido pelo Simflow-2D.

\subsection{Modelador de Moldes}

O módulo Modflow-2D é responsável pela introdução dos dados que caracterizam o escoamento a ser simulado e pela definição de elementos no domínio do escoamento. Informações como tamanho do domínio, formato do recipiente e valor da viscosidade para uma simulação são definidos neste módulo. Os dados coletados por este módulo são salvos em arquivos, para serem utilizados pelos outros módulos.

\subsection{Simulador}

O simulador resolve as equações de Navier-Stokes em duas dimensões para um fluido incompressível e a equação de conservação de massa (equação da continuidade) para o fluido e objetos geométricos definidos anteriormente no modelador. O fluido no simulador é representado por partículas apenas na fronteira utilizando a estrutura halfedge-2D. O método implementado no simulador é o método GENSMAC, visto previamente no Capítulo 2. A seguir, faz-se uma síntese das etapas para a movimentação da superfície livre na simulação.

A simulação inicia-se com a leitura dos arquivos de entrada criados pelo modelador. Em seguida, a injeção é iniciada. Depois, realiza-se o seguinte ciclo:

- cálculo das velocidades $u$ e $v$ pelas condições de contorno na superfície livre;

- cálculo das velocidades tangenciais $u$ e $v$ das células $S$ com as células $V$;

- cálculo das velocidades $u$ e $v$ pelas condições de contorno no contorno rígido;

- cálculo das velocidades tangenciais $u$ e $v$ nos injetores;

- cálculo da pressão $p$ nas condições de contorno na superfície livre;

- cálculo das velocidades intermediárias $\tilde{u}$ e $\tilde{v}$;

- resolução da equação de Poisson;

- cálculo das velocidades finais $u$ e $v$; 
- cálculo das velocidades $u$ e $v$ pelas condições de contorno na superfície livre;

- cálculo das velocidades tangenciais $u$ e $v$ das células $S$ com as células $V$;

- cálculo das velocidades $u$ e $v$ pelas condições de contorno no contorno rígido;

- cálculo das velocidades tangenciais $u$ e $v$ nos injetores;

- movimento das partículas virtuais na superfície livre;

- inserção das partículas virtuais nos injetores;

- eliminação das partículas virtuais;

- inserção das partículas virtuais no fluido;

- redefinição das células após o movimento das partículas virtuais;

- recomeço do ciclo.

As informações dos ciclos realizados são salvas em arquivos e, em seguida, o visualizador bidimensional utiliza estes arquivos para criar as imagens da simulação do escoamento do fluido.

\subsection{Visualizador de Escoamentos}

O visualizador de escoamentos bidimensionais Visflow-2D permite visualizar graficamente os resultados da simulação de escoamentos de fluidos. O simulador fornece ao visualizador os dados sobre o modelo de escoamento, a representação dos objetos geométricos e as propriedades em instantes previamente definidos.

A transferência dos dados do simulador para o visualizador é feita sob a forma de arquivos. Os dados estáticos estão localizados em um arquivo e os dados dinâmicos são compostos por informações sobre os objetos geométricos, velocidades, pressão, configuração das células, o tempo e ciclo da simulação.

\subsection{Reiniciador}

O módulo Resimflow-2D é utilizado para reiniciar uma simulação em caso de interrupção na execução do programa ou em caso de necessidade de aumentar o tempo de simulação. O simulador gera arquivos de saída com a mesma estrutura do modelador e arquivos de saída para a visualização dos resultados. No primeiro caso, os arquivos podem ser utilizados para reiniciar a simulação. Os arquivos de saída do Resimflow-2D possuem o mesmo formato dos arquivos de saída do modelador. 


\section{Capítulo 5}

\section{Ambiente de Simulação Freeflow-3D}

O ambiente de simulação Freeflow-3D é dividido em três módulos: Modflow-3D (especificações iniciais), Simflow-3D (simulador de escoamentos) e Visflow-3D (visualização dos escoamentos). A estrutura de dados deste ambiente foi criada com o propósito de permitir acesso fácil e interdependência de dados. Os módulos se comunicam entre si por arquivos de dados.

\subsection{Estrutura de Dados}

A estrutura de dados do ambiente Freeflow-3D [5] possui uma estrutura similar à do Freeflow-2D, descrita no Capítulo 4. A diferença entre a estrutura de dados do Freeflow3D e a do Freeflow-2D está na representação dos objetos geométricos. No Freeflow-3D, os objetos geométricos são representados pela estrutura de dados halfedge (figura 5.1), que é uma estrutura B-Rep (Boundary Representation).

A estrutura halfedge [9] é composta por seis níveis hierárquicos: Sólido, Face, Loop, Aresta, Semi-aresta e Vértice. A relação entre estes níveis hierárquicos (figura 5.1) é descrita a seguir

- Sólido: a lista aberta de sólidos permite o acesso a cada sólido da cena. Cada nó dá acesso por ponteiros para a lista de faces, arestas e vértices do modelo, e possui ponteiros para o sólido anterior e para o próximo sólido da lista.

- Face: cada nó da lista aberta de faces representa uma face planar do poliedro representado pela estrutura de dados halfedge. As faces podem possuir diversas fronteiras, como "buracos" em seu interior; assim, cada face está associada por ponteiro a uma lista de loops, cada um representando uma curva de fronteira poligonal da face. Um dos loops é denominado o loop "externo", e os outros representam os "buracos" de uma face. Os nós da lista de faces possuem um ponteiro para a face anterior e um ponteiro para a próxima face. Finalmente, cada nó possui um ponteiro para o sólido a que pertence. 
- Loop: um nó da lista aberta de loops descreve uma fronteira "fechada" (conectada), como discutido acima. Ele possui um ponteiro para a face a que pertence, um ponteiro para uma das semi-arestas que formam a fronteira e ponteiros para o próximo loop e para o loop anterior da face.

- Aresta: a lista aberta de arestas é formada por nós que associam as duas metades de uma aresta (semi-arestas). Os nós também são formados por ponteiros para as semi-arestas da "esquerda" e da "direita", e para as arestas anterior e posterior.

- Semi-aresta: um nó da lista fechada de semi-arestas descreve um segmento de linha de um loop. Ele é composto de um ponteiro para o loop a que pertence e um ponteiro para o vértice inicial do segmento de linha na orientação do loop. O nó está conectado através de ponteiros à semi-aresta anterior, à semi-aresta seguinte, e à aresta a que ela pertence.

- Vértice: cada nó da lista aberta de vértices contém as coordenadas do vértice, e ponteiros para o vértice anterior, para o vértice seguinte e para a semi-aresta que se origina nele.

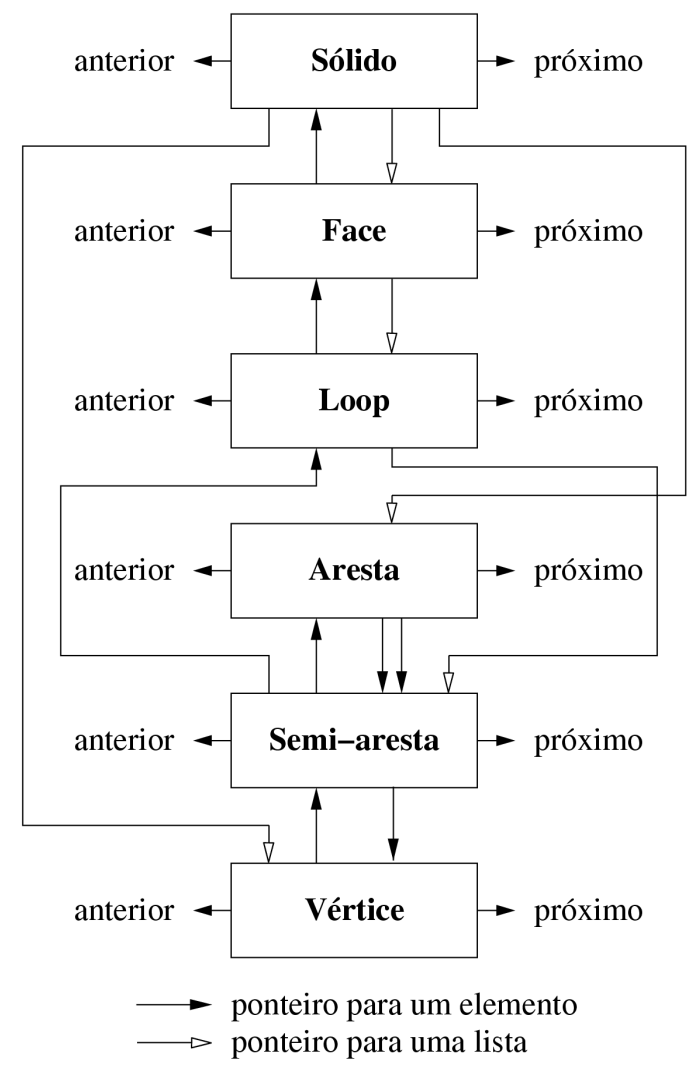

Figura 5.1: Níveis hierárquicos da estrutura de dados halfedge 


\subsection{Modelador de Moldes}

O modelador de moldes Modflow-3D é responsável pela inicialização dos dados para o simulador Simflow-3D. O modelador de moldes permite a visualização dos dados entrados, construindo os recipientes e os injetores. Para facilitar a visualização dos objetos são utilizadas técnicas de iluminação.

Podem ser alterados os seguintes parâmetros para a visualização:

- Distância do observador;

- Tipo de iluminação: Wire-Frame, Flat, Gourand, Phong;

- Potência da luz ambiente;

- Luz direcional;

- Propriedades de visualização dos objetos: cor, visibilidade, transparência, propriedades de reflexão da luz.

O modelador de moldes gera oito arquivos de saída. Estes arquivos possuem uma estrutura que pode ser lida pelo simulador.

\subsection{Simulador}

No módulo simulador, Simflow-3D, está implementado o método GENSMAC-3D, uma extensão do método GENSMAC, que aproxima a superfície livre por uma superfície linear por partes e é representada pela estrutura halfedge.

$\mathrm{Na}$ fronteira livre, as condições de contorno para a pressão e as velocidades são dadas por:

$$
\begin{aligned}
\mathbf{n} \cdot(\mathbf{T} \cdot \mathbf{n}) & =p_{c a p} \\
\mathbf{m}_{\mathbf{1}} \cdot(\mathbf{T} \cdot \mathbf{n}) & =0 \\
\mathbf{m}_{\mathbf{2}} \cdot(\mathbf{T} \cdot \mathbf{n}) & =0
\end{aligned}
$$

onde $\mathbf{n}=\left(n_{1}, n_{2}, n_{3}\right)$ é o vetor unitário normal à superfície, $\mathbf{m}_{\mathbf{1}}$ e $\mathbf{m}_{\mathbf{2}}$ são os vetores tangentes à superfície, $\mathbf{T}$ é o tensor tensão e $p_{\text {cap }}$ é a pressão capilar.

As etapas para a movimentação da superfície livre são análogas às etapas detalhadas no algoritmo do Capítulo 2, considerando que os vértices da estrutura halfedge são as partículas marcadoras presentes na superfície livre do fluido. Essas partículas são inseridas ou eliminadas de acordo com a relação entre o tamanho da célula e o comprimento das arestas das faces que representam a superfície livre.

Os oito arquivos de entrada do simulador possuem a mesma estrutura dos arquivos de saída do modelador, do próprio simulador e do reiniciador.

Os arquivos de saída do simulador são criados para quatro finalidades: para o final da simulação, para a ocorrência de erros durante a simulação, para evitar a perda de dados 
em caso de interrupção na simulação e para a visualização dos dados. Os arquivos dos três primeiros casos possuem a estrutura dos arquivos de saída do modelador. O último permite a leitura dos dados pelo visualizador.

\subsection{Visualizador}

O visualizador Visflow-3D é responsável pela apresentação da saída produzida pelo Simflow-3D. Os dados estáticos são armazenados em um único arquivo, enquanto que aqueles que são dinâmicos são armazenados em uma sequência de arquivos contendo informações sobre a geometria dos objetos, propriedades do fluxo, configuração de células, tempo e número do ciclo.

Para visualizar os recipientes, os injetores, os ejetores e os fluidos tridimensionalmente, são utilizadas técnicas de iluminação. Os objetos podem ser visualizados também através de cortes paralelos aos planos principais.

O valor da propriedade (velocidade, pressão) em um ponto da superfície é determinado utilizando-se interpolação linear entre os pontos das células vizinhas.

Os arquivos de entrada do visualizador são gerados pelo simulador exclusivamente para a visualização dos resultados.

\subsection{Reiniciador}

Análogo ao reiniciador do ambiente bidimensional, o Resimflow-3D é o módulo que permite reiniciar a simulação de escoamentos. Pode-se alterar alguns dados do modelo utilizando o Resimflow-3D: o ciclo final, o tempo final, o intervalo de tempo para impressão e gravação, a tolerância para a solução da equação de Poisson e o fator de controle do passo.

Os arquivos de entrada do reiniciador são gerados pelo simulador com a mesma estrutura dos arquivos de saída do modelador, e os arquivos de saída desse módulo possuem a estrutura adequada para a sua leitura pelo simulador. 


\section{Capítulo 6}

\section{Implementações}

O sistema Freeflow é composto de três módulos: Modflow (modelador de moldes), Simflow (simulador de escoamentos) e Visflow (visualizador de escoamentos). Cada módulo é independente, e a comunicação entre eles é feita através de arquivos.

Os módulos modelador de moldes, simulador e visualizador de escoamentos axissimétricos foram implementados a partir dos módulos bidimensionais.

\subsection{Modelador Axissimétrico}

Foram realizadas modificações no modelador bidimensional para a modelagem de moldes para o simulador axissimétrico.

Novos modelos axissimétricos foram adicionados, como:

- esfera de fluido axissimétrica (fig. 6.1): um semi-círculo de fluido sobre o eixo de simetria, de modo que, ao se fazer a varredura rotacional do modelo, obtém-se uma esfera tridimensional de fluido;

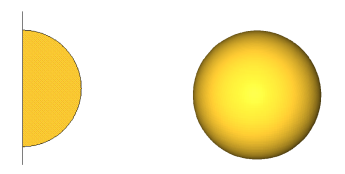

Figura 6.1: Modelo de esfera de fluido axissimétrica: 2D e 3D

- injetor axissimétrico (fig. 6.2): um injetor de fluido sobre o eixo de simetria, com apenas uma face de recipiente, de modo que, ao se fazer a varredura rotacional do modelo, obtém-se um injetor de fluido cilíndrico, e um recipiente cilíndrico ao seu redor;

- caixa axissimétrica (fig. 6.3): uma caixa bidimensional cortada ao meio, de modo que, ao se executar a varredura rotacional do modelo, obtém-se uma caixa cilíndrica tridimensional; 


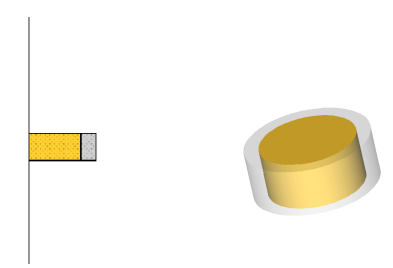

Figura 6.2: Modelo de injetor de fluido axissimétrico: 2D e 3D
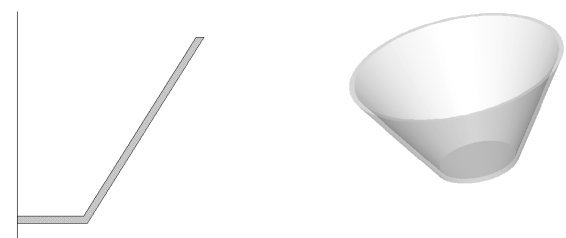

Figura 6.3: Modelo de caixa axissimétrica: 2D e 3D

\subsection{Simulador Axissimétrico}

O simulador axissimétrico foi implementado a partir do simulador bidimensional. A seguir estão listadas algumas das modficações efetuadas no simulador bidimensional:

- Todas as equações em coordenadas cartesianas foram substituídas pelas equações discretizadas em coordenadas cilíndricas;

- Foi implementado o método VONOS em coordenadas cilíndricas;

- A condição de fronteira de escorregamento livre foi implementada em $r=0$ (eixo de simetria) e em $r=R M A X$ (raio máximo);

- Foi implementado o efeito da tensão superficial e a aplicação do ângulo de contato prescrito em coordenadas cilíndricas, calculando a curvatura $\kappa$ e a pressão capilar $p_{\text {cap }}$ na superfície livre.

\subsection{Visualizador de Escoamentos Axissimétricos}

O visualizador axissimétrico, implementado a partir dos visualizadores bidimensional e tridimensional, permite a visualização das simulações em diversos tempos em duas e três dimensões.

Em duas dimensões, é possível visualizar a simulação nos seguintes modos:

- Fio de Arame: somente as arestas podem ser visualizadas. Veja a figura 6.4.

- Pintado: o contorno é preenchido de acordo com as cores pré-definidas no visualizador ou definidas pelo usuário para o(s) fluido(s), o(s) recipiente(s), o(s) injetor(es), e assim por diante. Veja a figura 6.5. 


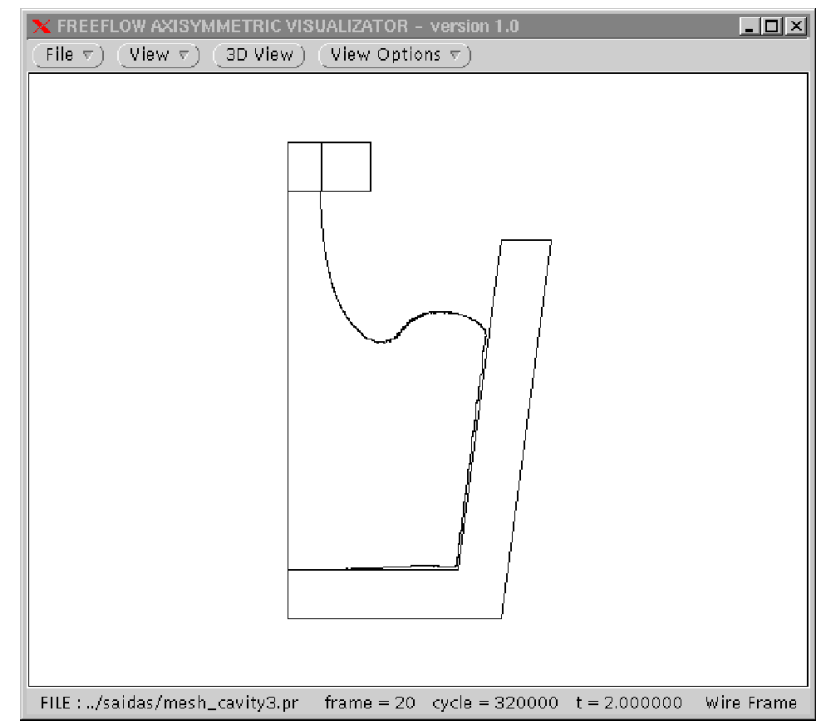

Figura 6.4: Visualização Fio de Arame

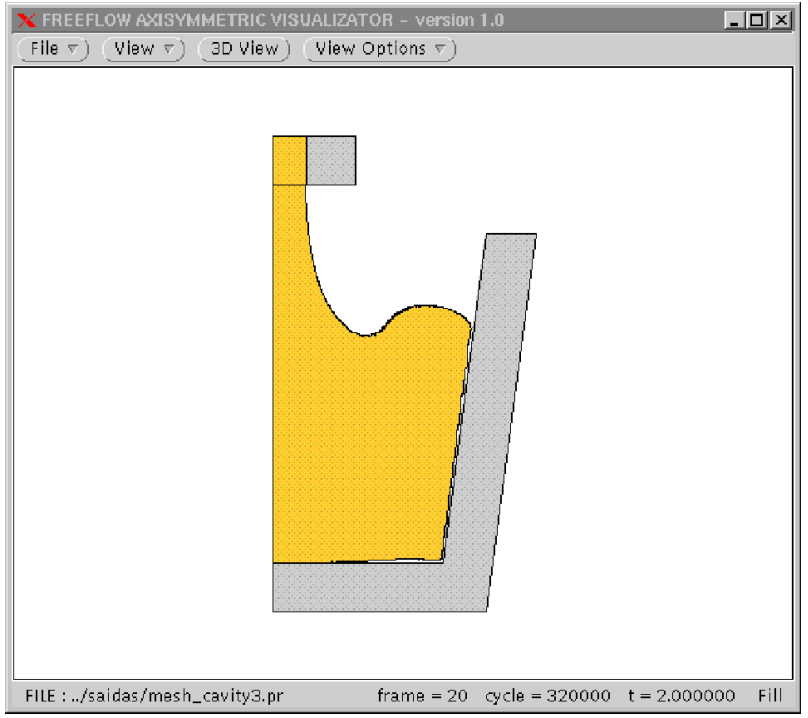

Figura 6.5: Visualização Pintado

- Pressão: o contorno do fluido é preenchido com a pressão, que pode variar de um valor mínimo a um valor máximo, sendo a cor para cada valor definida em uma barra de referência posicionada na parte superior da janela. Veja a figura 6.6.

- Velocidade na direção r: visualiza-se o contorno do fluido preenchido com a velocidade na direção radial, com a cor para cada valor definida na barra de referência, como pode ser observado na figura 6.7.

- Velocidade na direção z: visualiza-se o contorno do fluido preenchido com a 


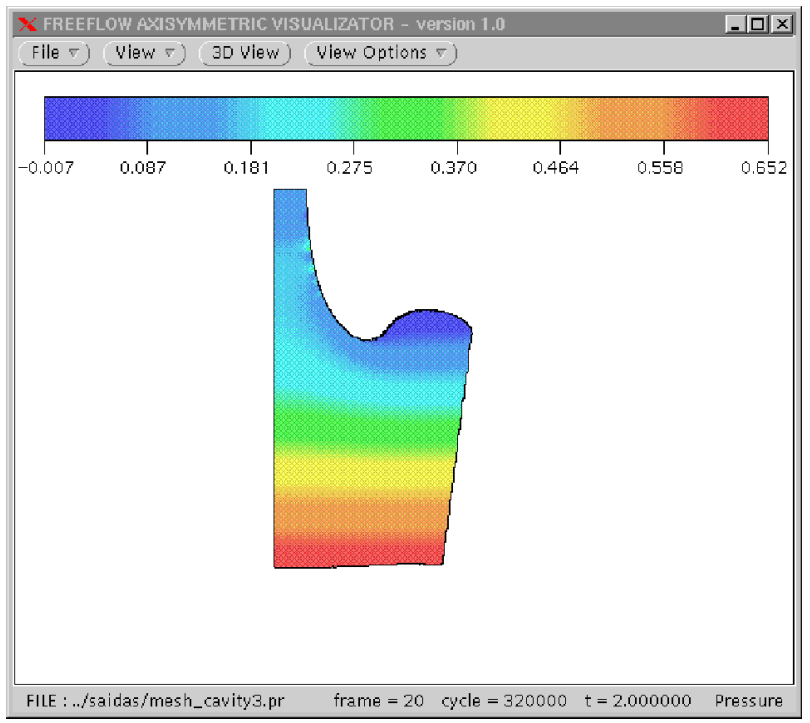

Figura 6.6: Visualização da Pressão

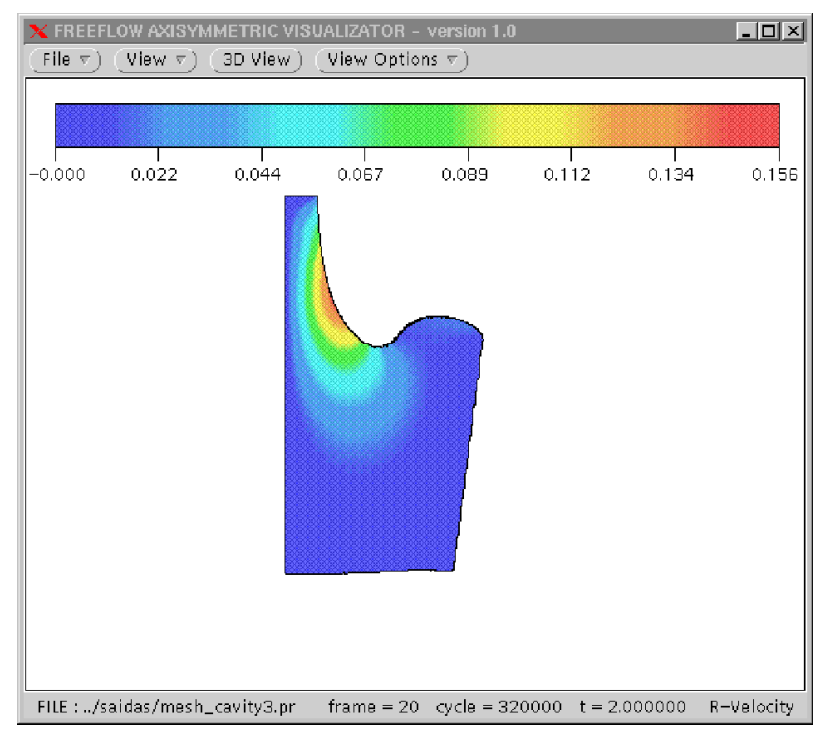

Figura 6.7: Visualização da Velocidade na direção r

velocidade na direção z, com a cor para cada valor definida na barra de referência. Veja a figura 6.8 .

A visualização em três dimensões ocorre após a varredura rotacional imposta sobre o modelo bidimensional. O número de passos tomados na varredura rotacional, ou seja, o número de lados do sólido formado, é fornecido pelo usuário (figura 6.9), onde pode-se também optar pela remoção de faces do fluido para a redução do número de partículas no domínio. A varredura rotacional é executada utilizando os Operadores de Euler com representação B-Rep ( "Boundary Representation") [9]. 


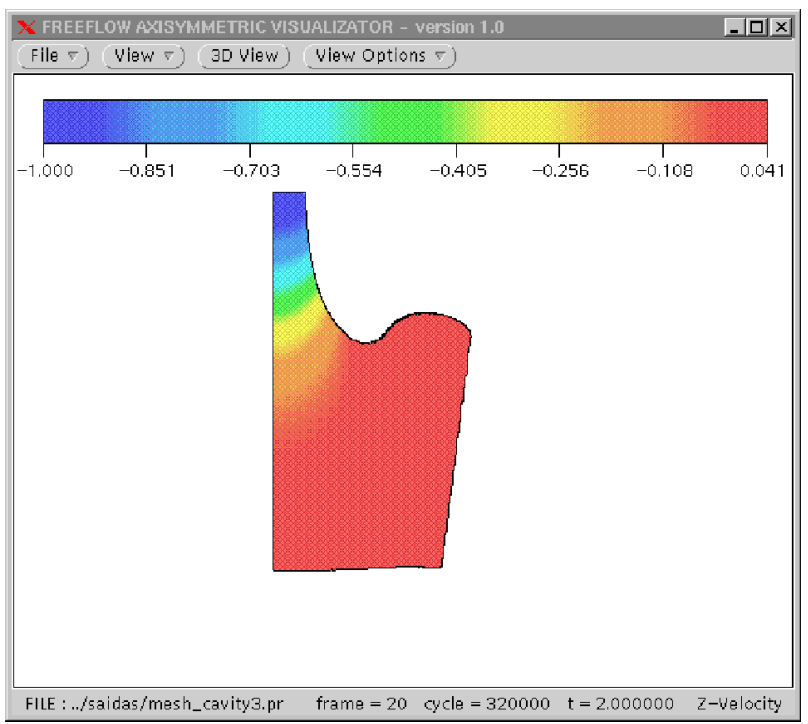

Figura 6.8: Visualização da Velocidade na direção z

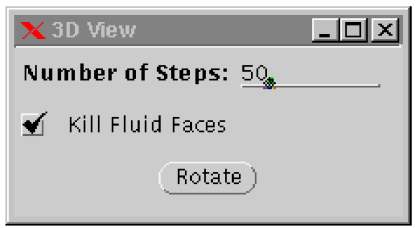

Figura 6.9: Janela "3D View"

Há dois tipos de varredura rotacional: a varredura rotacional aberta e a varredura rotacional fechada. A varredura rotacional aberta deve ser aplicada quando o objeto a ser rodado possui pelo menos dois pontos sobre o eixo de simetria. Por exemplo, a caixa axissimétrica representada na figura 6.3 é um modelo que utiliza a varredura rotacional aberta para a sua vizualização em três dimensões.

Já a varredura rotacional fechada é aplicada em modelos que possuem menos de dois pontos em contato com o eixo de simetria. Como exemplo, veja a figura 6.10. O objeto bidimensional não possui vértices sobre o eixo de simetria e, consequentemente, o objeto em três dimensões é um tóro.

Em três dimensões, só é possível visualizar a simulação nos modos Fio de Arame (figura 6.11) e Pintado (figura 6.12). 

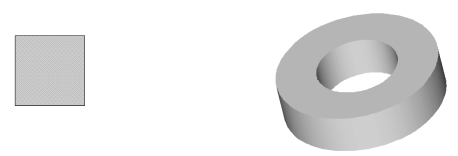

Figura 6.10: Exemplo de varredura rotacional fechada: 2D e 3D

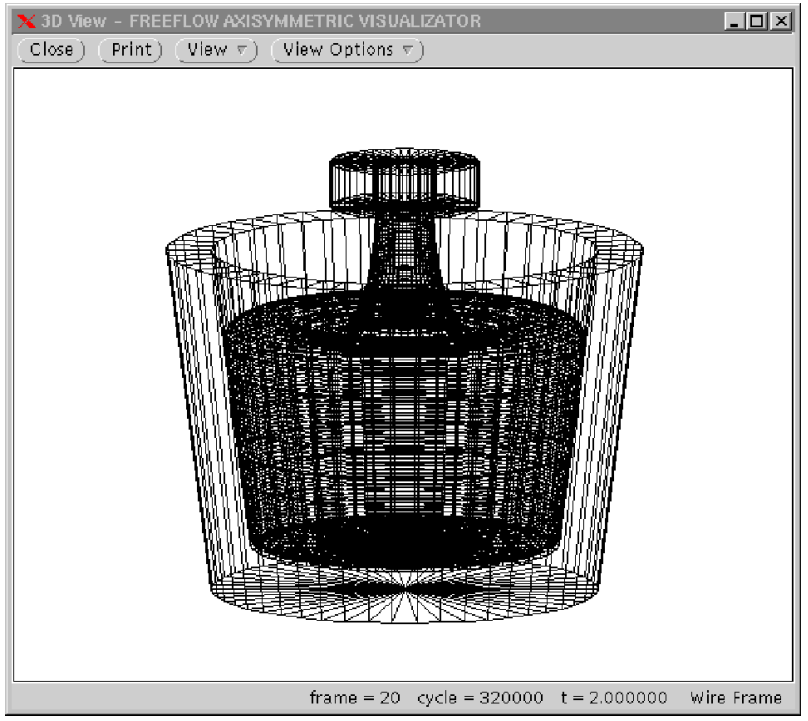

Figura 6.11: Visualização tridimensional Fio de Arame

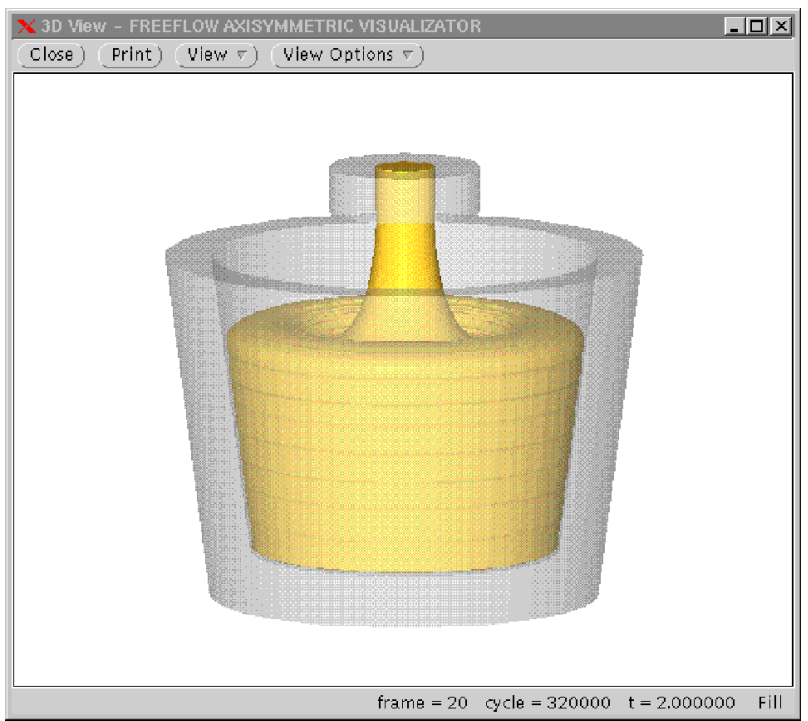

Figura 6.12: Visualização tridimensional Pintado 


\section{Capítulo 7}

\section{Validação do Código}

Para a validação do código implementado no simulador axissimétrico serão considerados alguns exemplos numéricos para uma validação qualitativa. Em seguida, será realizada uma validação quantitativa comparando o resultado numérico com o resultado analítico e a comprovação de convergência no refinamento de malhas. Finalmente, será validada a implementação do efeito da tensão superficial e do ângulo de contato.

\subsection{Exemplos Numéricos e Validação Qualitativa}

Três problemas serão considerados para a validação qualitativa: um jato vertical injetado em um fluido, uma gota caindo em uma piscina de fluido e o enchimento de uma cavidade pela injeção de fluido através de um injetor.

\subsubsection{Jato Vertical ("Jet Flow")}

G. I. Taylor [13] realizou experimentos com jatos verticais de fluidos injetados em um recipiente contendo o mesmo fluido. Ele identificava o jato colorindo-o enquanto o fluido no recipiente permanecia incolor. Este jato se infiltra no fluido, desenvolvendo um formato de cogumelo.

Para validar o código do simulador, foi executada a simulação de um jato colorido sendo injetado em um recipiente com o mesmo fluido de modo que possa ser realizada uma comparação com os resultados de Taylor. Foi utilizado um recipiente cilíndrico de diâmetro $12 \mathrm{~cm}$ e altura $17 \mathrm{~cm}$, contendo a piscina de fluido com $12 \mathrm{~cm}$ de diâmetro e $16 \mathrm{~cm}$ de altura. O injetor, de $4 \mathrm{~mm}$ de diâmetro e $3 \mathrm{~cm}$ de altura, está localizado a 1 $\mathrm{cm}$ acima do fluido e com velocidade de injeção de $50 \mathrm{~cm} / \mathrm{s}$. O critério de convergência para a equação de Poisson foi de EPS $=10^{-6}$ e 3 partículas por célula foram utilizadas. A constante gravitacional foi tomada como sendo $g=-9.81 \mathrm{~m} / \mathrm{s}^{2}$, gerando um número de Froude 2.5240939. A viscosidade do fluido é de $2 \mathrm{~cm}^{2} / \mathrm{s}$, de modo que o número de Reynolds é igual a 10 , e o tamanho da malha é de $\delta r=\delta z=0.05 \mathrm{~cm}(400 \times 120$ células na malha). 
Pode-se observar na figura 7.1 a evolução no tempo da simulação para $\mathrm{Re}=10 \mathrm{Na}$ figura 7.2, tem-se a comparação da fotografia de Taylor (figura 7.2(a)) com uma vista frontal do jato tridimensional gerado na simulação (figura 7.2(b)). A comparação da foto de Taylor com a imagem da simulação mostra que o resultado obtido é excelente.

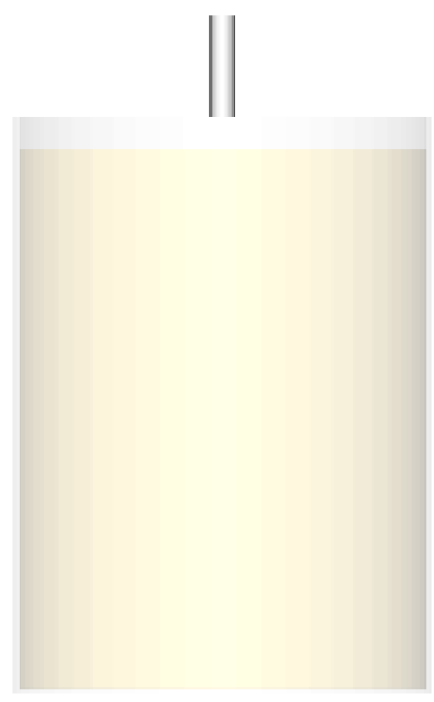

$t=0.000 \mathrm{~s}$

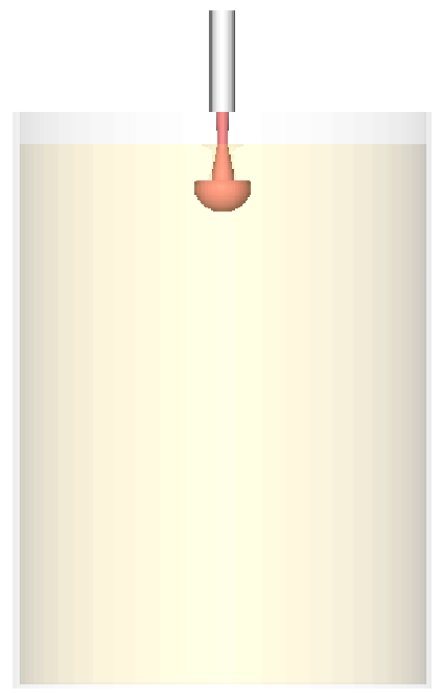

$t=0.240 \mathrm{~s}$

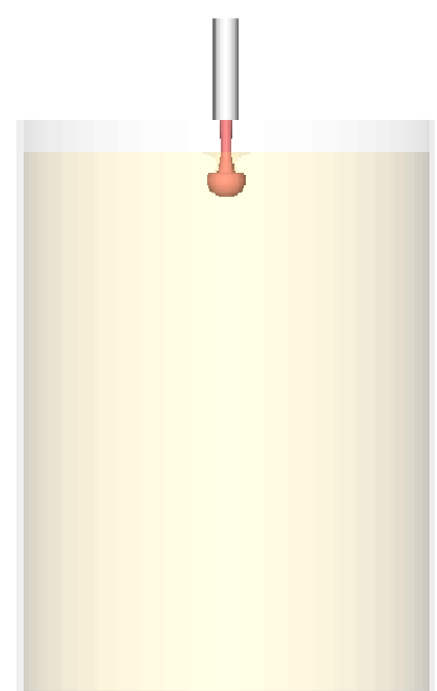

$t=0.120 \mathrm{~s}$

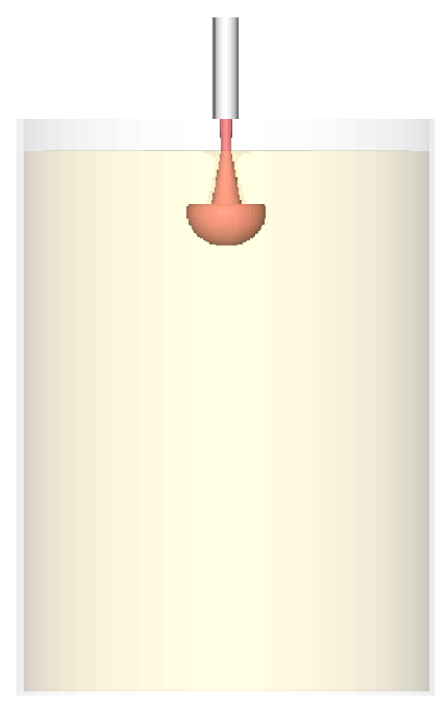

$t=0.480 \mathrm{~s}$

Figura 7.1: Simulação "Jet Flow" em diversos tempos (vista frontal) 


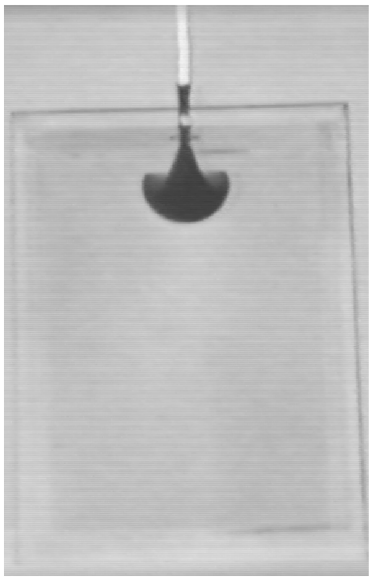

(a)

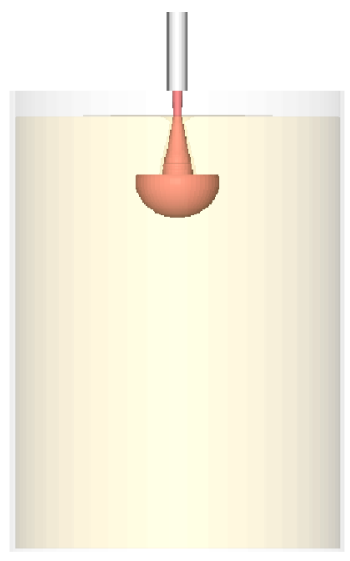

(b)

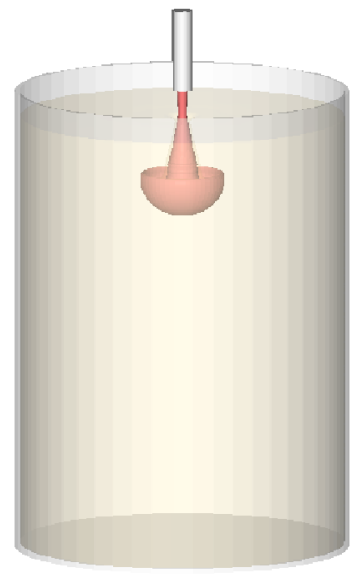

(c)

Figura 7.2: Comparação com dados experimentais $(t=0.920 \mathrm{~s})$ : (a) fotografia de Taylor; (b) vista frontal; (c) vista tridimensional.

\subsection{2 "Splashing Drop"}

A simulação "Splashing Drop" consiste em observar uma gota de fluido com uma velocidade inicial caindo em um recipiente, contendo o mesmo fluido em repouso.

O fluido em repouso no recipiente possui $22 \mathrm{~cm}$ de diâmetro e $7 \mathrm{~cm}$ de altura. A gota esférica, de diâmetro $3.2 \mathrm{~cm}$, foi posicionada a $3 \mathrm{~cm}$ acima do fluido com velocidade inicial $v=-1 \mathrm{~m} / \mathrm{s}$. O tamamnho da célula utilizada foi de $\delta r=\delta z=0.2 \mathrm{~cm}$, a constante gravitacional foi definida como $g=-9.81 \mathrm{~m} / \mathrm{s}^{2}$ e a viscosidade $\nu=3 \mathrm{~cm}^{2} / \mathrm{s}$. Os parâmetros de adimensionalização adotados foram $U=1 \mathrm{~m} / \mathrm{s}$ e $L=3.2 \mathrm{~cm}$, gerando o número de 
Reynolds $\operatorname{Re}=106.667$ e o número de Froude $\mathrm{Fr}=1.7848$. A figura 7.3 mostra a evolução no tempo da simulação da queda da gota.

\subsubsection{Enchimento de Cavidade ("Container Filling")}

A injeção de fluido em uma cavidade é comumente utilizada pelas indústrias, como por exemplo, no enchimento de um pote de margarina ou de uma garrafa de refrigerante. A seguir, apresenta-se a simulação de enchimento de um pote cilíndrico, com o fluido sendo injetado a partir de um injetor circular. Os dados utilizados na simulação foram: escala de velocidade $U=1 \mathrm{~m} / \mathrm{s}$; escala de comprimento $L=16 \mathrm{~mm}$; viscosidade cinemática $\nu=50 \mathrm{~cm}^{2} / \mathrm{s}$; constante gravitacional $g=-9.81 \mathrm{~m} / \mathrm{s}^{2}$. Esses dados fornecem um número de Reynolds $\operatorname{Re}=3.2$ e um número de Froude $\mathrm{Fr}=2.5240939$. O domínio do escoamento foi definido como: raio menor do recipiente $r_{\text {menor }}=4 \mathrm{~cm}$; raio maior do recipiente $r_{\text {maior }}=$ $5.2 \mathrm{~cm}$; altura do recipiente $h=9.2 \mathrm{~cm}$; raio do injetor de fluido $r=8 \mathrm{~mm}$; altura do injetor $h=1.2 \mathrm{~cm}$; distância entre o injetor e o pote $d=1.2 \mathrm{~cm}$. O espaçamento da malha foi de $\delta r=\delta z=1 \mathrm{~mm}(116 \times 64$ células $)$ e 3 partículas por célula foram utilizadas para representar a superfície livre. A figura 7.4 mostra a evolução no tempo da simulação do enchimento do pote.

\subsection{Validação Quantitativa}

A validação quantitativa do código será realizada em três etapas: através da comparação de uma solução numérica com sua correspondente solução analítica, do refinamento de malhas, e do estudo de convergência.

\subsubsection{Comparação com Solução Analítica}

Para a validação por comparação do resultado numérico com o resultado analítico, foi considerado um problema que consiste em um escoamento irrotacional axissimétrico (piscina cilíndrica) com uma perturbação suficientemente pequena na superfície. Comparou-se as soluções analítica e numérica, utilizando teoria linear para ondas de gravidade estacionárias axissimétricas (linear theory for axisymmetric standing gravity waves) [12]. Podese mostrar que a solução para este problema é composta de combinações lineares de modos da forma

$$
\begin{aligned}
u(r, z, t) & =-A m \cos (\sigma t) J_{1}(m r) \cosh (m z) ; \\
v(r, z, t) & =A m \cos (\sigma t) J_{0}(m r) \sinh (m z) ; \\
\xi(r, t) & =\frac{A \sigma}{g} \sin (\sigma t) J_{0}(m r) \cosh (m H),
\end{aligned}
$$

onde $g$ é a aceleração da gravidade, $J_{n}(x)$ é a função de Bessel de ordem $n$ :

$$
J_{n}(x)=\sum_{i=0}^{\infty}(-1)^{i} \frac{\left(\frac{x}{2}\right)^{2 i+n}}{i !(i+n) !}
$$




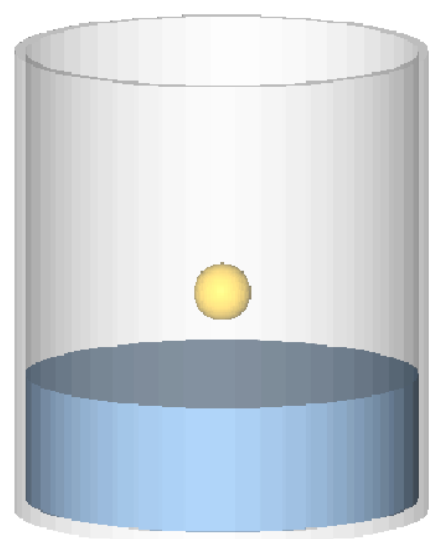

$t=0.000 \mathrm{~s}$

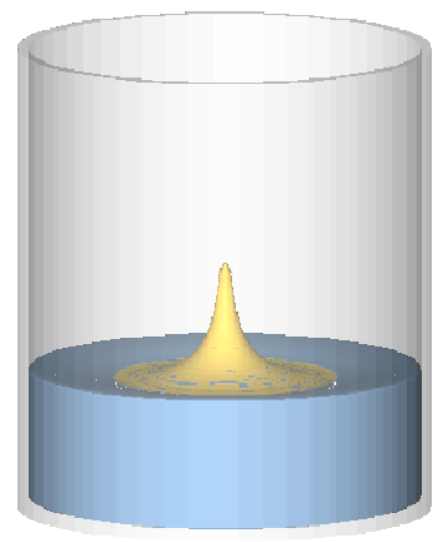

$t=0.240 \mathrm{~s}$

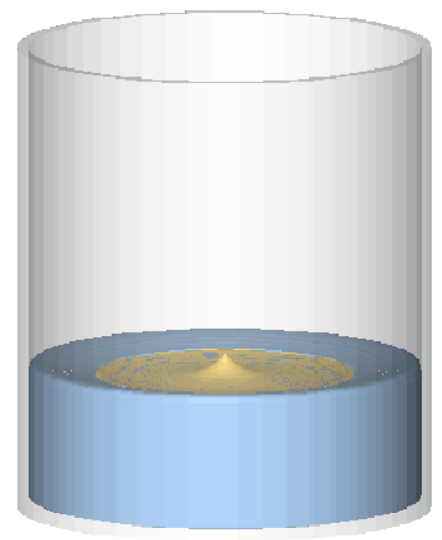

$t=0.480 \mathrm{~s}$

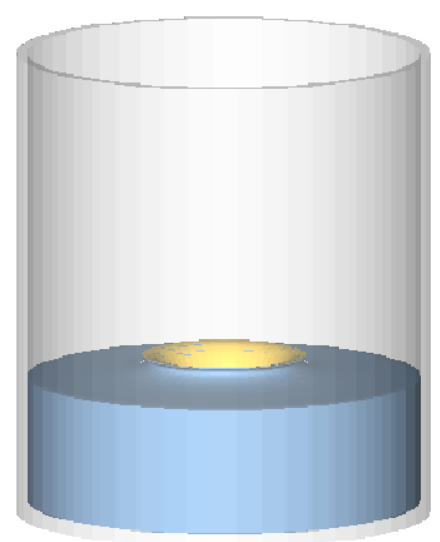

$t=0.080 \mathrm{~s}$

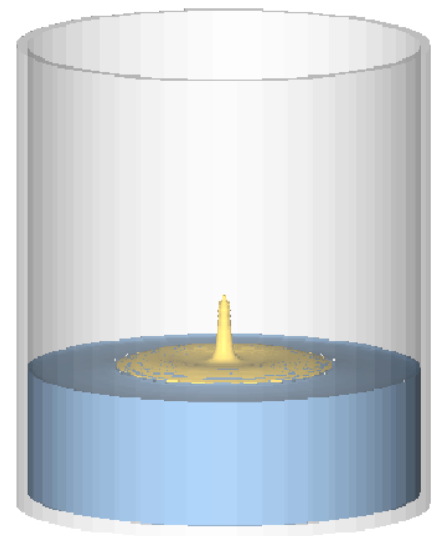

$t=0.320 \mathrm{~s}$

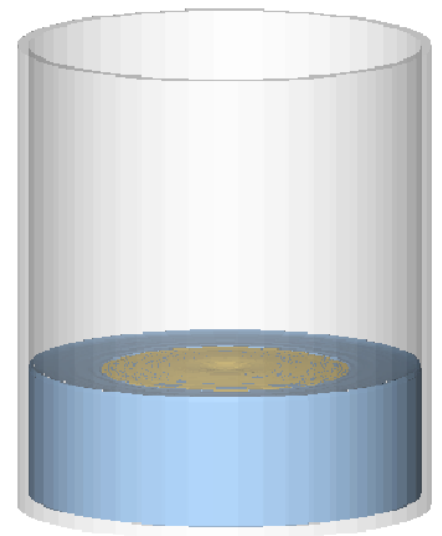

$t=0.560 \mathrm{~s}$

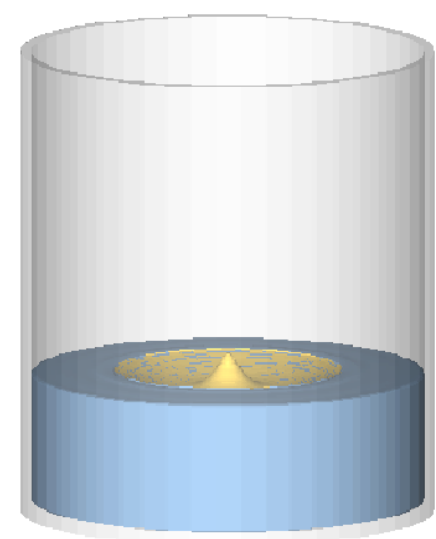

$t=0.160 \mathrm{~s}$

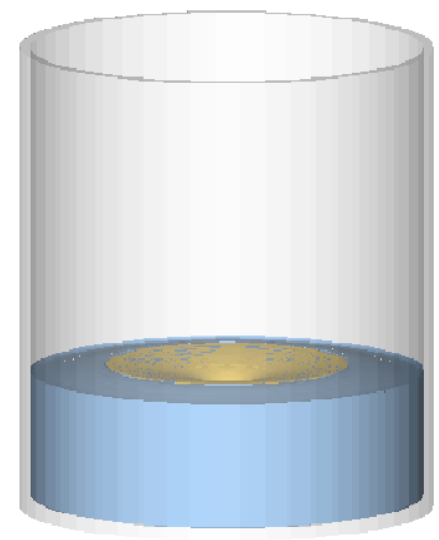

$t=0.400 \mathrm{~s}$

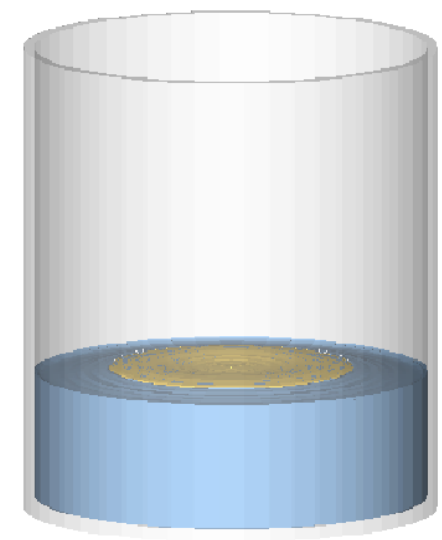

$t=0.640 \mathrm{~s}$

Figura 7.3: Simulação "Splashing Drop" em diversos tempos 


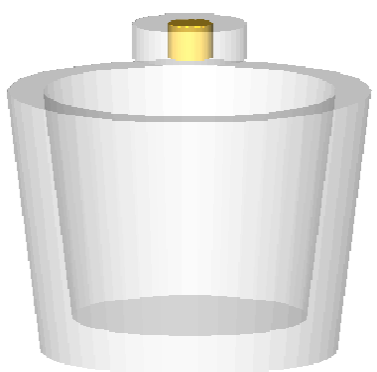

$t=0.00 \mathrm{~s}$

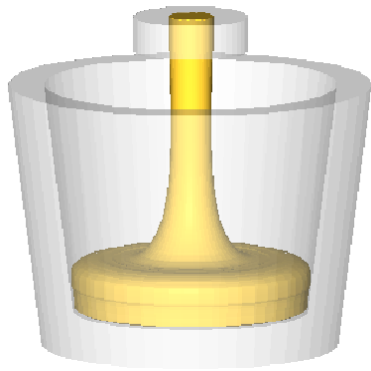

$t=0.60 \mathrm{~s}$

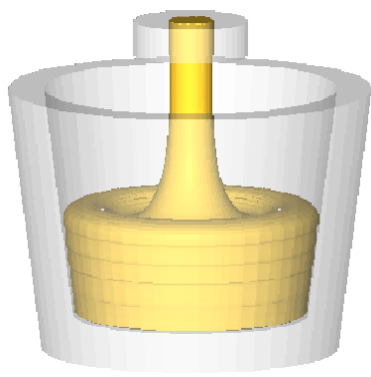

$t=1.20 \mathrm{~s}$

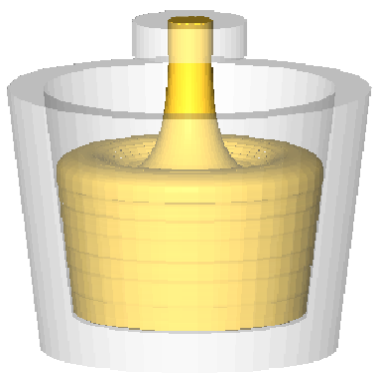

$t=1.80 \mathrm{~s}$

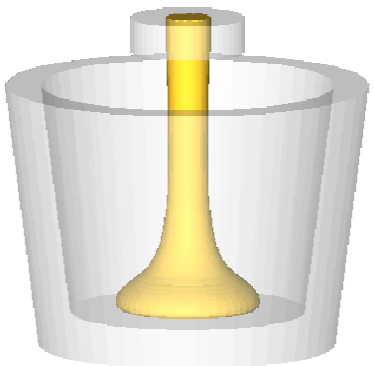

$t=0.20 \mathrm{~s}$

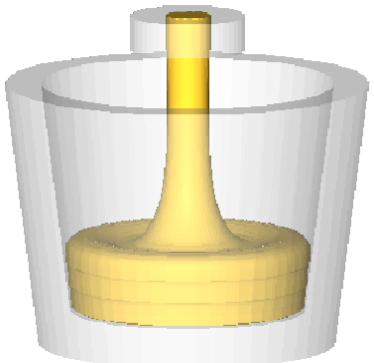

$t=0.80 \mathrm{~s}$

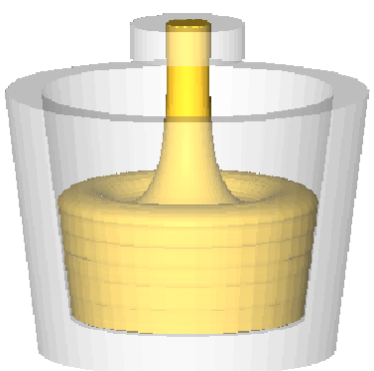

$t=1.40 \mathrm{~s}$

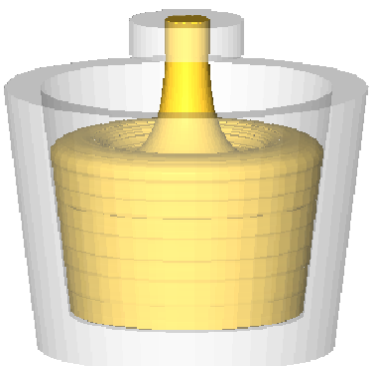

$t=2.00 \mathrm{~s}$

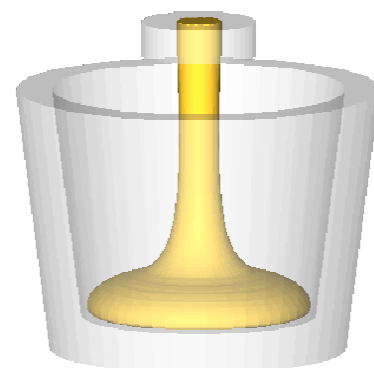

$t=0.40 \mathrm{~s}$

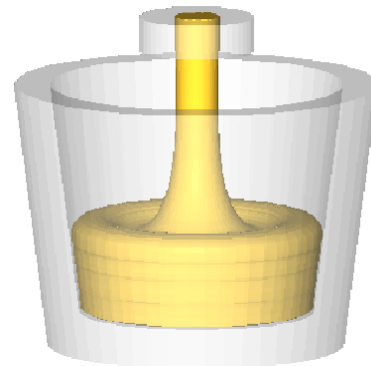

$t=1.00 \mathrm{~s}$

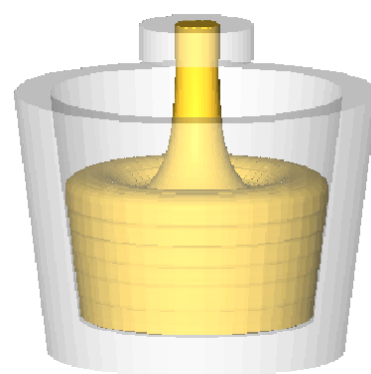

$t=1.60 \mathrm{~s}$

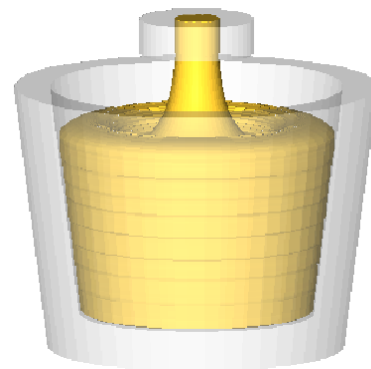

$t=2.20 \mathrm{~s}$

Figura 7.4: Simulação "Container Filling" em diversos tempos 
$\sigma=\sqrt{g m \tanh (m H)}$ é a frequência angular da onda. $H$ é a profundidade inicial da piscina de fluido, $R$ é o raio da piscina, $m$ é uma constante tal que $J_{1}(m r)=0$, $A$ é uma constante pequena arbitrária que define a amplitude da onda, e $\xi$ é o deslocamento da superfície livre em relação à superfície inicial.

O perfil inicial das componentes de velocidade e da elevação da superfície é obtido tomando $t=0$ nas equações (7.1), (7.2) e (7.3). A solução, definida pelas equações (7.1), (7.2) e (7.3), satisfaz as seguintes condições de fronteira:

$$
\begin{aligned}
& \left.\frac{\partial v(r, z, t)}{\partial r}\right|_{r=0}=\left.0 \quad \frac{\partial v(r, z, t)}{\partial r}\right|_{r=R}=\left.0 \quad \frac{\partial u(r, z, t)}{\partial z}\right|_{z=0}=0
\end{aligned}
$$

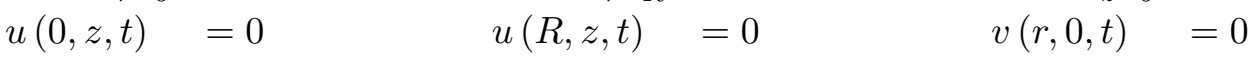

A seguir apresenta-se os resultados obtidos das simulações realizadas, comparando as soluções numéricas com as soluções exatas dadas pelas equações (7.1), (7.2) e (7.3). Os dados empregados foram: viscosidade cinemática $\nu=0.1 \mathrm{~m}^{2} / \mathrm{s}$, aceleração da gravidade $g=-9.81 \mathrm{~m} / \mathrm{s}^{2}$, altura inicial do fluido $H=7.6251029 \mathrm{~m}$, escala de comprimento $L=1 \mathrm{~m}$ e escala de velocidade $U=1 \mathrm{~m} / \mathrm{s}$, e dimensões das células $\delta r=\delta z=0.0766342 \mathrm{~m}$. Os parâmetros $m$ e $R$ foram variados, e todos os outros parâmetros permaneceram fixos. Os resultados quantitativos, apresentados na tabela 7.1, mostram uma concordância razoável entre as frequências de oscilação analítica e calculada, e a amplitude máxima da elevação da onda. No entanto, as diferenças são significantes. Acredita-se que elas ocorrem devido ao fato que estão sendo resolvidas as equações de Navier-Stokes completas, enquanto que as equações analíticas (7.1), (7.2) e (7.3) são somente válidas para escoamentos potenciais irrotacionais.

Observa-se na tabela que as diferenças decrescem conforme o aumento do raio da piscina de fluido: quanto maior o comprimento de onda menor serão os efeitos não-lineares e viscosos, já que tanto a profundidade inicial quanto a amplitude máxima da onda foram fixadas. As figuras 7.5 e 7.6 referem-se à simulação com raio $R=15.32684$ e $m=0.25$. A figura 7.5 mostra a evolução no tempo da elevação da superfície em $r=0$ (isto é, $\xi(0, t)$ ). Observa-se que há boa concordância entre os resultados analítico e numérico. A figura 7.6 mostra a variação espacial da elevação da superfície no tempo $t=\frac{\pi}{2 \sigma}$, que corresponde à primeira crista da onda. Observa-se, novamente, a boa concordância entre as duas soluções.

\begin{tabular}{|c|c|c|c|c|c|c|c|}
\hline $\mathbf{m}$ & $\mathbf{R}$ & $\sigma_{\text {exato }}$ & $\sigma_{\text {num }}$ & Erro \% & $\xi_{\text {max }}^{\text {exato }}$ & $\xi_{\text {max }}^{\text {num }}$ & Erro \% \\
\hline 1.00 & 3.83171 & 3.1321 & 3.1042 & 0.891 & 0.383171 & 0.397640 & 3.776 \\
\hline 0.50 & 7.66342 & 2.2136 & 2.2274 & 0.622 & 0.383171 & 0.393461 & 2.685 \\
\hline 0.25 & 15.32684 & 1.5318 & 1.5441 & 0.802 & 0.383171 & 0.387046 & 1.011 \\
\hline
\end{tabular}

Tabela 7.1: Comparação entre resultados analíticos e numéricos

\subsubsection{Refinamento de Malhas}

Para demonstrar que o método apresentado converge com o refinamento da malha, foram realizadas três simulações, com espaçamentos decrescentes, para dois modelos: uma 


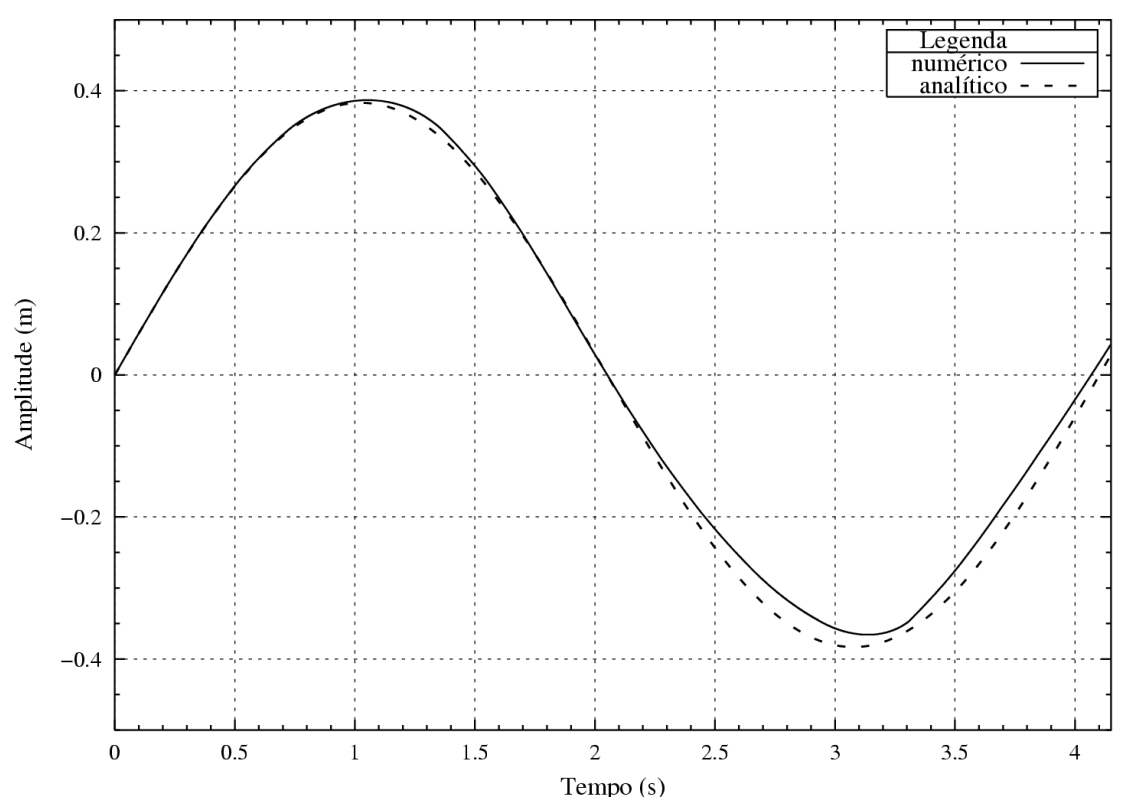

Figura 7.5: Evolução temporal da elevação da superfície em $r=0$

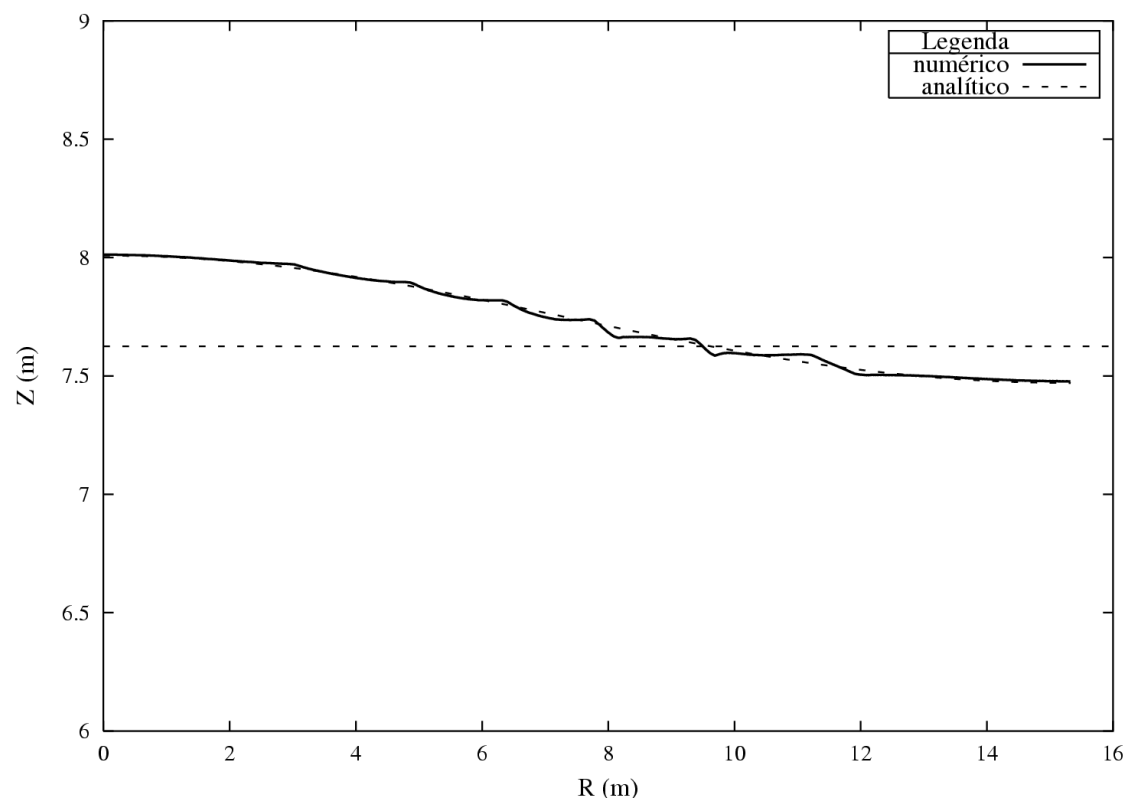

Figura 7.6: Variação espacial da elevação da superfície em $t=\frac{\pi}{2 \sigma}$

gota caindo em uma piscina de fluido ("splashing drop") e o enchimento de uma cavidade ("cavity filling").

Para a simulação "splashing drop" foram utilizados os seguintes dados:

- piscina de fluido quiescente com raio $11.2 \mathrm{~cm}$ e altura $7.2 \mathrm{~cm}$; 
- uma gota esférica de fluido com diâmetro $3.2 \mathrm{~cm}$ posicionada inicialmente a $3.0 \mathrm{~cm}$ acima da superfície da piscina com velocidade inicial $v=-1.0 \mathrm{~m} / \mathrm{s}$;

- aceleração da gravidade atuando na direção $z$ com valor $g_{z}=-9.81 \mathrm{~m} / \mathrm{s}^{2}$;

- viscosidade cinemática $\nu=3.0 \mathrm{~cm}^{2} / \mathrm{s}$;

- parâmetros de escala de comprimento, $L=3.2 \mathrm{~cm}$ (diâmetro da gota), e de velocidade, $U=1.0 \mathrm{~m} / \mathrm{s}$ (velocidade inicial da gota), obtendo os fatores adimensionais $\operatorname{Re}=106.67$ e $\mathrm{Fr}=1.7848$

- condição de não-escorregamento nas fronteiras rígidas;

- três partículas por célula empregadas para representar a superfície livre do fluido.

A figura 7.7 apresenta uma comparação entre os perfis das componentes de velocidade radial $(R)$ e vertical $(Z)$, calculados através dos dados acima e utilizando três malhas diferentes. A primeira malha possui espaçamento $\delta r=\delta z=0.4 \mathrm{~cm}$, com tamanho $28 \times 38$; a segunda malha, espaçamento $\delta r=\delta z=0.2 \mathrm{~cm}$ e tamanho $56 \times 76$; a terceira malha, espaçamento $\delta r=\delta z=0.1 \mathrm{~cm}$ e tamanho $112 \times 152$. Os espaços em branco no interior do fluido no campo de velocidade significam que a intensidade da velocidade é muito baixa para ser representada vetorialmente pelo software utilizado na geração do gráfico (gnuplot).

Na simulação "cavity filling", foram realizadas três simulações para verificar a convergência da solução com o refinamento de malhas. Os seguintes dados foram utilizados:

- cavidade circular com dimensões: raio superior $L_{1}=5.2 \mathrm{~cm}$, raio inferior $L_{2}=$ $4.2 \mathrm{~cm}$, e altura $H=8.0 \mathrm{~cm}$;

- injetor com diâmetro $D=1.6 \mathrm{~cm}$ e velocidade inicial do fluido $V_{o}=-1.0 \mathrm{~m} / \mathrm{s}$, posicionado a uma altura $h=1.2 \mathrm{~cm}$ da cavidade;

- aceleração da gravidade agindo na direção vertical com $g_{z}=-9.81 \mathrm{~m} / \mathrm{s}^{2}$;

- viscosidade cinemática $\nu=50.0 \mathrm{~cm}^{2} / \mathrm{s}$;

- parâmetros de escala de comprimento $L=1.6 \mathrm{~cm}$ (diâmetro do injetor) e de velocidade $U=1.0 \mathrm{~m} / \mathrm{s}$ (velocidade inicial do fluido no injetor), obtendo os fatores adimensionais $\operatorname{Re}=3.2$ e $\mathrm{Fr}=2.52409$;

- três partículas por célula na superfície livre;

- condições de não-escorregamento aplicadas nas fronteiras rígidas.

A figura 7.8 apresenta uma comparação entre os perfis das componentes de velocidade radial $(\mathrm{R})$ e vertical $(\mathrm{Z})$, calculados através dos dados acima e utilizando três malhas diferentes: a primeira malha, possuindo espaçamento $\delta r=\delta z=0.4 \mathrm{~cm}$, com tamanho 


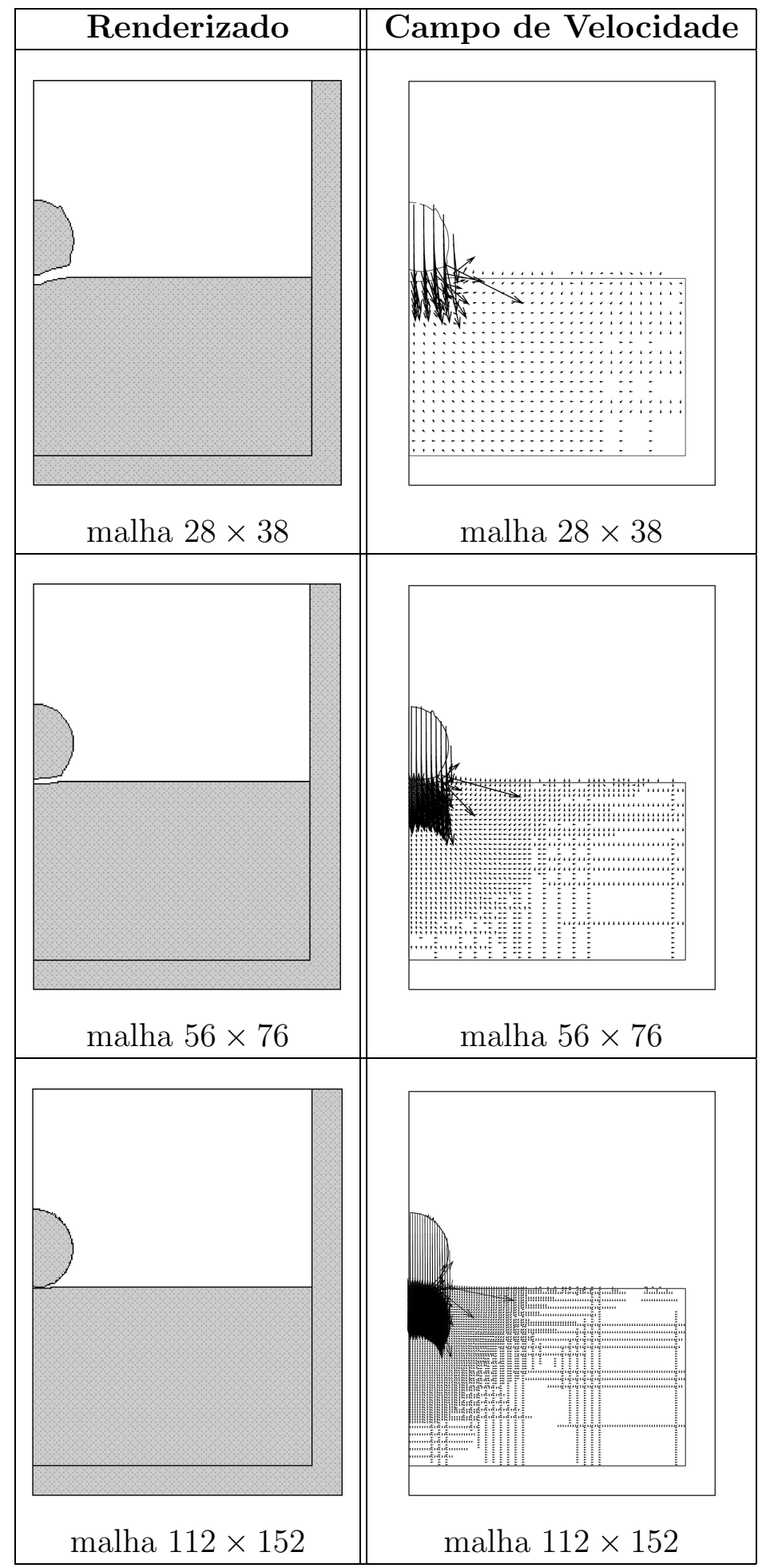

Figura 7.7: Refinamento de malha - simulação "Splashing Drop" 
$13 \times 26$; a segunda malha, possuindo espaçamento $\delta r=\delta z=0.2 \mathrm{~cm}$ e tamanho $26 \times 52$; e a terceira malha, possuindo espaçamento $\delta r=\delta z=0.1 \mathrm{~cm}$ e tamanho $52 \times 104$. Os espaços em branco no interior do fluido no campo de velocidade significam que a intensidade da velocidade é muito baixa para ser representada vetorialmente pelo software utilizado na geração do gráfico (gnuplot).

Em ambos os casos, observa-se que a convergência é obtida.

\subsubsection{Estudo da Convergência}

Através dos resultados obtidos com o refinamento das malhas, mostra-se que o método converge conforme a malha é refinada. Para se obter uma estimativa da taxa de convergência, foram realizadas diversas simulações do modelo de enchimento de cavidade sobre um conjunto de malhas com espaçamentos decrescentes. O modelo utilizado é composto pelos seguintes dados:

- cavidade com raio $R=4.8 \mathrm{~cm}$ e altura $H=7.68 \mathrm{~cm}$;

- injetor com raio $r=0.96 \mathrm{~cm}$ e velocidade inicial do fluido $V_{o}=-2.0 \mathrm{~m} / \mathrm{s}$, posicionado a uma altura $h=0.96 \mathrm{~cm}$ da cavidade;

- aceleração da gravidade agindo na vertical com $g_{z}=-9.81 \mathrm{~m} / \mathrm{s}^{2}$;

- viscosidade cinemática $\nu=80.0 \mathrm{~cm}^{2} / \mathrm{s}$;

- parâmetros de escala de comprimento $L=1.92 \mathrm{~cm}$ (diâmetro do injetor) e de velocidade $U=2.0 \mathrm{~m} / \mathrm{s}$ (velocidade inicial do fluido no injetor), obtendo os fatores adimensionais $\operatorname{Re}=4.8$ e $\mathrm{Fr}=4.60834$;

- três partículas por célula na superfície livre;

- condições de não-escorregamento nas fronteiras rígidas.

Os espaçamentos utilizados nas simulações com as sete malhas são: Malha 1 ( $h=$ 0.0032), Malha $2(h=0.0024)$, Malha $3(h=0.0016)$, Malha $4(h=0.0012)$, Malha 5 $(h=0.0008)$, Malha $6(h=0.0006)$ e Malha $7(h=0.0004)$. Como não se conhece a solução analítica deste modelo, utiliza-se os dados da malha mais refinada (Malha 7) como solução analítica e calcula-se a norma $l_{2}$ dos erros entre esta malha (Malha 7) e as outras malhas (Malha 1, Malha 2, Malha 3, Malha 4, Malha 5 e Malha 6). A tabela 7.2 apresenta as normas $l_{2}$ dos erros para as componentes da velocidade e para a pressão. Estes erros foram calculados nos pontos da malha mais grossa (Malha 1) considerando somente as células cheias, através da interpolação dos dados das malhas mais finas. A razão para considerar somente as células cheias é que há pontos próximos às fronteiras na malha mais grossa que não estão definidos nas malhas mais finas de modo que uma comparação correta não pode ser feita. 


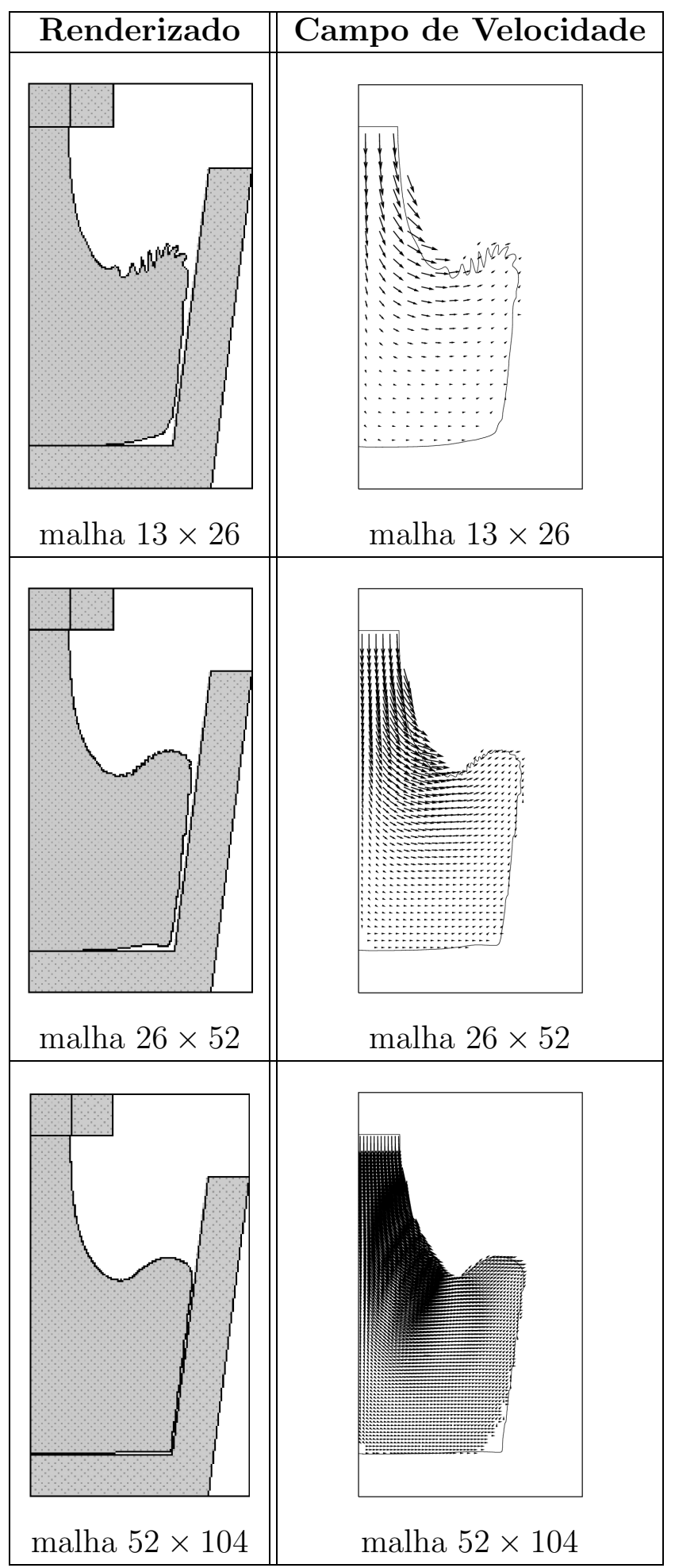

Figura 7.8: Refinamento de malha - simulação "Cavity Filling" 


\begin{tabular}{|c|c|c|c|}
\hline $\mathbf{h}$ & $\left\|\mathbf{U}-\mathbf{U}_{\mathbf{h}}\right\|_{\mathbf{2}}$ & $\left\|\mathbf{V}-\mathbf{V}_{\mathbf{h}}\right\|_{\mathbf{2}}$ & $\left\|\mathbf{P}-\mathbf{P}_{\mathbf{h}}\right\|_{\mathbf{2}}$ \\
\hline 0.0032 & 0.07968 & 0.2729 & 0.45242 \\
\hline 0.0024 & 0.06762 & 0.2250 & 0.29080 \\
\hline 0.0016 & 0.06143 & 0.1959 & 0.13106 \\
\hline 0.0012 & 0.05442 & 0.1250 & 0.07217 \\
\hline 0.0008 & 0.02740 & 0.0888 & 0.07137 \\
\hline 0.0006 & 0.01060 & 0.0734 & 0.04180 \\
\hline
\end{tabular}

Tabela 7.2: Normas $l_{2}$ dos erros entre malhas mais grossas e malha mais fina

Como pode ser observado na tabela 7.2, os erros das componentes de velocidade e da pressão decrescem monotonicamente com o refinamento das malhas. Para obter uma estimativa da taxa de convergência, ajusta-se uma linha de mínimos quadrados aos dados da tabela 7.2; a taxa de convergência é, então, dada pela inclinação da linha ajustada. A figura 7.9 apresenta o gráfico log-log das normas $l_{2}$ dos erros das componentes de velocidades e a figura 7.10 apresenta o gráfico log-log das normas $l_{2}$ dos erros das pressões. A inclinação para as normas da componente de velocidade $u$ é de 0.814 , para as normas da componente de velocidade $v$ é de 0.856, e para as normas da pressão, 1.666. Estas taxas de convergência são aproximadas. Se as normas das malhas mais grossas forem descartadas e forem adotadas somente as normas a partir da Malha $3(h=0.0016)$, então obtémse taxas de convergência maiores para as componentes de velocidade. De fato, obtém-se taxas de convergência acima de 1.3 para $u$ e $v$. Assim, os resultados mostram que o método apresentado é convergente com pelo menos $O(h)$.

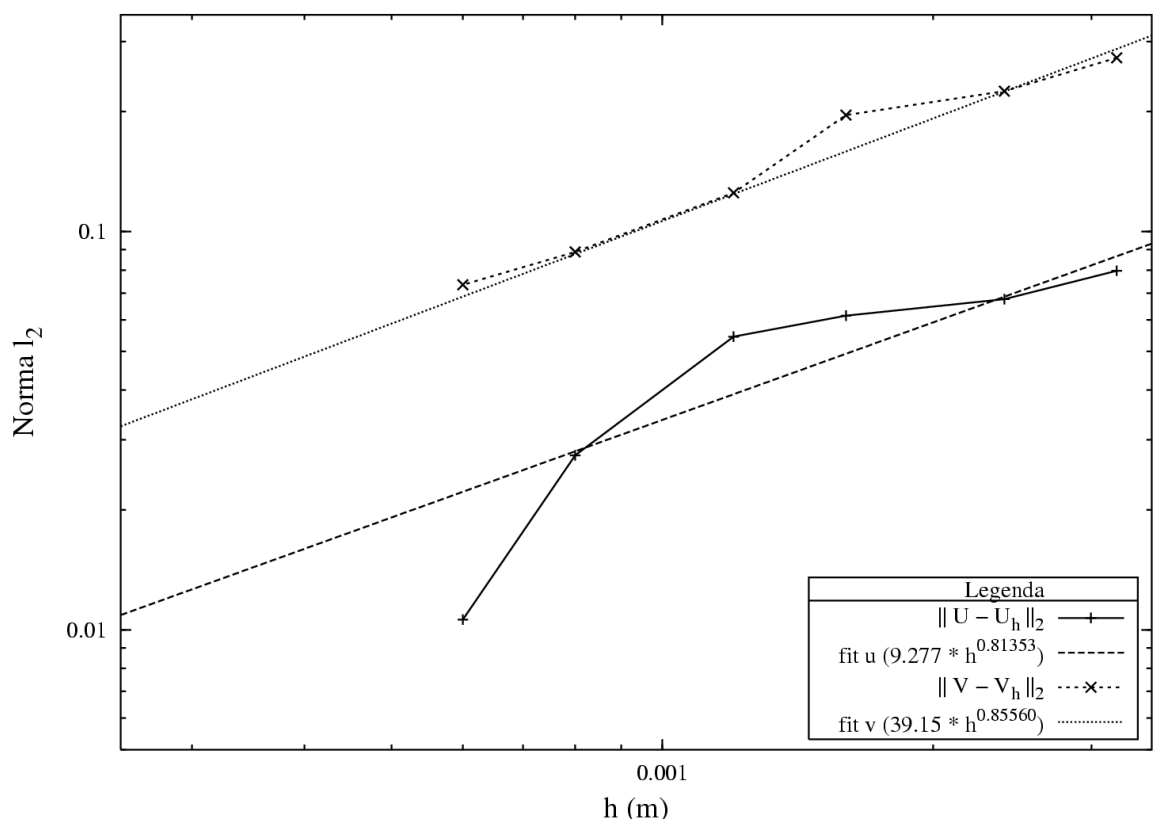

Figura 7.9: Normas $l_{2}$ dos erros das componentes de velocidade para cada malha 


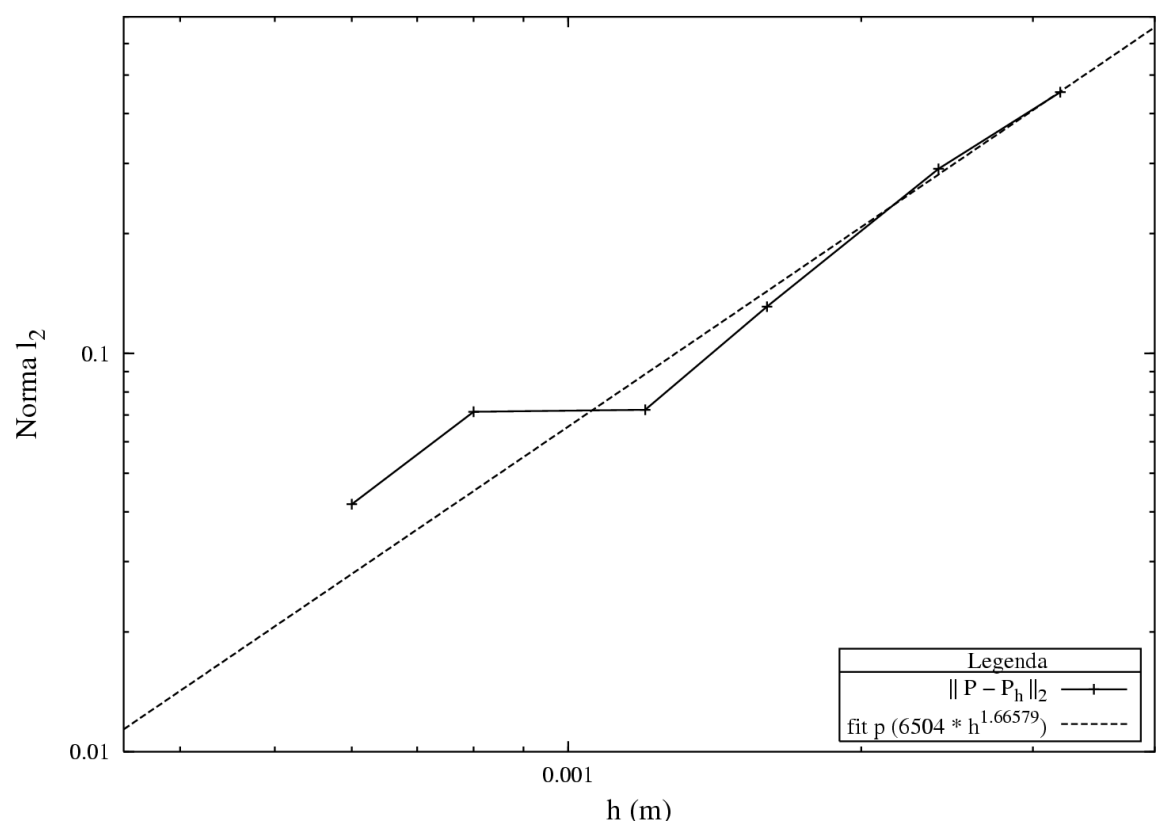

Figura 7.10: Normas $l_{2}$ dos erros da pressão para cada malha

\subsection{Efeito da Tensão Superficial e do Ângulo de Con- tato}

Todos os resultados obtidos até o momento não apresentam o efeito da tensão superficial ou do ângulo de contato.

Para validar qualitativamente a implementação do efeito da tensão superficial, será realizada a simulação da gota apoiada, que consiste em uma gota esférica de fluido inicialmente em repouso sobre uma superfície rígida, com aceleração gravitacional $g_{z}=-9.81 \mathrm{~m} / \mathrm{s}^{2}$.

O modelo utilizado na simulação é:

- Raio máximo $R M A X=2.0 \mathrm{~m}$ e altura máxima $H M A X=3.0 \mathrm{~m}$ do domínio, com espaçamento da malha $d r=d z=0.04 \mathrm{~m}(50 \times 75$ células $)$;

- coeficientes de adimensionalização de escala de comprimento $L=2.0 \mathrm{~m}$ e de velocidade $V=4.43 \mathrm{~m} / \mathrm{s}$, viscosidade $\nu=9.0 \mathrm{~m}^{2} / \mathrm{s}$ e coeficiente de tensão superficial $\sigma=10.0 \mathrm{~kg} / \mathrm{s}^{2}$, gerando os fatores adimensionais $\mathrm{Re}=0.984, \mathrm{Fr}=1.0$ e We $=3.924$;

- uma superfície circular com raio $r=2.0 \mathrm{~m}$ e altura $h=0.2 \mathrm{~m}$;

- gota esférica de fluido com raio $r=1.0 \mathrm{~m}$ e velocidade inicial nula, com a parte inferior da gota posicionada sobre a superfície rígida.

A seguir são apresentados alguns instantes da simulação.

Para a validação quantitativa do efeito da tensão superficial, foi simulado um modelo de gota apoiada sobre duas malhas distintas e comparou-se os estados estacionários com 

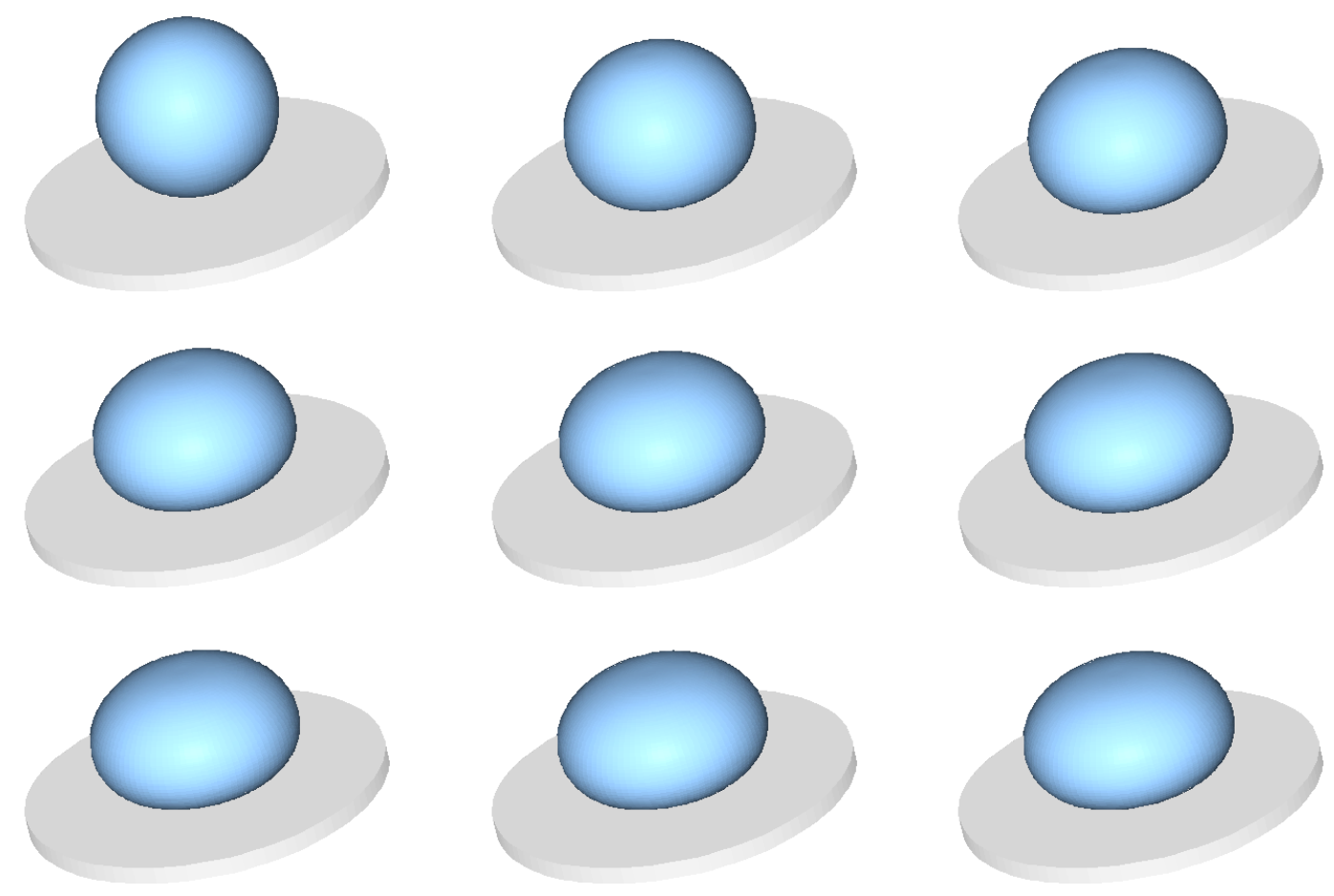

Figura 7.11: Simulação da gota apoiada

uma solução semi-analítica. O modelo utilizado foi:

- Raio máximo $R M A X=2.0$ m e altura máxima $H M A X=3.0$ m do domínio;

- coeficientes de adimensionalização de escala de comprimento $L=2.0 \mathrm{~m}$ e de velocidade $V=4.429 \mathrm{~m} / \mathrm{s}$, viscosidade $\nu=9.0 \mathrm{~m}^{2} / \mathrm{s}$, aceleração da gravidade $g_{z}=$ $-9.81 \mathrm{~m} / \mathrm{s}^{2}$ e coeficiente de tensão superficial $\sigma=20.0 \mathrm{~kg} / \mathrm{s}^{2}$, gerando os fatores adimensionais $\mathrm{Re}=0.984, \mathrm{Fr}=1.0$ e $\mathrm{We}=1.962$;

- uma superfície circular com raio $r=2.0 \mathrm{~m}$ e altura $h=0.2 \mathrm{~m}$;

- gota esférica de fluido com raio $r=1.0 \mathrm{~m}$ e velocidade inicial nula, com a parte inferior da gota posicionada sobre a superfície rígida.

As duas malhas utilizadas foram $d r=d z=0.04 \mathrm{~m}(50 \times 75$ células $)$ e $d r=d z=0.067 \mathrm{~m}$ (30 $\times 45$ células).

A solução semi-analítica, obtida por integração numérica das equações para a posição de equilíbrio de uma superfície livre axissimétrica [8], é dada por:

$$
\frac{d \theta}{d s}=c\left(p_{o}-z\right)-\frac{\sin \theta}{r} ; \quad \frac{d r}{d s}=\cos (\theta) ; \quad \frac{d z}{d s}=-\sin (\theta),
$$


onde $\theta$ é o ângulo da superfície, $s$ é a coordenada ao longo da superfície, e

$$
c=\frac{\rho g L^{2}}{\sigma} ; \quad p_{o}=\frac{\tilde{p}_{o}}{\rho g L},
$$

Pode-se observar, na figura 7.12(a), a comparação dos resultados numéricos da simulação do modelo nas duas malhas com a solução semi-analítica. Nota-se que o resultado obtido é excelente, com convergência no refinamento de malha (figura 7.12(b)).

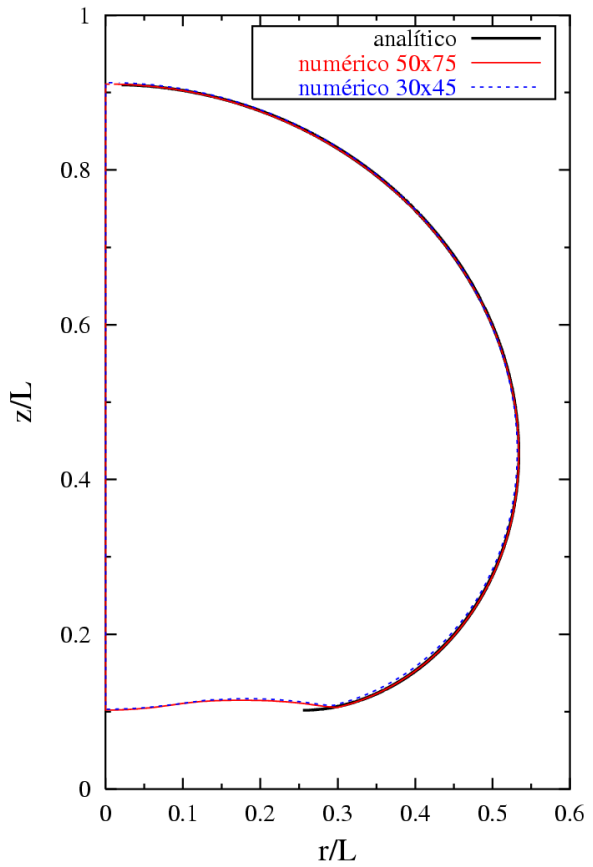

(a)

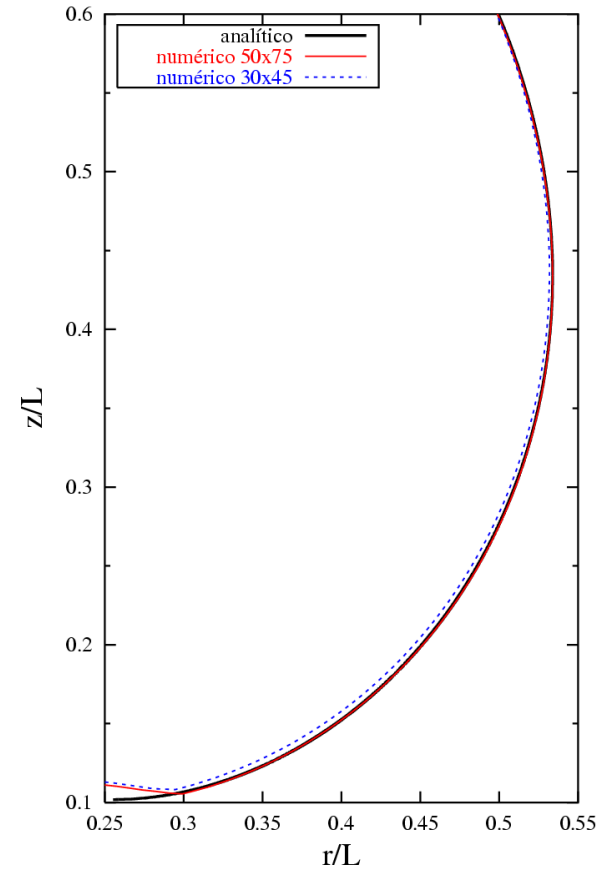

(b)

Figura 7.12: Validação da gota apoiada: (a) comparação entre malhas e solução semianalítica; (b) zoom de região do gráfico (a).

Para a validação da implementação do ângulo de contato, foi utilizado um modelo de gota apoiada com aceleração da gravidade nula. O modelo utilizado foi:

- Raio máximo $R M A X=2.0 \mathrm{~m}$ e altura máxima $H M A X=3.0 \mathrm{~m}$ do domínio;

- coeficientes de adimensionalização de escala de comprimento $L=2.0 \mathrm{~m}$ e de velocidade $V=4.429 \mathrm{~m} / \mathrm{s}$, viscosidade $\nu=9.0 \mathrm{~m}^{2} / \mathrm{s}$, aceleração da gravidade $g_{z}=$ $0.0 \mathrm{~m} / \mathrm{s}^{2}$ e coeficiente de tensão superficial $\sigma=2.0 \mathrm{~kg} / \mathrm{s}^{2}$, gerando os fatores adimensionais $\operatorname{Re}=0.984, \mathrm{Fr}=1.0$ e $\mathrm{We}=19.62$;

- uma superfície circular com raio $r=2.0 \mathrm{~m}$ e altura $h=0.3 \mathrm{~m}$; 
- gota esférica de fluido com raio $r=1.0 \mathrm{~m}$ e velocidade inicial nula, com a parte inferior da gota posicionada sobre a superfície rígida.

Aplicando três valores para o ângulo de contato $\phi_{c}, \frac{3 \pi}{4}, \frac{\pi}{2}$ e $\frac{\pi}{4}$, comparou-se os resultados numéricos dos estados estacionários com a solução analítica.

A solução analítica consiste em um arco de circunferência com raio $R$ calculado a partir do ângulo de contato $\phi_{c}$ prescrito e da altura máxima do fluido $h$. Assim, as coordenadas do centro da circunferência, $X_{c}=\left(r_{c}, z_{c}\right)$, com raio $R=\frac{h}{1-\cos \left(\phi_{c}\right)}$ são:

$$
r_{c}=0.0 ; \quad z_{c}=-\frac{h \cos \left(\phi_{c}\right)}{1-\cos \left(\phi_{c}\right)}
$$

Observa-se, nas figuras 7.13(a), 7.13(b) e 7.13(c), a comparação dos resultados numéricos com os arcos de circunferência para cada ângulo de contato. Os resultados obtidos são excelentes.

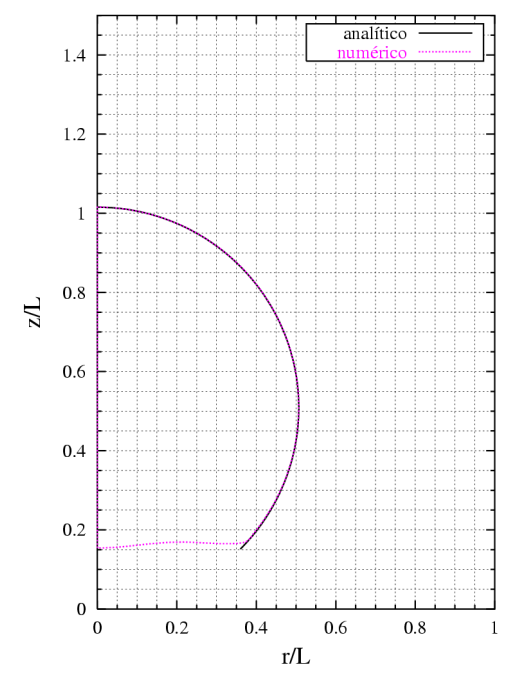

(a)

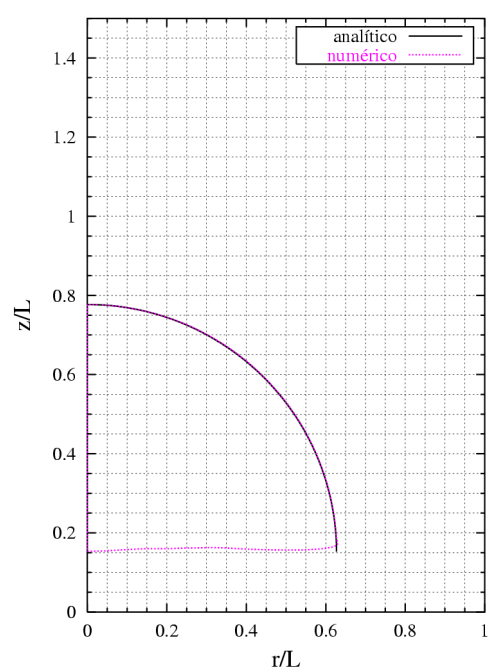

(b)

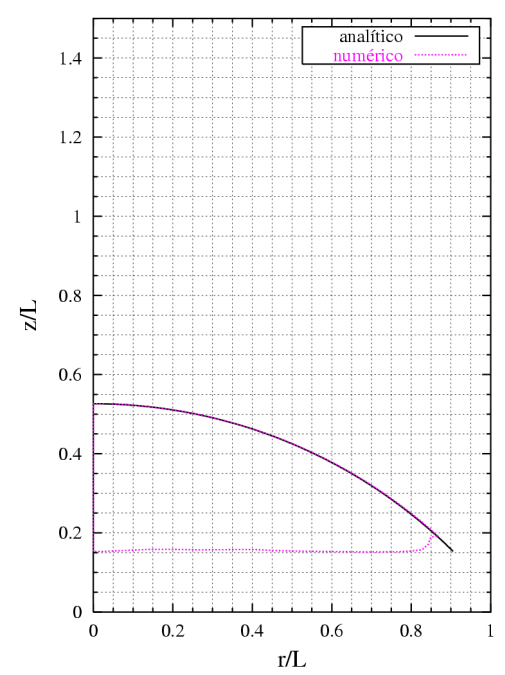

(c)

Figura 7.13: Validação do ângulo de contato com aceleração da gravidade $g_{z}=0.0$ : Ângulos de contato (a) $\frac{3 \pi}{4}$; (b) $\frac{\pi}{2}$; (c) $\frac{\pi}{4}$. 



\section{Conclusão}

Neste trabalho foi desenvolvido um ambiente de simulação de escoamentos axissimétricos, composto por um modelador de moldes, um simulador de escoamentos e um visualizador de escoamentos, baseados no sistema Freeflow.

No Capítulo 1, foram apresentados alguns conceitos fundamentais de Mecânica dos Fluidos, incluindo a tensão superficial e o ângulo de contato. Também foram apresentadas e desenvolvidas as equações de Navier-Stokes em coordenadas cilíndricas.

No Capítulo 2, foi descrito o algoritmo computacional do método GENSMAC para resolver os escoamentos axissimétricos com superfícies livres e as modificações realizadas no método bidimensional para sua adaptação ao simulador axissimétrico.

No Capítulo 3, foram realizadas as aproximações por diferenças finitas das equações utilizadas no método GENSMAC para as simulações axissimétricas, e foram apresentados os algoritmos para a implementação dos efeitos da tensão superficial e do ângulo de contato sobre o fluido.

No Capítulo 4, o ambiente de simulação de escoamentos bidimensionais Freeflow-2D foi apresentado, introduzindo a estrutura de dados halfedge-2d utilizada para representar os objetos e descrevendo os módulos que compõem o ambiente.

No Capítulo 5, apresentou-se o ambiente de simulação de escoamentos tridimensionais Freeflow-3D, com a breve descrição dos módulos modelador de moldes, simulador de escoamentos e visualizador de escoamentos.

No Capítulo 6, as implementações realizadas para o desenvolvimento do ambiente de simulações Freeflow-AXI foram descritas, apresentando exemplos de modelos para serem utilizados pelo simulador axissimétrico e modos de visualização dos resultados gerados pelo simulador.

No Capítulo 7, foram realizadas validações qualitativas e quantitativas com diversos modelos. Também foram realizadas validações para a implementação dos efeitos da tensão superficial e do ângulo de contato.

Os resultados obtidos nas validações qualitativas, com as simulações do jato vertical injetado em um recipiente contendo o mesmo fluido, da "splashing drop" e do enchimento de cavidade, apresentaram a versatilidade do ambiente Freeflow-AXI.

$\mathrm{Na}$ validação quantitativa, foi realizada uma comparação com solução analítica, a convergência com o refinamento de malhas e um estudo da convergência do método. Os resultados obtidos da validação quantitativa foram muito bons, mostrando que o ambiente Freeflow-AXI realiza simulações com precisão. 
As aplicações da tensão superficial e do ângulo de contato nas simulações axissimétricas foram validadas com resultados excelentes, mostrando que suas implementações foram realizadas com sucesso.

Como propostas para trabalhos futuros, podem ser citados como exemplo:

- a extensão do código para a simulação de fluidos não newtonianos;

- a implementação de um método implícito para o cálculo das velocidades;

- a inclusão da temperatura nas simulações com simetria radial. 


\section{Referências Bibliográficas}

[1] Internet: http://math.uwyo.edu/ sdufour/IMG/bug-water.gif.

[2] D. J. Acheson. Elementary Fluid Dynamics. Oxford University Press, Nova York, 1990.

[3] A. Amsden e F. Harlow. The SMAC Method: A Numerical Technique for Calculating Incompressible Fluid Flows. Technical Report, Los Alamos Scientific Laboratory Report LA-4370, Los Alamos, NM, 1970.

[4] A. Castelo Filho, N. Mangiavacchi, M. F. Tomé, J. A. Cuminato, A. O. Fortuna, J. Oliveira, V. G. Ferreira e S. McKee. Surface Tension Implementation for Gensmac2d. J. of the Braz. Soc., 23, vol. 23, n. 4, 2001.

[5] A. Castelo Filho, M. F. Tomé, S. McKee, J. A. Cuminato e C. N. L. César. Freeflow: An Integrated Simulation for Three-Dimensional Free Surface Flows. Journal of Computing and Visualization in Science, 103, pp. 77-92, 1999.

[6] A. O. Fortuna. Técnicas Computacionais para Dinâmica dos Fluidos: Conceitos Básicos e Aplicações. Editora da Universidade de São Paulo, São Paulo, 2000.

[7] F. H. Harlow e J. E. Welch. The MAC Method. Phys. Fluids, 8, pp. 2182-2189, 1965.

[8] N. Mangiavacchi, A. Castelo Filho, M. F. Tomé, J. A. Cuminato, V. G. Ferreira, L. G. Nonato e S. McKee. Numerical Simulation of Surface Tension Dominated Axisymmetric Free Surface Flows. Em Proceedings ENCIT 2000, Porto Alegre, 2000. CD-ROM.

[9] M. Mäntylä. An Introduction to Solid Modeling. Principles of Computer Science Series, 0888-2096 ; 13. Computer Science Press, 1988.

[10] J. Oliveira. Desenvolvimento de um Sistema de Simulação de Escoamentos de Fluidos com Superfícies Livres Bidimensionais. Dissertação de Mestrado, ICMC-USP, 1999.

[11] M. C. Potter e D. C. Wiggert. Mechanics of Fluids. Prentice-Hall, 1997.

[12] J. J. Stoker. Water Waves. Interscience, New York, 1957. 
[13] G. I. Taylor. Film Notes for Low-Reynolds Number Flows. Cambridge University Press, Cambrigde, UK, 1967.

[14] M. F. Tomé e S. McKee. GENSMAC: A Computational Marker-and-Cell Method for Free Surface Flows in General Domains. J. Comp. Phys., 110, vol. 110, n. 1, pp. 171-186, 1994.

[15] A. Varonos e G. Bergeles. Development and assessment of a variable-order nonoscillatory scheme of convection term discretization. Int. J. Num. Meth. Fluids, 26, pp. 1-16, 1998.

[16] J. E. Welch, F. H. Harlow, J. P. Shannon e B. J. Daly. The MAC Method. Technical Report, Los Alamos Scientific Laboratory Report LA-3425, Los Alamos, 1966. 